\title{
MARMARA SEA EARTHQUAKE RECONNAISSANCE REPORT
}

\section{Report of the NZSEE Reconnaissance Team on the 17 August 1999 Marmara Sea, Turkey Earthquake}

\author{
R.D. Sharpe ${ }^{1}$, D. Bradshaw ${ }^{2}$, N. Brown ${ }^{3}$, R. Van Dissen ${ }^{4}$, \\ D. Kirkcaldie ${ }^{5}$, K.J. McManus ${ }^{6}$, T. Pham ${ }^{7}$ and C. Stevenson ${ }^{8}$
}

\begin{abstract}
On 17 August 1999 a $M_{w} 7.4$ earthquake struck western Turkey killing at least 15,000 people and leaving some 600,000 homeless. Three weeks later a New Zealand Society for Earthquake Engineering reconnaissance team was sent to the area to investigate the causes of the destruction and the reported confusion and delay in the emergency response and to bring back information that will help to better prepare for similar earthquakes in New Zealand. Few new lessons were to be learned in structural behaviour, the numerous collapsed apartment buildings were not adequately designed or constructed for the intensity of shaking they were subjected to. The enormous scale of the disaster and extent of damage far exceeded media reports and simply overwhelmed the emergency response preparations that were in place. New Zealand is ill prepared for a disaster of such magnitude.
\end{abstract}

\section{TABLE OF CONTENTS}

\section{ABSTRACT}

3

4

5

6
Introduction

Seismology and Ground Motions

Emergency Response

Geotechnical Features

Buildings

Dams

$\begin{array}{ll}7 & \text { Lifelines } \\ 8 & \text { Summary and Recommendations } \\ 9 & \text { Acknowledgements } \\ 10 & \text { References }\end{array}$

1 INTRODUCTION

On 17 August 1999 at 3:02 am (local time) a $\mathbf{M}_{w} 7.4$ earthquake struck western Turkey causing heavy damage (Figure 1). The epicentre, shown in Figure 2, was about 7

\footnotetext{
${ }^{1}$ Principal, Beca Carter Hollings \& Ferner Ltd., Wellington (Fellow).

${ }^{2}$ Sinclair Knight Merz Ltd., Auckland (Member).

${ }^{3}$ Emergency Manager, Dunedin City Council (Member).

${ }^{4}$ Senior Geologist, Institute of Geological \& Nuclear Sciences, Lower Hutt (Member).

${ }^{5}$ Opus International Consultants Ltd., Wellington (Member).

${ }^{6}$ Senior Lecturer, Department of Civil Engineering, University of Canterbury, Christchurch (Member).

${ }^{7}$ Principal, AC Consulting Group Ltd., Wellington (Member).

${ }^{8}$ Senior Associate, Connell Wagner Ltd., Auckland (Member).
} 
$\mathrm{km}$ southeast of the city of Izmit, $100 \mathrm{~km}$ east-southeast from Istanbul, in the heavily populated industrial heartland of the country. The region of heavy damage extended from Yalova, $50 \mathrm{~km}$ west of the epicentre, to Duzce, about $100 \mathrm{~km}$ east of the epicentre, with some of the heaviest damage in Adapazzari shown in Figure 3. The recorded death toll stands at 15,500 while unofficial estimates put the toll much higher at 30,000 or more. Some 20,000 buildings were destroyed, mainly multi-unit apartment blocks, with another 30,000 ruled uninhabitable and some 600,000 people left homeless.

On 11 September, 25 days after the event, the NZSEE reconnaissance team arrived in Istanbul. The eight person team comprising engineers, a geoscientist, and an emergency manager spent 10 days in Turkey, 6.5 of these in the field in the worst affected areas. This report is not intended as a detailed technical overview of the earthquake and resulting damage. Rather, it is a record of our brief visit, our experiences and impressions, and a summary of our conclusions and lessons for New Zealand. It is a brief overview through New Zealand eyes. Other groups have spent more time in the field and on follow-up investigations and have provided more detailed technical information which is becoming available in the literature and on the internet.

The team was lead by Dr Richard Sharpe, a structural engineer with experience in building codes, seismic risk assessment, and seismic design of industrial plant. Russ Van Dissen, a geologist, observed the faulting, and complemented Dr Kevin McManus's observations on geotechnical effects. Neil Brown, Emergency Manager for Dunedin City Council, concentrated on emergency response, while Donald Kirkcaldie researched damage to bridges and highways. Tan Pham, a mechanical engineer, paid attention to damage to utilities, while David Bradshaw and Craig Stevenson took special note of industrial and commercial structures respectively.
Dr Tony Gillies a NZSEE member resident in Canada, joined the team in Turkey for part of the time, being sponsored by the Canadian Earthquake Engineering Society. He kindly contributed observations on damage to the water supply network. Dr Peter Riley of Auckland, also a member, was coincidentally attending an international Large Dams colloquium in Turkey at the same time, and provided the report on affected dams for the team. Don Anderson from the University of British Columbia spent Monday with the team and provided valuable briefing.

The timing of the NZSEE team's visit was, on advice from colleagues in Turkey, chosen to avoid the intensive search and rescue stage, while allowing reconnaissance observations before significant evidence of the damage was removed. The team arrived in Turkey on 10 September, just over three weeks after the main event. This proved to be an ideal time for the team. In particular, people were very willing to share their experiences of the previous weeks with the team.

By the end of the first day in the epicentral area, it was apparent that it was unlikely that there would be any new lessons for New Zealand in the area of structural engineering. From visual inspection of damaged and collapsed apartment buildings, it was apparent that these structures had not been prepared by way of design or construction for survival under the seismic forces they experienced. Moreover, the team was already questioning whether the intensity of shaking that had been experienced in the area had been as large as would have been expected in the epicentral region of a similar magnitude earthquake in New Zealand.

From the very beginning, team members were also reflecting on whether New Zealand's emergency management infrastructure is sufficiently prepared for a disaster of this scale within New Zealand.

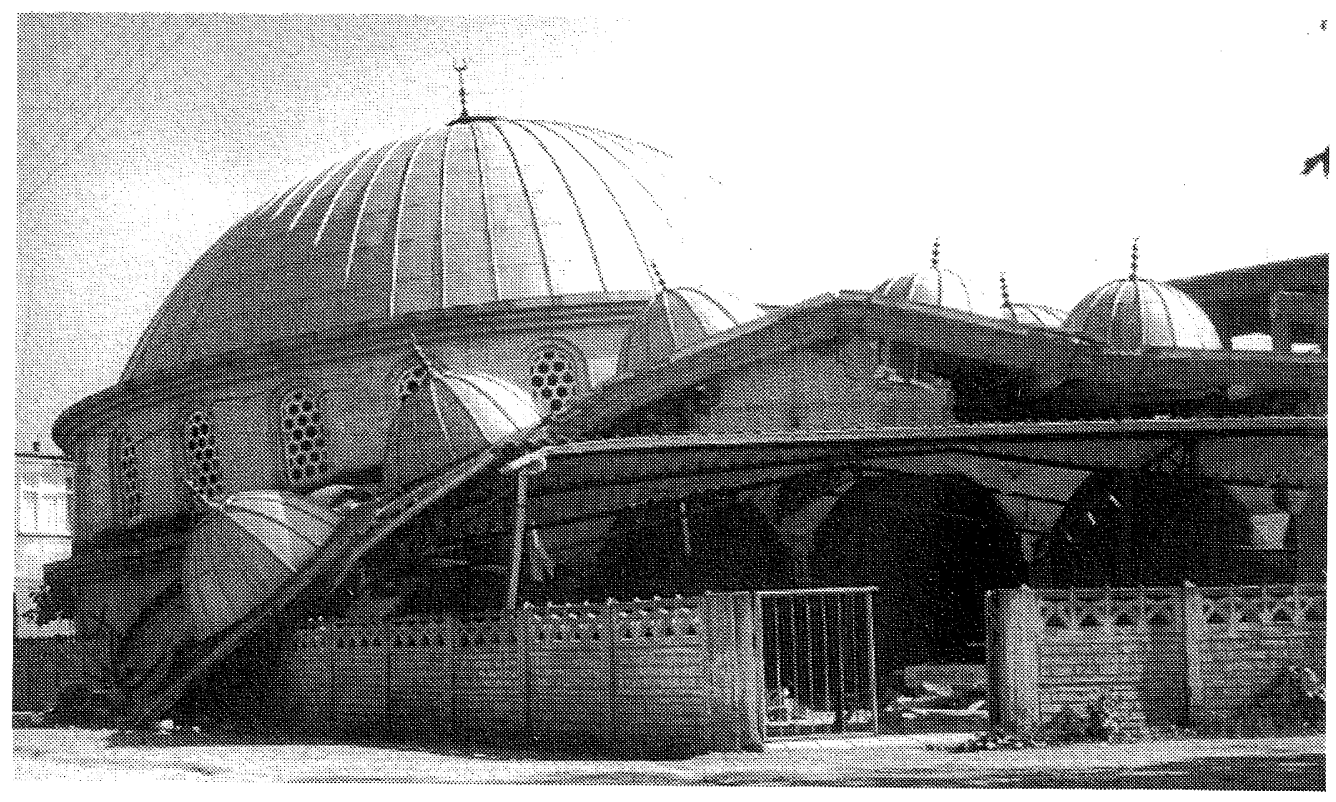

Figure 1: $\quad$ Collapsed Mosque near Golcuk. 


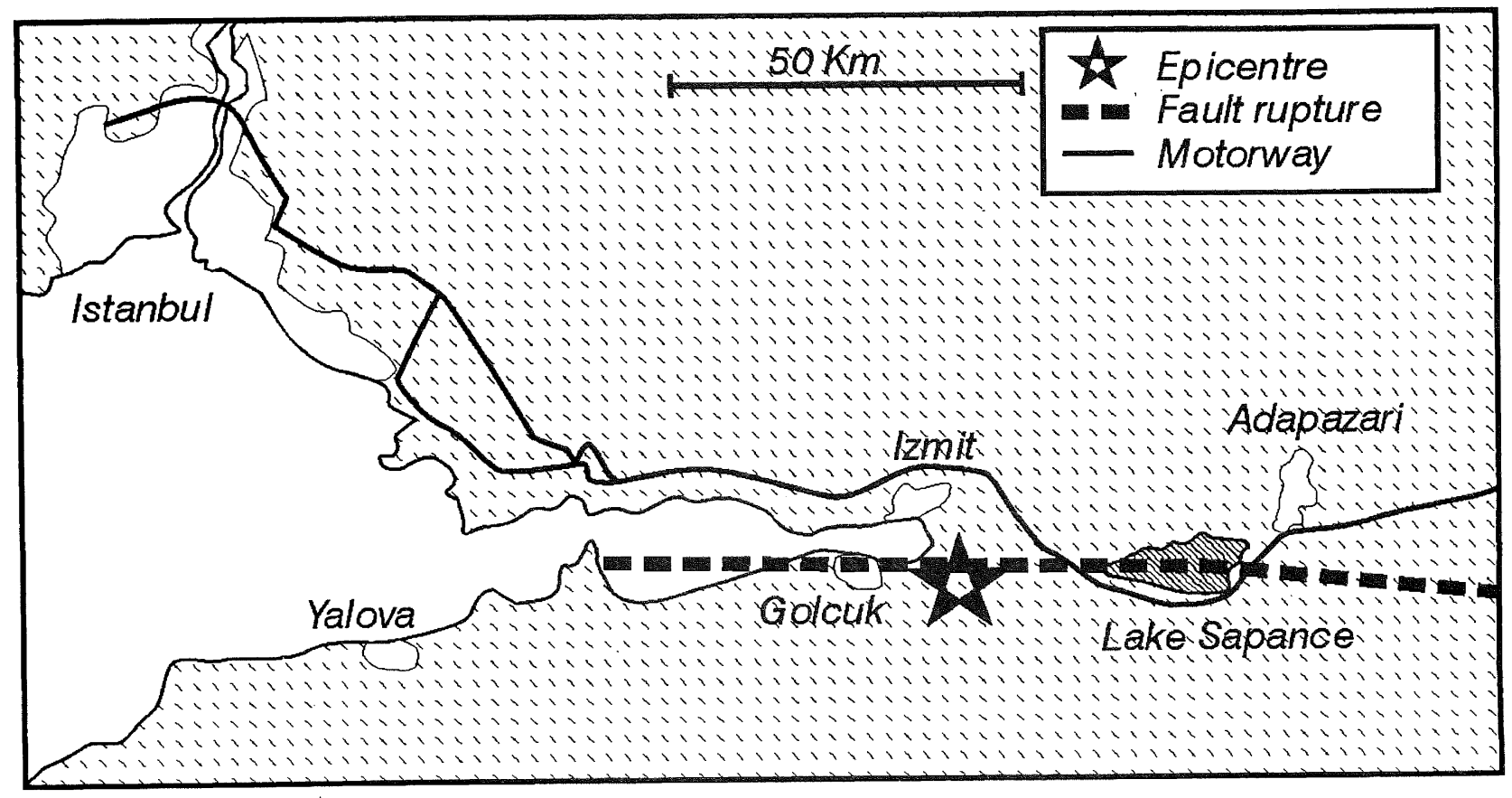

Figure 2: $\quad$ Map of affected area.

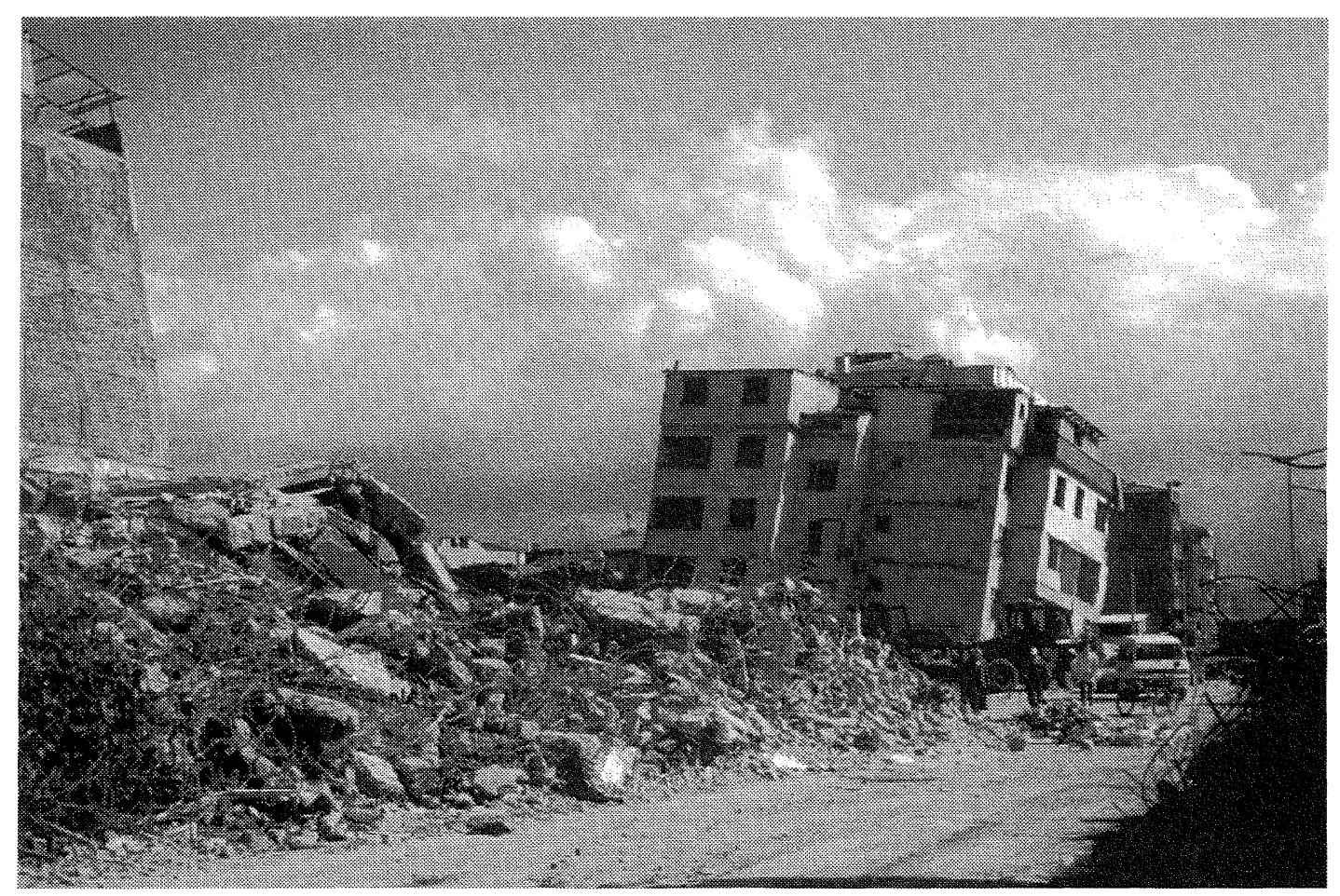

Figure 3: $\quad$ Typical street scene showing devastation of Adapazzari. 


\section{SEISMOLOGY AND GROUND MOTIONS}

\subsection{Tectonic Setting}

Like New Zealand, Turkey is geologically active and frequently experiences large, shallow earthquakes (e.g [1]). It is located within the collisional boundary zone between the Eurasian plate, and the northward-moving African and Arabian plates. (Refer to Figure 4, [2], [3]]). Within this boundary zone, a large block of continental crust, termed the Anatolian block, which encompassed much of Turkey, is being squeezed westward. This westward movement is, to a large extent, accommodated by slip along two major strike slip-slip faults that bound the northern and southeastern sides of the Anatolian block, respectively, the $1500 \mathrm{~km}$ long rightlateral North Anatolian fault, and the $550 \mathrm{~km}$ long left-lateral East Anatolian fault (e.g. [4], [5]).

The Marmara Sea earthquake of 17 August, 1999, resulted from rupture of the western portion of the North Anatolian fault. For much of its length, the North Anatolian fault appears to have a slip-rate in the order of $20 \mathrm{~mm} / \mathrm{yr}$ [5], [6], [7], [8], [9], and by way of comparison with major, predominantly strike-slip faults in New Zealand this is a similar or slightly slower rate than that of the Alpine and Hope faults in the South Island, but faster than the Clarence, Awatere, and Wairau faults in the South Island, and the Wairarapa, Wellington-Mohaka, and Ohariu faults in the North Island.

\subsection{Ground Motions}

The $M_{w}$ 7.4 Marmara Sea earthquake has almost a pure rightlateral focal mechanism, and nucleated from a depth of about $16 \mathrm{~km}$. It resulted from bi-lateral rupture of the east-west striking North Anatolian fault (though the epicenter was located closer to the western extent of rupture), and generated about $110-130 \mathrm{~km}$ of surface fault rupture (Figure 5, e.g. [10]). About 20 strong motion instruments recorded the main shock, but few, if any, of these stations were free-field sites, and most were located near Istanbul. Most of the strong motion data recorded for this earthquake are available on the Internet. The Turkish institutions from which these data are available, and their Internet sites, are as follows: National Strong Motion Network, operated by the Earthquake Research Department, Directorate for Disaster Affairs of the Ministry of Public Works and Settlement, [http://angora.deprem.gov.tr/]; Kandilli Observatory and Earthquake Research Institute, [http://www.koeri.boun.edu.tr/earthqk.html]; Istanbul Technical University, [http://www.itu.edu.tr/]; Public Water Works, [http://www.dsi.gov.tr/]; Middle East Technical University, [http://www.metu.edu.tr/home/wwweerc/ and http://www.metu.edu.tr/home/wwwdmc/]. The peak ground accelerations (PGA) recorded by the three strong motion stations closest to the fault rupture, which were within $7.5 \mathrm{~km}$ of the rupture, ranged from $0.23 \mathrm{~g}-0.41 \mathrm{~g}(0.41 \mathrm{~g}$ is maximum PGA recorded for this earthquake), and are generally lower than would be expected for an earthquake the size and depth of the Marmara Sea earthquake. In fact, recorded peak ground accelerations out to about $50 \mathrm{~km}$ from the fault rupture generally appear to be below average e.g. [11].

The general lack of rock fall and landslides on susceptible slopes, and lack of failure of brittle electrical sub-station components within the epicentral region further support the low acceleration strong motion data. However, despite the apparent below-average peak ground accelerations generated by this earthquake, peak ground velocities were high, approaching $1 \mathrm{~m} / \mathrm{sec}$, as were displacements, possibly exceeding $2 \mathrm{~m}$, were high.

It is interesting to note that when compared to design spectra for the current Turkish Building code, the normalized response spectra of several of the Marmara Sea near-source strong motion records actually, or nearly, exceed the design spectra between 0.1 and 1 second. Considering that the majority of structures in the epicentral region would have been constructed to a lower design spectra before the current code was implemented, the strength of many of these structures would have been exceeded by the forces generated by the Marmara Sea earthquake even if the structures had. been built to existing codes [11].

Following the main shock, a number of portable seismograph arrays were deployed in the epicentral region. These have demonstrated local amplification of ground motions related to local geological conditions.

\subsection{Surface Faulting}

The earthquake resulted in at least $100 \mathrm{~km}$ of surface rupture and perhaps an additional $80-100 \mathrm{~km}$ of offshore rupture, as judged by aftershock activity. The map pattern of surface rupture is characterised as an along strike series of 4-5 rightstepping, E-W to ENE-WSW trending, 20-40 km long sections. At each right-step a releasing bend, or pull-apart, has developed. At one of these releasing bends, located immediately adjacent to the Sea of Marmara near the town of Golcuk, tectonic subsidence across the fault of up to $2.4 \mathrm{~m}$ associated with normal faulting resulted in the permanent inundation of a $4 \mathrm{~km}$ long portion of the town (Figures 6 and 7). Along most of the surface rupture, strike-slip displacement averaged about 3-4 m, as shown in Figure 8, with a maximum close to $5 \mathrm{~m}$. The surface rupture, shown in Figure 9, was typically confined within a narrow zone of cracking some 5-25 metres wide.

\section{$2.4 \quad$ Earthquake Forecasting}

The Marmara Sea earthquake was the most devastating earthquake to strike Turkey since the 1939 Erzincan earthquake which killed 30,000 people. The earthquake was predicted, or at least forecast [12], [13] based on the modelling of static stress changes on the North Anatolian fault resulting from the constant loading of the fault at depth at its geodetically determined slip rate (ca $20 \mathrm{~mm} / \mathrm{yr}$ ), and the stresses induced by the remarkable series of seven $\mathrm{M} 7+$ earthquakes that have ruptured $1000 \mathrm{~km}$ of the fault in the last 60 years, primarily from east to west. (Is Istanbul next?). The Marmara Sea earthquake was the tenth in a general westward progression of earthquakes that have "un-zipped" $1000 \mathrm{~km}$ of the North Anatolian fault since 1939. In a paper published prior to the Marmara Sea earthquake, Stein et al. [12] found that nine out of ten of these earthquake ruptures were brought closer to failure by the preceding earthquake. Understanding how earthquakes and active faults interact with each other, may prove useful for improving probabilistic earthquake forecasts in New Zealand (e.g. [14]). 


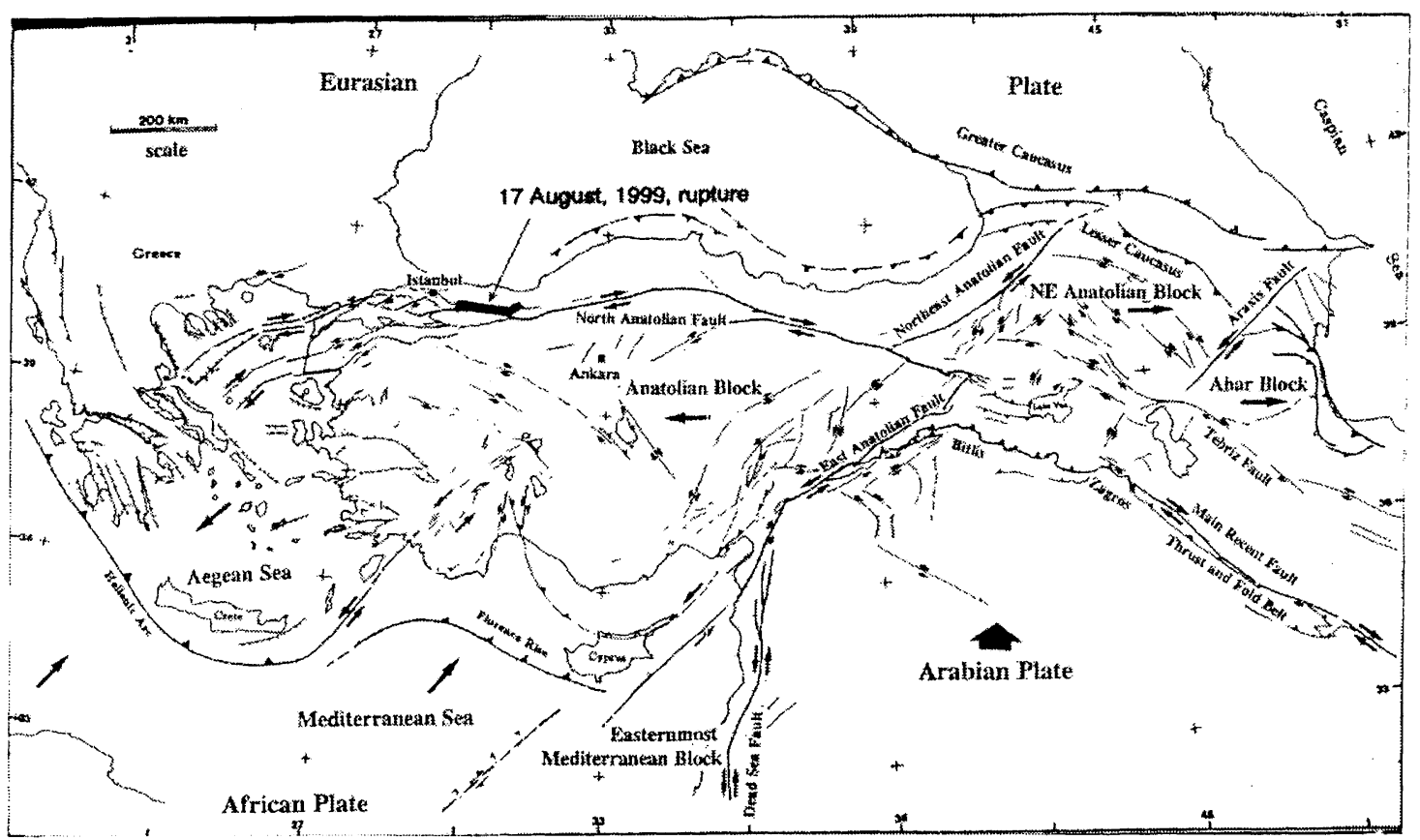

Figure 4: $\quad$ Tectonic map of the eastern Mediterranean region. As a result of collision between the Eurasian plate, Arabian and African plates, the Anatolian block is escaping westwards, and the Northeast Anatolian block is escaping eastwards. The North Anatolian fault defines the northern boundary of the Anatolian block. Source: [10].

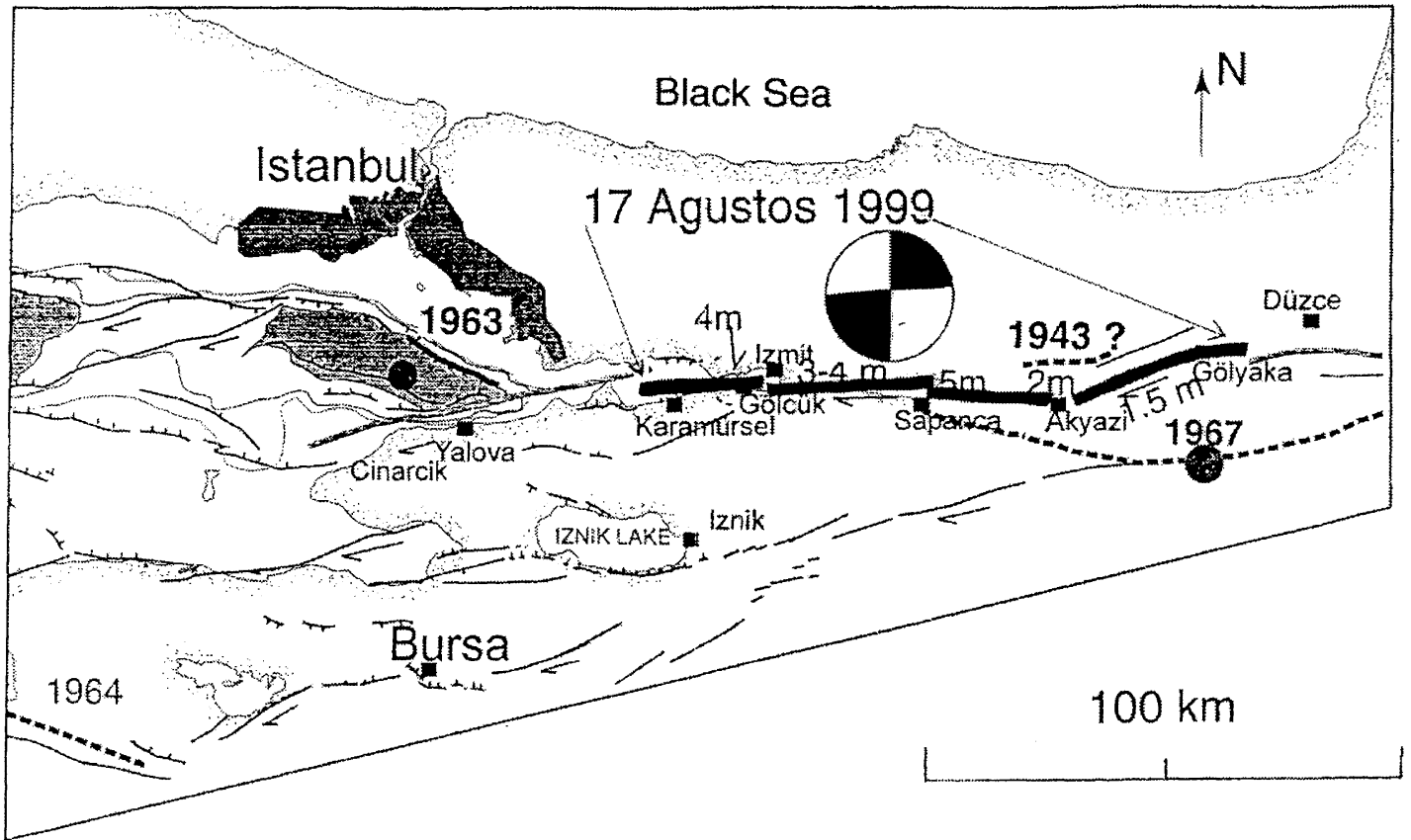

Figure 5: $\quad$ Extent of fault rupture resulting from the 17 August, 1999, earthquake (bold line) on the North Anatolian fault, and the 1943, 1964 and 1967 earthquakes (dashed lines). The epicentre of the 17 August 1999 earthquake was located about $7 \mathrm{~km}$ southeast of Izmit, and the focal mechanism, "beach ball", shows that the earthquake rupture was almost pure strike-slip on a near vertical dipping fault plane. Indicative rightlateral surface rupture displacements, in metres, are shown for each of the right-stepping rupture segments of the 17 August 1999 earthquake. Source: [10]. 


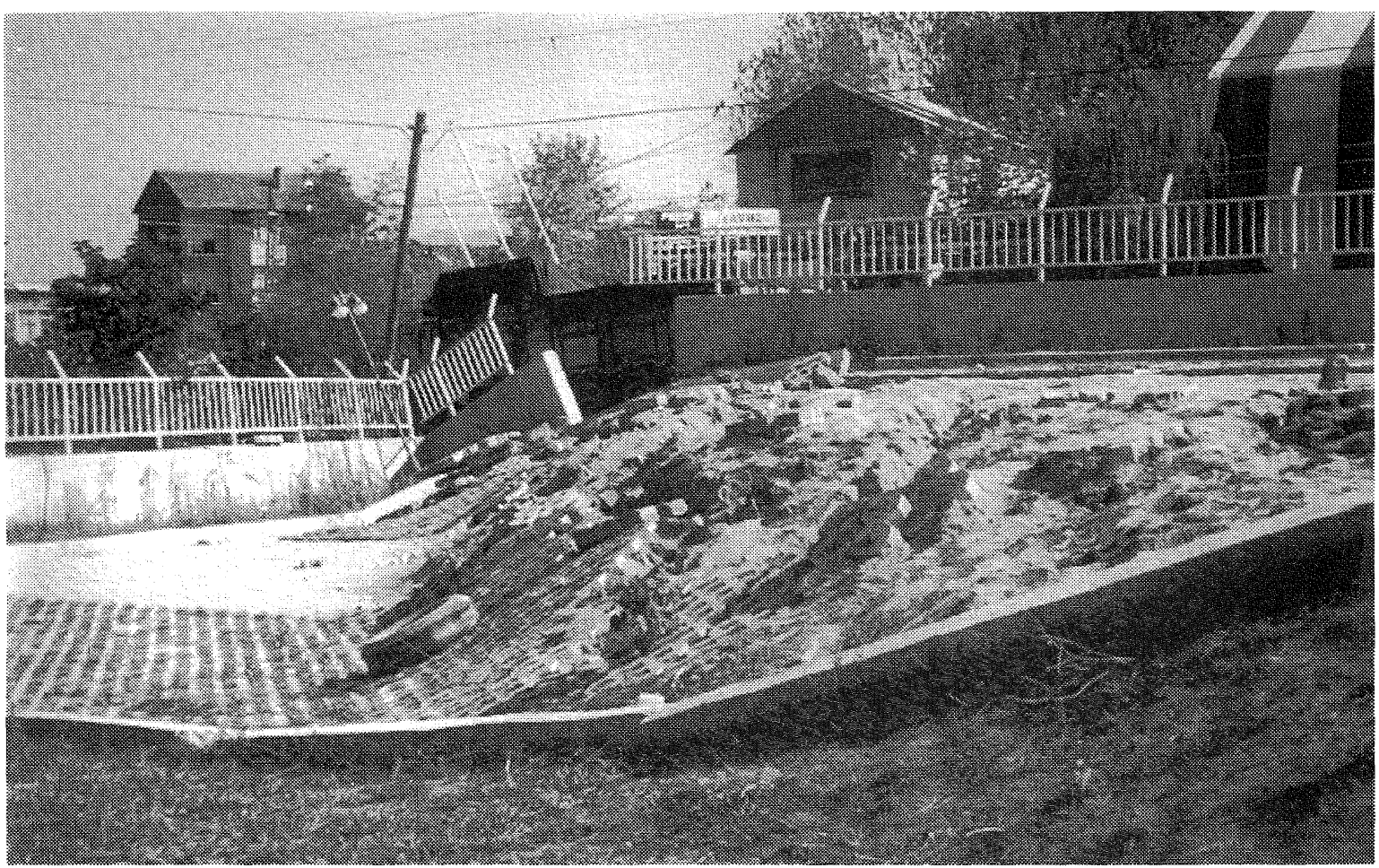

Figure 6: In the Golcuk area, a right-step, or releasing bend, in the fault trace resulted in tectonic subsidence, instead of lateral displacement, across the fault. The tectonic down-drop is expressed in this photo as a normal fault scarp (1-2 $\mathrm{m}$ high) in cobblestone pavement.

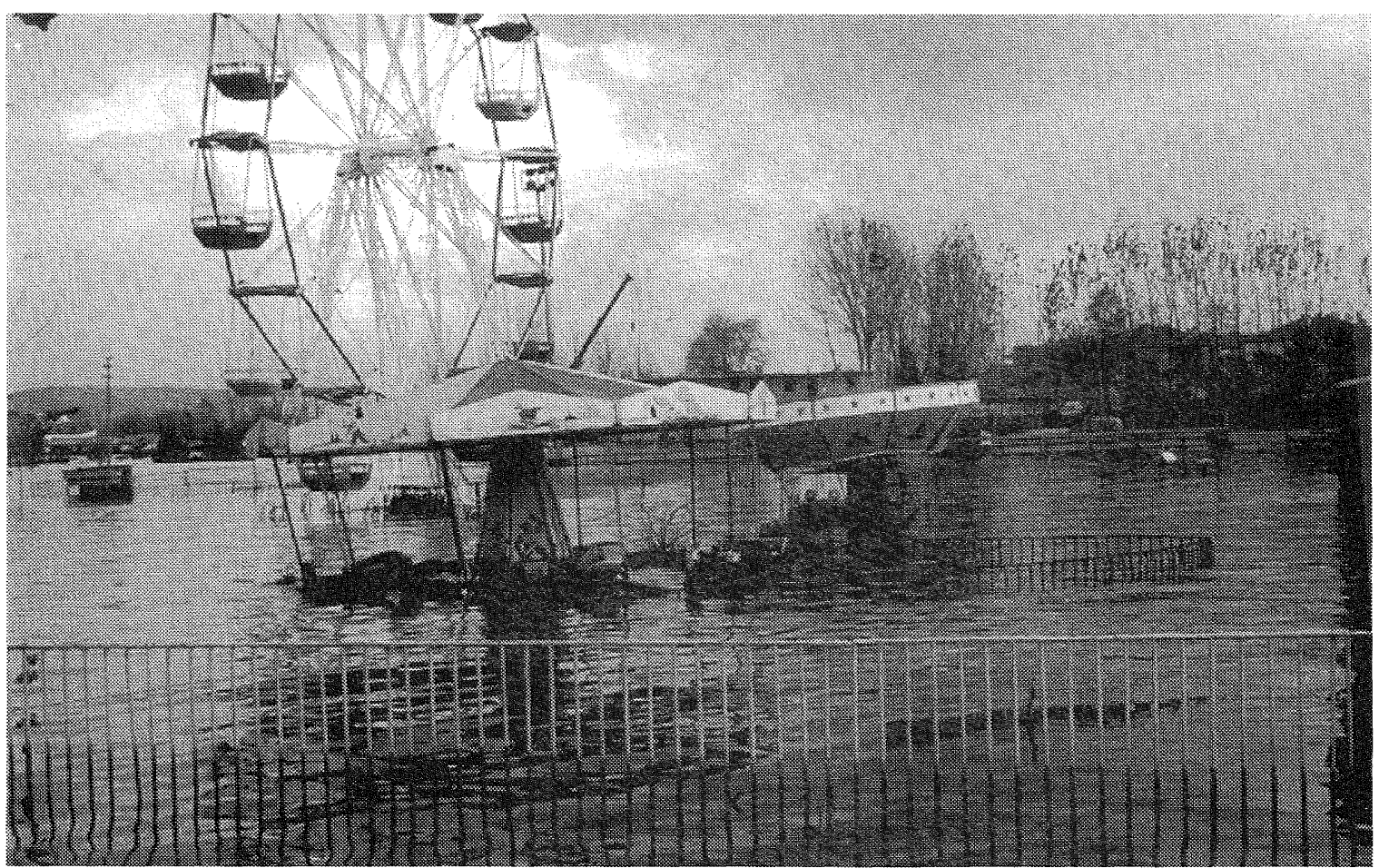

Figure 7:

Tectonic subsidence near Golcuk (up to $2 \mathrm{~m}$ ) resulted in the permanent inundation of a $4 \mathrm{~km}$ length of coast line including this amusement park. 


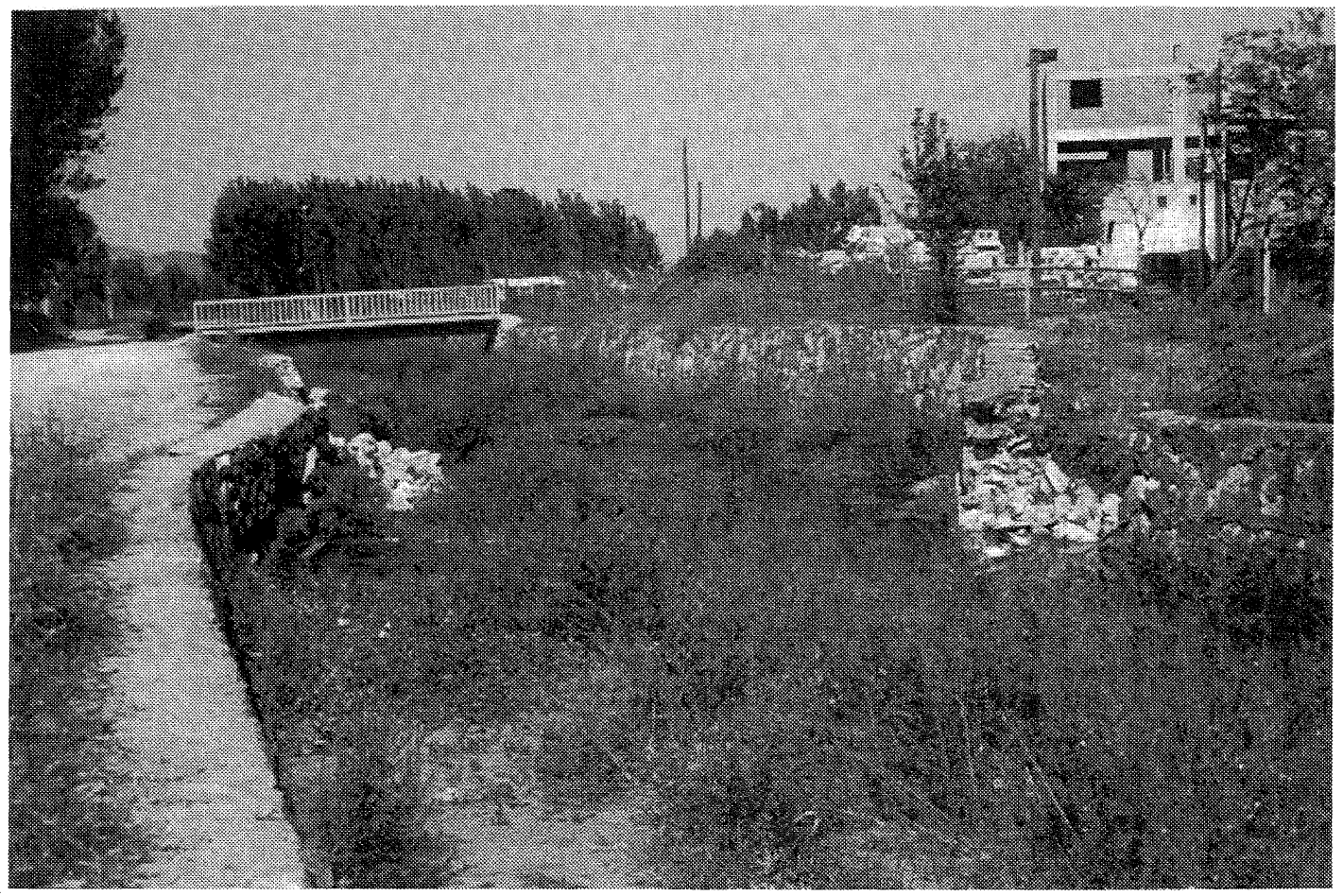

Figure 8: $\quad$ Right-lateral offset (ca $1.5 \mathrm{~m}$ ) of a canal near Izmit. This photo shows just one or two fault traces at this locality; the total lateral displacement exceeding $2.5 \mathrm{~m}$.

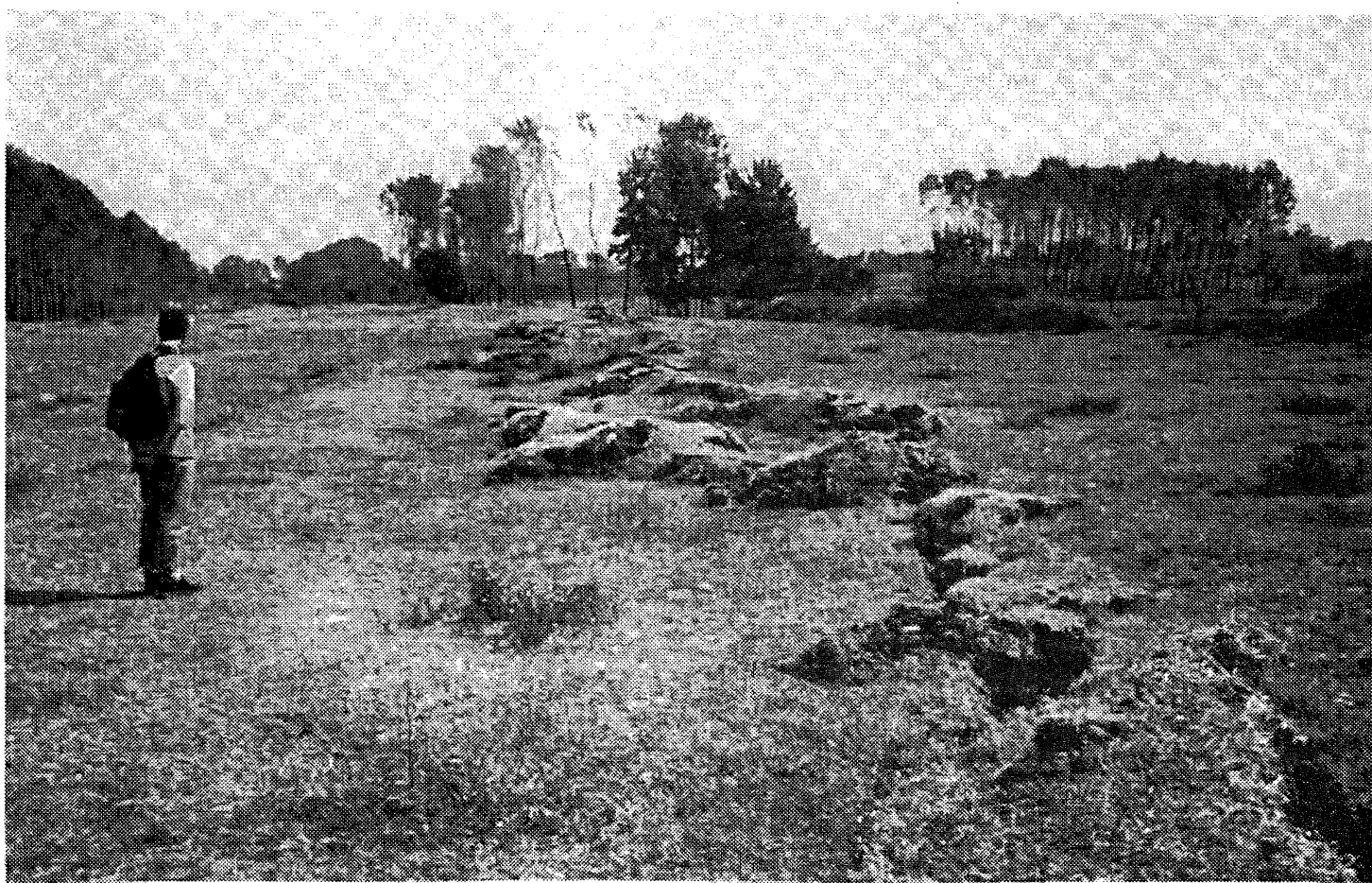

Figure 9:

Complex surface rupture pattern from the 17 August 1999 earthquake. At this location, right-lateral strikeslip displacement was in the order of several metres. Despite the small-scale complexity of the surface rupture pattern at this site, the rupture in general was well defined and usually contained within a 5-25 $\mathrm{m}$ wide zone of cracking. 


\section{EMERGENCY RESPONSE}

3.1 Effects of the Earthquake

Deaths, injuries and severe property damage were experienced over a large area approximately $130 \mathrm{~km}$ east and $60 \mathrm{~km}$ south of Istanbul. The most severe losses were experienced in Golcuk, Izmit, Adapazzari and Yalova.

The death toll and injuries would have been worse but for two factors: A proportion of the population was away from home on their annual holidays at the time of the earthquake. Also, many of the buildings fell or collapsed relatively slowly, allowing people to escape from them. An engineer from Adapazzari described how his house tilted sideways quite slowly, allowing him and his family to escape, although their home and his business are now destroyed and he is living on his savings. Buildings continued to collapse for some hours after the initial damage.

There was a small tsunami or seiche at Golcuk, evidenced by boats washed $10 \mathrm{~m}$ inland from their moorings. This was probably caused by the approximately $2 \mathrm{~m}$ drop of the land on the seaward side of the fault at this location.

The aftershocks (including one of $\mathrm{M}_{\mathrm{w}}$ 5.8) which occurred during our reconnaissance were not reported to cause any further damage to buildings but did lead to some deaths and injuries, frequently due to people leaping from upper stories of buildings, in fear of being trapped inside them. Members of international aid teams observed that local people were more sensitive to aftershocks than they were and a number of locals experienced severe trauma from aftershocks.

It is estimated that around 10 million people have been affected by the earthquake in some way, about 3 million of them directly. The number left homeless has not been accurately assessed but is in the order of 600,000 .

\subsection{Control and Coordination of Emergency Response}

No information has been obtained on what the planned emergency response should have been, other than that a civil defence organisation (Sivil Savunma) exists and had performed well in previous more 'routine' emergency situations.

Reports in newspapers and other media prior to the departure of the reconnaissance team indicated a significant lack of effective management of the emergency response by Turkish authorities. This is a not uncommon feature of early reports emanating from emergency events. While the scale of effects from this event could be expected to tax the capacity of any administration, the situation in Turkey appears to be that, while physical resources were available, expertise and overall coordination may have been severely lacking.

In the early stages of the emergency, international assistance was offered but initially rejected in a number of reported instances. When international and domestic assistance did arrive, there was no apparent co-ordination of response and incoming teams and personnel were left to determine their own priorities and areas of operation.

- A Portuguese rescue team was delayed for 48 hours until the Turkish Government agreed they were needed.
When they arrived at Istanbul airport, there were only two rental cars provided to transport 20 personnel and their equipment to the area of operation.

- A search and rescue team from a university in Ankara arrived to deliver donated goods, realised there was a need for assistance, started helping by making toilet enclosures and became, by default, the designated recipients and distributors of incoming portable toilet units.

Significant wastage of effort and resources resulted from the lack of coordination, particularly during the rescue phase:

- Many rescue sites were searched more than once, with rescue teams being unaware that sites had already been searched.

- A dog search team checked and marked a number of sites to indicate the probability of trapped persons being present but, due to lack of co-ordination, rescue teams did not know about this and therefore failed to follow up with rescue activities.

- Helicopters were deployed to disaster areas and became stranded due to their inability to refuel.

- Tent and food distribution was carried out on a haphazard basis, with some people reportedly taking a tent for now and one to store for later holiday use. This type of practice led to riots on 16 September.

- Truckloads of biscuits were sent because the only information about what was needed was from television broadcasts where someone, when asked by an interviewer what they wanted, said they would like some biscuits. It should be noted that donations of money were not considered appropriate in Turkey as there was concern expressed about where the donations would end up.

Dedicated communications for control purposes was not apparent at the time of the reconnaissance (although normal telecommunications were operating by then) and had obviously not been available in the earlier stages of the emergency. When the Prime Minister of Turkey visited Adapazzari initially and realised how serious the situation was, the only way he could pass instructions back to Ankara was through public television broadcast.

Some control systems were still being established one month after the event and appeared to be bureaucratic in nature and probably not fully effective. A series of crisis centres had been established, with an operational structure shown in Figure 10.

It was reported that there was often conflict between the politically appointed governor of a province, who has authority but no resources, and the elected mayors of the districts, who have the resources but not the authority to determine their emergency use.

After the initial, inequitable distribution of disaster aid supplies, the process for providing aid to individuals became long and involved, as follows: 


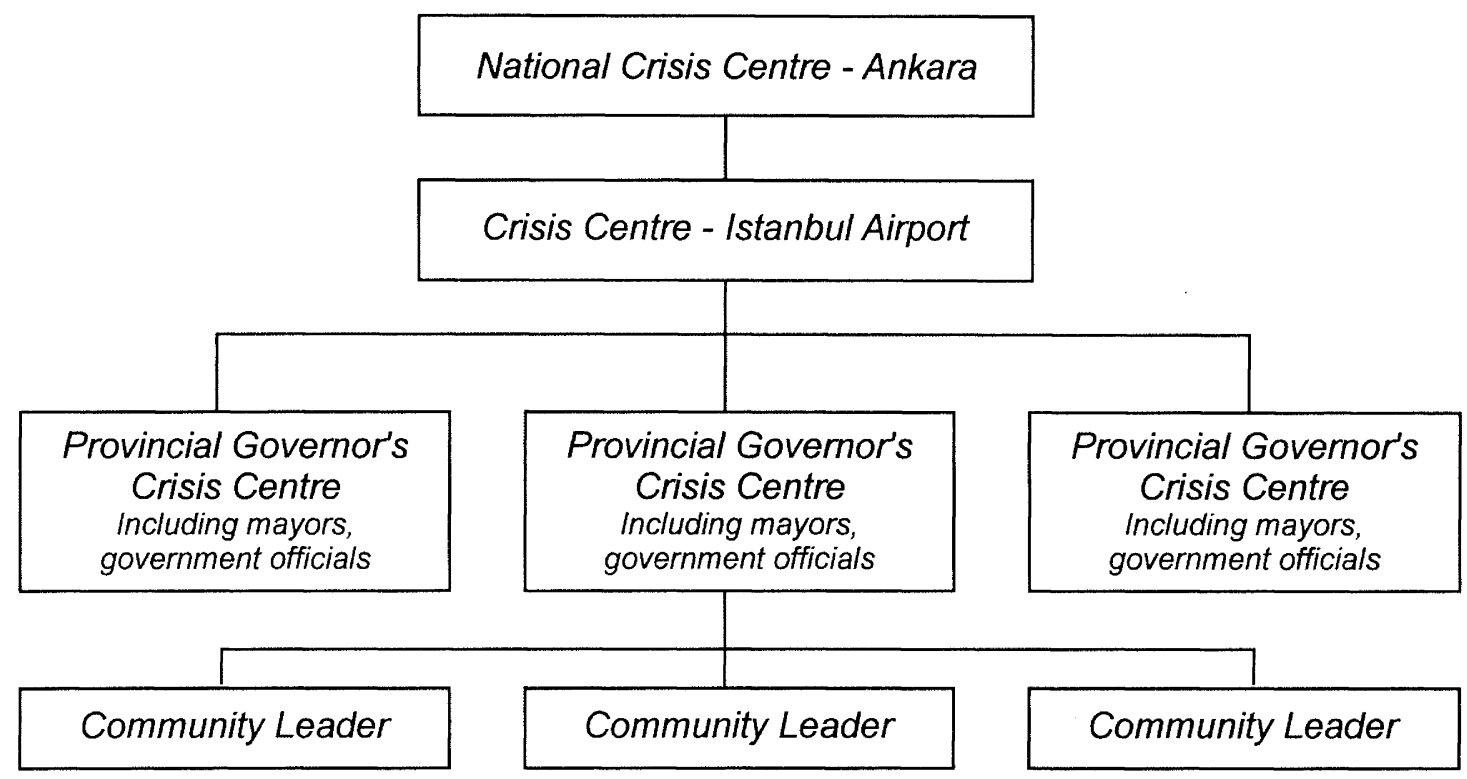

Figure 10: $\quad$ Emergency response Operational Structure.

- A letter has to be obtained from the community leader (NZ equivalent would be a community board chairperson) explaining why the person needs assistance.

- The letter must be taken to the provincial centre and seen by an assistant governor, who will stamp the letter if they agree the assistance is justified.

- The person may then have to go to any one or more of five locations to get the types of assistance they need.

- Assistance is given on a short-term basis only so the person is likely to have to return regularly to get their ongoing requirements.

In spite of the apparent lack of official co-ordination, many agencies and individuals made significant contributions to the emergency operation:

- The Portuguese rescue team, once at the emergency, is reported to have rescued around 300 people.

- A Canadian Disaster Assistance Response Team (DART) treated over 200 patients per day and purified and distributed over 200,000 litres of water per day, as well as advising the local authority on reinstatement of its water treatment and reticulation systems.

- A large manufacturing company (Unilever) purchased high quality military tents for its staff who were homeless and will provide loans of up to one year's salary (depending on the level of loss they have suffered) to help employees recover from the disaster.

- Turkey Telekom provided free access to phones and free calls within Turkey at no charge to allow affected people to contact relatives.

\subsection{Rescue}

All rescue operations had ceased by the time the NZ Reconnaissance Team arrived 24 days after the earthquake and no teams were encountered during our time there. An interpreter attached to the Canadian DART had been in Adapazzari since the third day after the earthquake and had worked with rescue and medical teams. Some of the issues described were:

- In the first two days there was local activity to retrieve those who could be heard calling from the damaged buildings.

- When the first formal rescue teams arrived, the primary means of locating trapped people was still by listening for their calls.

- It was often difficult to get silence on rescue sites to accurately locate the source of calls. Police and soldiers detailed to assist were often the worst at continuing to make noise.

- There were instances of relatives imitating calls from buildings to keep rescuers on site.

- Dog teams worked previously searched sites and got indications of people still trapped.

- Listening devices and camera equipment were also used, but their effectiveness is unknown.

- One of the teams reported to have been most effective at extricating trapped people was a mines rescue team.

- There was inadequate logistic support for rescue teams, including a lack of heavy rescue support, even though appropriate equipment appeared to be available.

- Systems for marking sites was needed indicating either trapped people located there or that the site had been 
searched and cleared were either not communicated to or not understood by all.

Rescue activities would have been more successful had there been proper co-ordination. Teams had expected to be given proper search grids but were apparently told to figure out for themselves where they should operate, which led to both omission and duplication of search areas.

\subsection{Medical and Health Issues}

Medical treatment of casualties and on-going public health seems to have been managed effectively, given the magnitude of the task.

- In the three government-built hospitals in Adapazzari there appeared to be no significant structural damage and little or no damage to medical equipment and hospital services. By contrast a private hospital collapsed.

- One of these (a maternity hospital) was still operating from tents and an old part of the hospital buildings over a month after the earthquake. They were not allowed to re-occupy the three modern wings of the hospital until a government inspection had cleared them. Apart from superficial damage due to some settlement the buildings and their services appeared to be fully operable.

- Many of the injured were initially treated in the grounds of the hospitals and later in tent treatment facilities.

- Medical evacuation by ambulance and ferry to Istanbul and then on to other treatment facilities happened relatively early in the emergency, but no records were made of who was evacuated and to where.

- A number of countries sent medical and health teams. The Canadian DART team provided a psychological support capability.

- Some of the local medical staff, who were directly affected by the emergency were still on extended leave from their duties, which were being covered by medical personnel from other cities.

- The Turkish government was reported to have mounted an aggressive public health campaign to avoid disease outbreaks.

\subsection{Welfare Issues}

No formal system for welfare management appeared to be in place one month after the event, although more order was being brought to bear on various aspects of welfare delivery.

- Welfare initially consisted of a totally non-managed process of delivery and random distribution of donated relief goods. Many of the donated goods were inappropriate, there was spoilage of improperly stored perishable items, and distribution often failed to reach target groups. In the early stages emergency volunteers attempted to rationalise this situation and four collection and distribution points were established in one town.

- No registration of evacuees or homeless has been carried out and many people do not know whether other family members have been evacuated, are in medical care, are in one of the 'tent cities', or are still missing in collapsed buildings.

- A total of 46 formal tent camps have been established, the largest of which is accommodating 7,000 people. Responsibility for the ongoing management of these is being handed to the Turkish Red Crescent organisation. Some rationalisation of the number of camps is expected.

- Food, health and education services are to be provided at the larger camps, with mobile facilities serving smaller ones.

- Many of the tent camps were provided and set up by organisations such as Rotary on their own initiative. Some appear well ordered, with good quality tents and well laid out (Figure 11), while other less formal camps are often of a makeshift nature and are established on roadsides, traffic islands and other open areas (Figure 12).

- Many thousands are camping on land near their intact residences for fear of being indoors during another earthquake. It is assumed that they are, in the main, self-sufficient.

- A large number of people are reported to be camping only until the government gives a firm indication on the future of their buildings, which appears likely to take considerable time.

- Some pre-fabricated housing units (similar to campingground cabin units) are being erected by the Turkish government and more are expected to be built over time, although it is unlikely that they will meet the demand. Serdovan, a town with a population of 40,000 suffered considerable damage, yet only 20 pre-fabricated housing units had been supplied.

- Portable toilets, portable shower units and mobile banking, telephone and postal services are in use at various operational and welfare locations.

- Serious concerns are held for the continued well being of homeless people who face the winter in tents, most of which are not designed for such conditions. If the estimates of the Canadian DART personnel are correct, it may be up to three years before permanent housing solutions are found for all evacuees.

\subsection{Emergency services}

Police and Army personnel were in evidence throughout the damaged areas. Additional personnel were deployed to damage areas early in the emergency and were used to establish security at key points. Police or army personnel are stationed at most of the larger tent camps. Apparently gold shops in Adapazzari were looted shortly after the earthquake, but this ceased once Police shot some of the looters.

There were no reports or evidence of fire having been a major issue after the earthquake (except at the Tupras oil refinery) although it was reported that foam systems were successfully used to extinguish some fires. There was no obvious presence of fire units carrying out rescue or recovery work in 
the damaged areas although they were keeping the water reservoir at the maternity hospital filled.
Ambulance services were utilised after the earthquake to evacuate injured to Istanbul and were stationed at rescue sites during rescue operations. Other roles such as assistance with triage or treatment were not established.

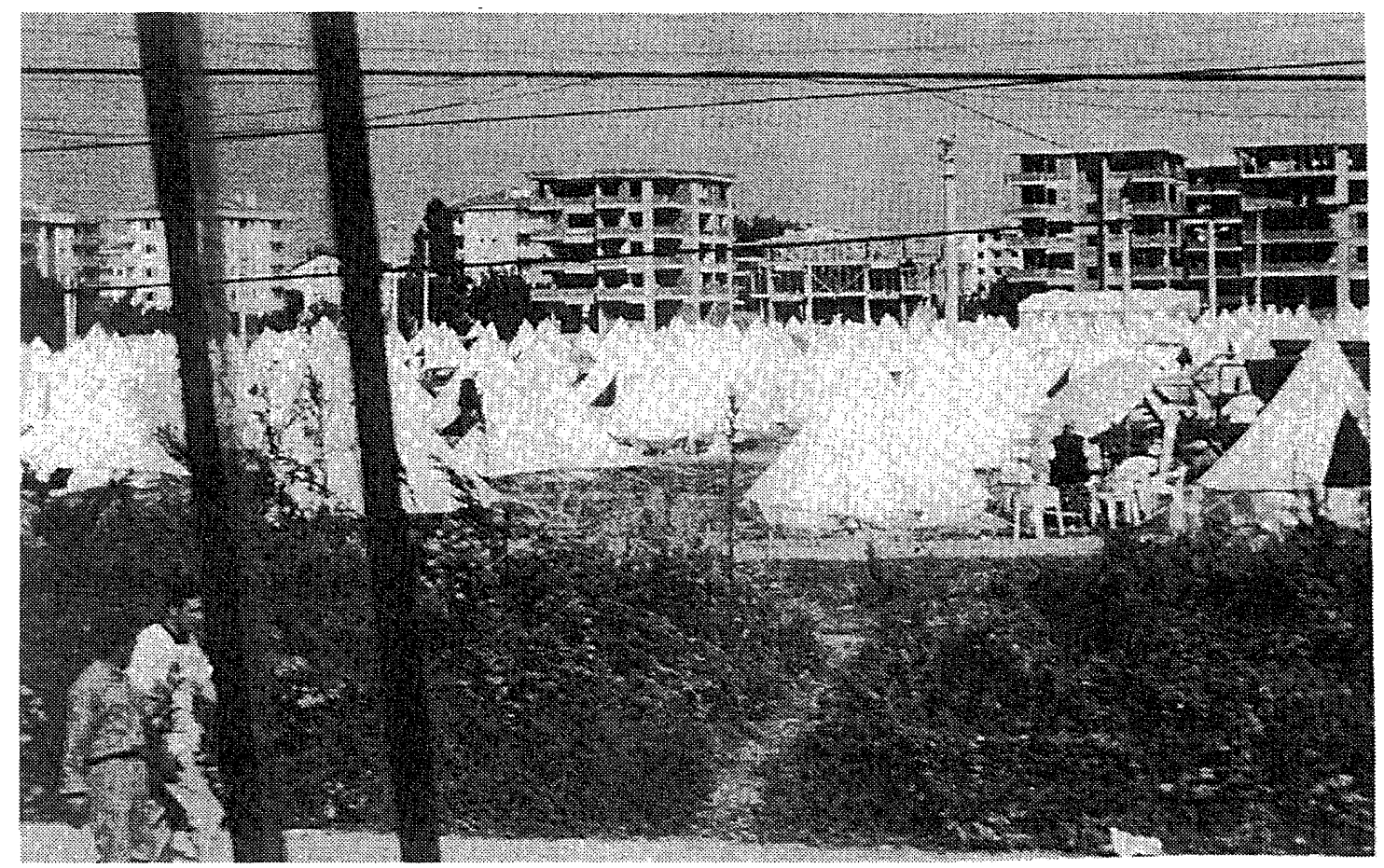

Figure 11:

Typical tent city organised by the Red Crescent.

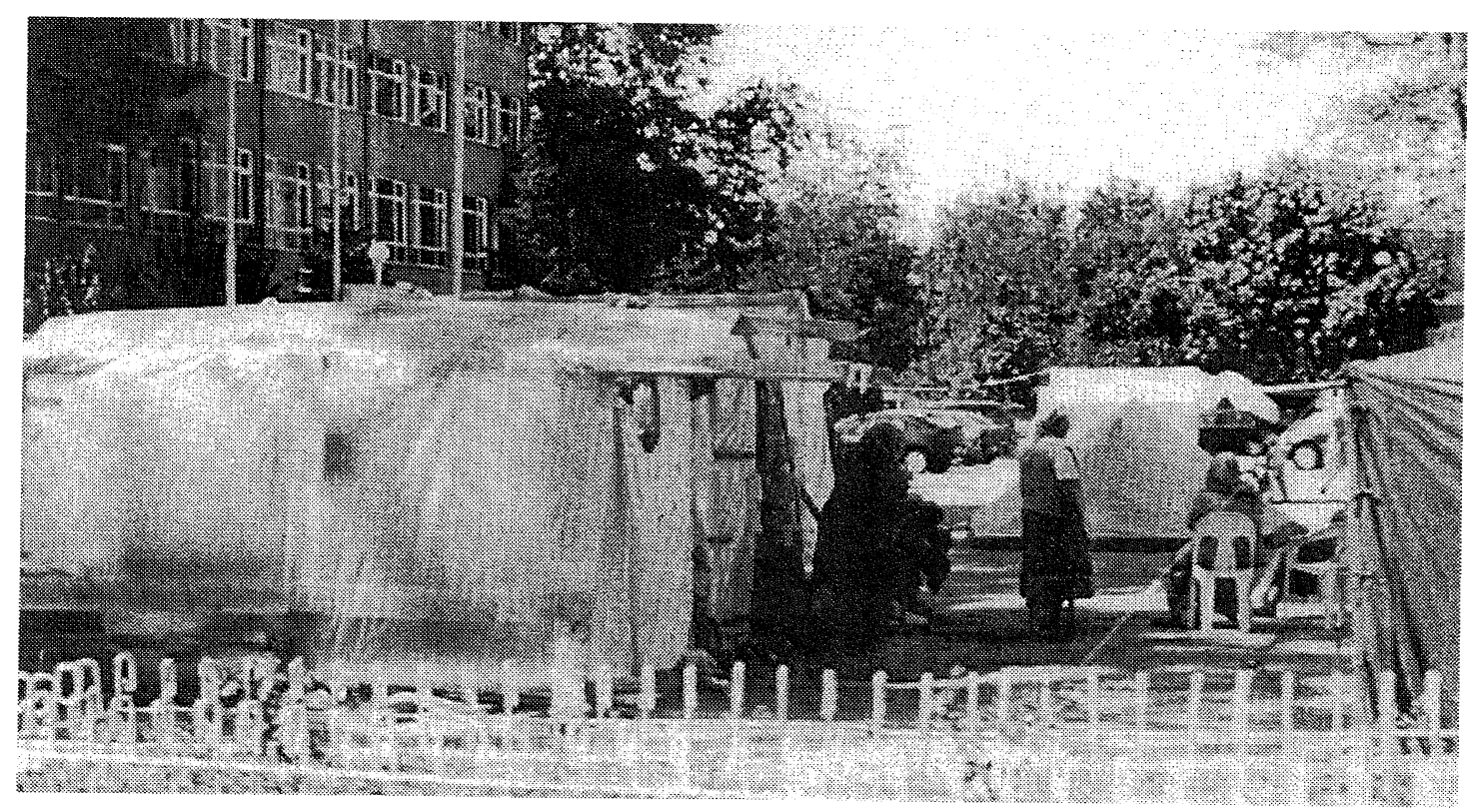

Figure 12:

Typical makeshift camp. 


\section{4}

\section{GEOTECHNICAL FEATURES}

4.1

\section{Slope Stability}

The region in Turkey affected by the earthquake has a hilly topography not unlike many parts of New Zealand. The fault trace runs generally east-west along the south shore of the Gulf of Izmit, through a coastal plain extending west from the gulf, and into a sedimentary basin in the Adapazzari area. Immediately south of the fault trace, the topography rises up into a range of steep sided hills. Slopes exceeding 30 degrees were observed during our road journey from Yalova to Izmit. The steeper slopes are mostly wooded.

Very little slope instability was observed. Only one significant landslide was seen, and this was in the steeper wooded country. Viewed from a distance, it was impossible to determine whether or not this was triggered by the earthquake. The landslide did not appear to have impacted. on any populated area or facility.

Driving from Yalova to Izmit the road cuts along the edge of some steep wooded country. No significant landsliding was observed during this drive, with no evidence of any material falling down onto the roadway. Some buildings were located on slopes estimated to be as steep as 25 degrees. None of these buildings were seen to have suffered from any land instability.

The Trans European Motorway (TEM) runs east-west along the northern side of the Gulf of Izmit, some $15-20 \mathrm{~km}$ from the fault trace. The motorway in places is cut into steep hillsides in highly fractured rock. Again, there were no indications of any instability or of any rock material falling onto the roadway. In places light weight netting had been placed over cut faces to prevent small rock fragments from falling onto the roadway. These nets were undamaged and were not retaining any material.

The high degree of land stability observed for this earthquake was surprising compared to similar events in New Zealand. The reasons may be that the earthquake occurred during late summer in dry conditions, and that the ground motions generated by this earthquake may not have been extreme.

\subsection{Earth Retaining Structures}

A number of earth retaining structures were observed. A number of gravity masonry retaining structures were observed along the TEM through rock cuts, along the Yalova - Izmit road through cuts in weathered rock and colluvium, and lining a drainage canal near Golcuk. These structures appeared to have been well constructed and none appeared to have been damaged, with the exception of the canal lining where it had been offset by the fault trace.

A reinforced earth approach ramp to a motorway overbridge crossing the TEM near Arifre was observed. The overbridge had been destroyed because the fault trace had offset the abutments. However, the reinforced earth retaining structure was in excellent condition apart from one section which had been wrenched by the fault trace offset, as shown in Figure 13.

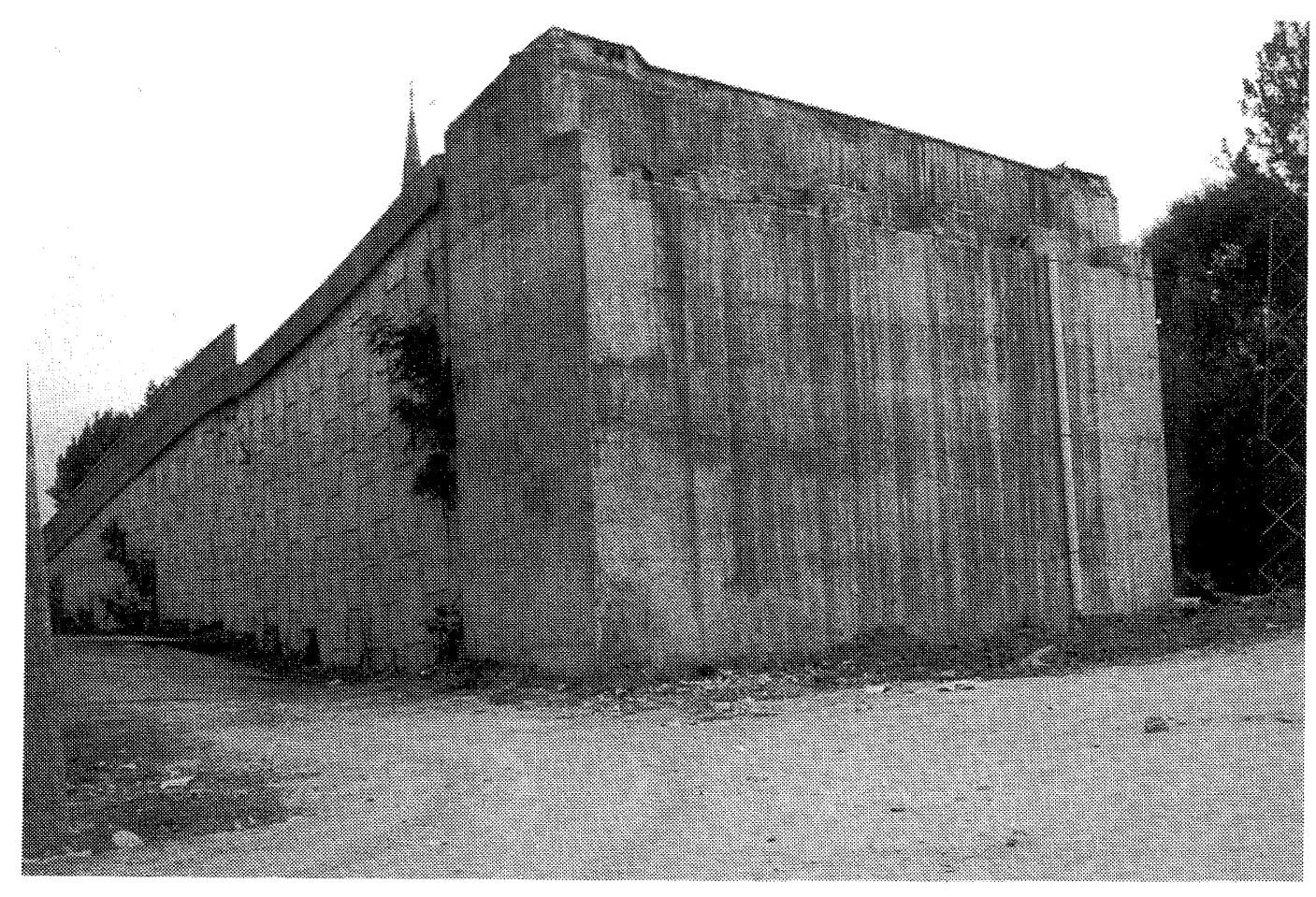

Figure 13: $\quad$ Reinforced earth approach to collapsed motorway overpass near Arifre. Fault trace passes underneath structure at dip in road. 


\section{3}

\section{Ground Deformation}

Very little ground deformation was observed throughout the earthquake affected areas apart from three specific zones: west of Golcuk near to the coast, the lakefront at Sapance, and central Adapazzari. Other areas were remarkably unaffected with roads, kerbing, and pipe networks visibly straight and intact, even in zones where there was heavy damage to structures.

West of Golcuk a large area of several square kilometres adjacent to the coast has subsided by approximately 2 metres causing inundation of low lying areas including a number of buildings, an amusement park (shown in Figure 7), and a football field. Near to the sea front on the eastern fringe of the affected area there is evidence of liquefaction and lateral spreading. Further west there is evidence of local slumping along the seashore with rotated lamp stands and one building reported to be completely submerged.

However, the main part of the subsidence does not seem to have been caused either by liquefaction or by landsliding but by tectonic subsidence with a graben forming at a releasing bend in the fault trace. The ground surface of the subsided area is intact with long walls remaining straight and uncracked. There is no evidence of rotation with structures being measured as vertical. Almost the entire Ford Motor Plant sits on the subsided block and is reported to have been undamaged (with exception of one corner of a building which straddles the fault trace). The southern extent of the subsidence is marked off by a scarp which exhibits a right lateral movement as well as vertical subsidence, as shown in Figure 6 .

The lakefront at Sapance has been severely affected by liquefaction and lateral spreading towards the lake. The associated subsidence has caused minor inundation of the waterfront. Unfortunately, a resort hotel recently constructed on the waterfront had subsided by at least 1 metre and probably also moved laterally towards the lake. The hotel appeared to have been founded on two separate concrete rafts which had settled differentially causing major disruption to an atrium area connecting the two halves. The hotel is a complete loss with the foyer now below lake level, as shown in Figure 14.

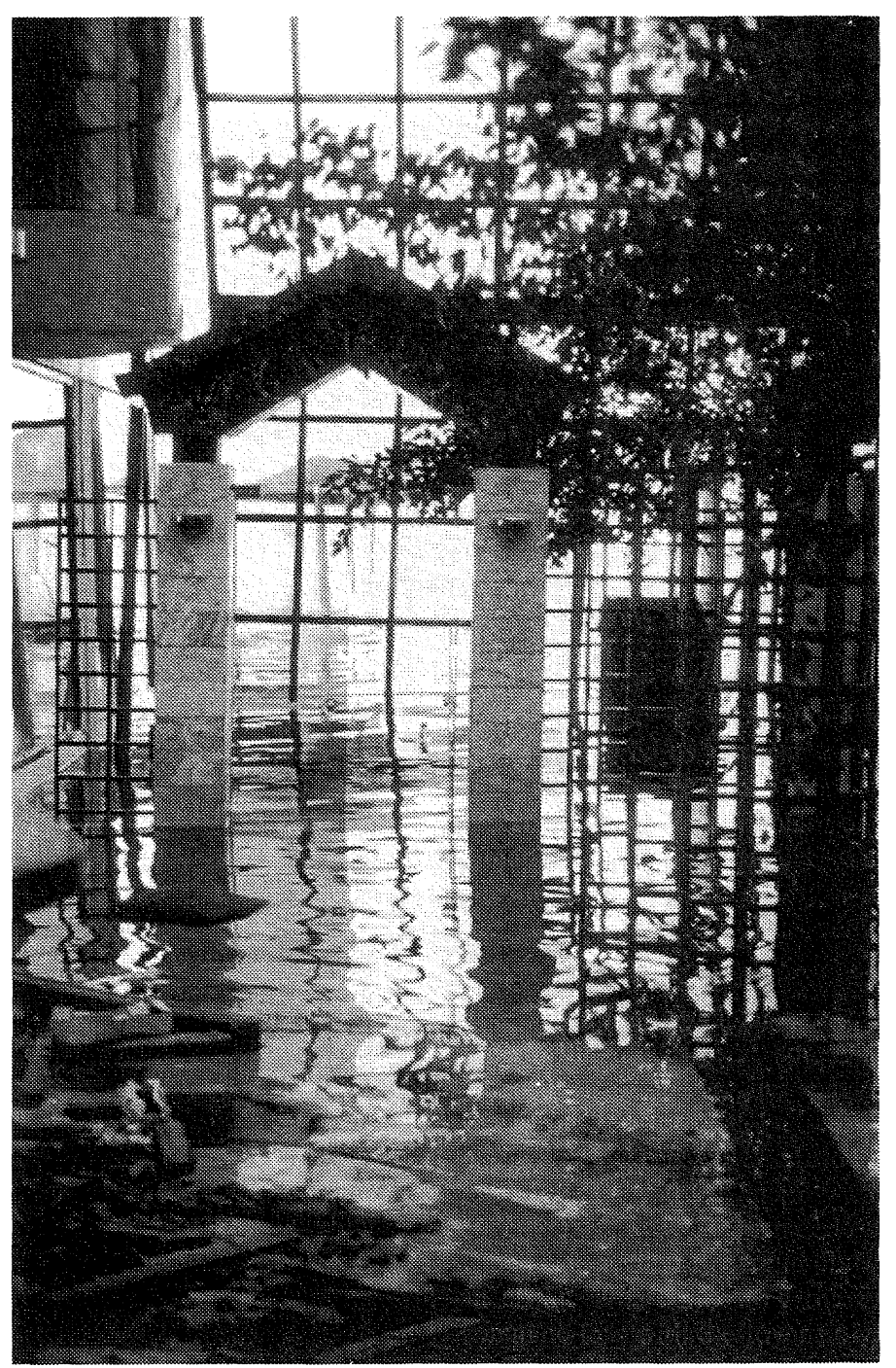

Figure 14: $\quad$ Flooded atrium of hotel at Lake Sapance caused by soil liquefaction and lateral spreading. The building has settled and moved out into the Lake. 
Much of central Adapazzari has been affected by liquefaction with associated ground deformations and building settlement problems. The area affected is at least several square kilometres from our observations although no attempt was made to map the total extent. Ground deformations were generally "patchy" throughout the area with some areas having no damage or only minor damage while other areas were affected by ground fractures and lateral movements and heaving associated with settlement of adjacent buildings. In the worst affected areas building settlements of one metre were typical, as shown in Figure 15. Pipeline damage in Adapazzari seems to have been extensive with the main lines already under re-construction. Sand boils were not widely observed but close inspection of many settled buildings showed small amounts of ejected, stratified, fine sand. Some large sand boils were observed. Many smaller features have probably been lost because of the intervening clean-up operations.

\subsection{Structure Foundations}

Most of the typical apartment structures have very strong foundations consisting of a hollow reinforced concrete raft utilising a $400 \mathrm{~mm}$ slab with upstand beams of approximately
1 metre in depth. Outside of the three areas affected by mass ground deformation foundation performance was observed to be excellent and presumed to have had no detrimental effect on structural performance. In the liquefaction zones of Adapazzari these shallow raft foundations were subject to settlements of up to 1 metre. Some structures settled vertically, others were tilted (Figure 15), some overturned completely (Figure 16). In all observed cases the rafts remained intact. Most settled buildings showed signs of water ejection and often minor quantities of fine sand ejection. The water table was approximately 0.5 metre from the ground surface and had entered the settled ground floors of many buildings. Generally, those buildings in the liquefaction zones had suffered much less structural damage with few collapses but still represent a total economic loss.

It was possible to observe the underside of two foundations where the building had completely overturned, such as Figure 16. Apparently, the sites had been excavated to approximately 1 metre depth to a brown sand/silt/clay, a small depth of gravel was placed, and the bottom slab of the foundation raft was poured directly onto the gravel. The original condition of the subgrade was impossible to determine because of subsequent dessication.

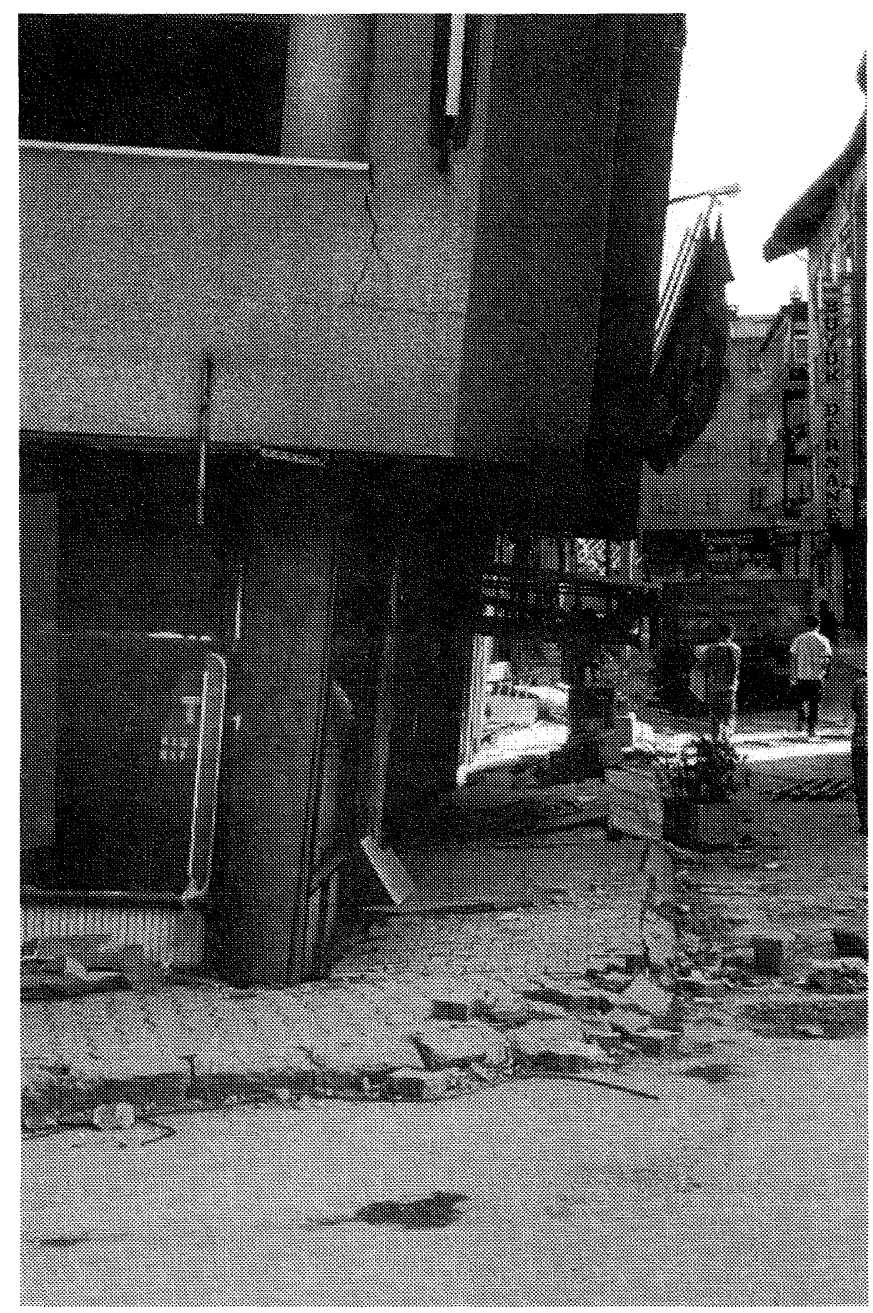

Figure 15: $\quad$ Settlement of approximately 1 metre was typical for buildings in Central Adapazzari where soil liquefaction occurred. 


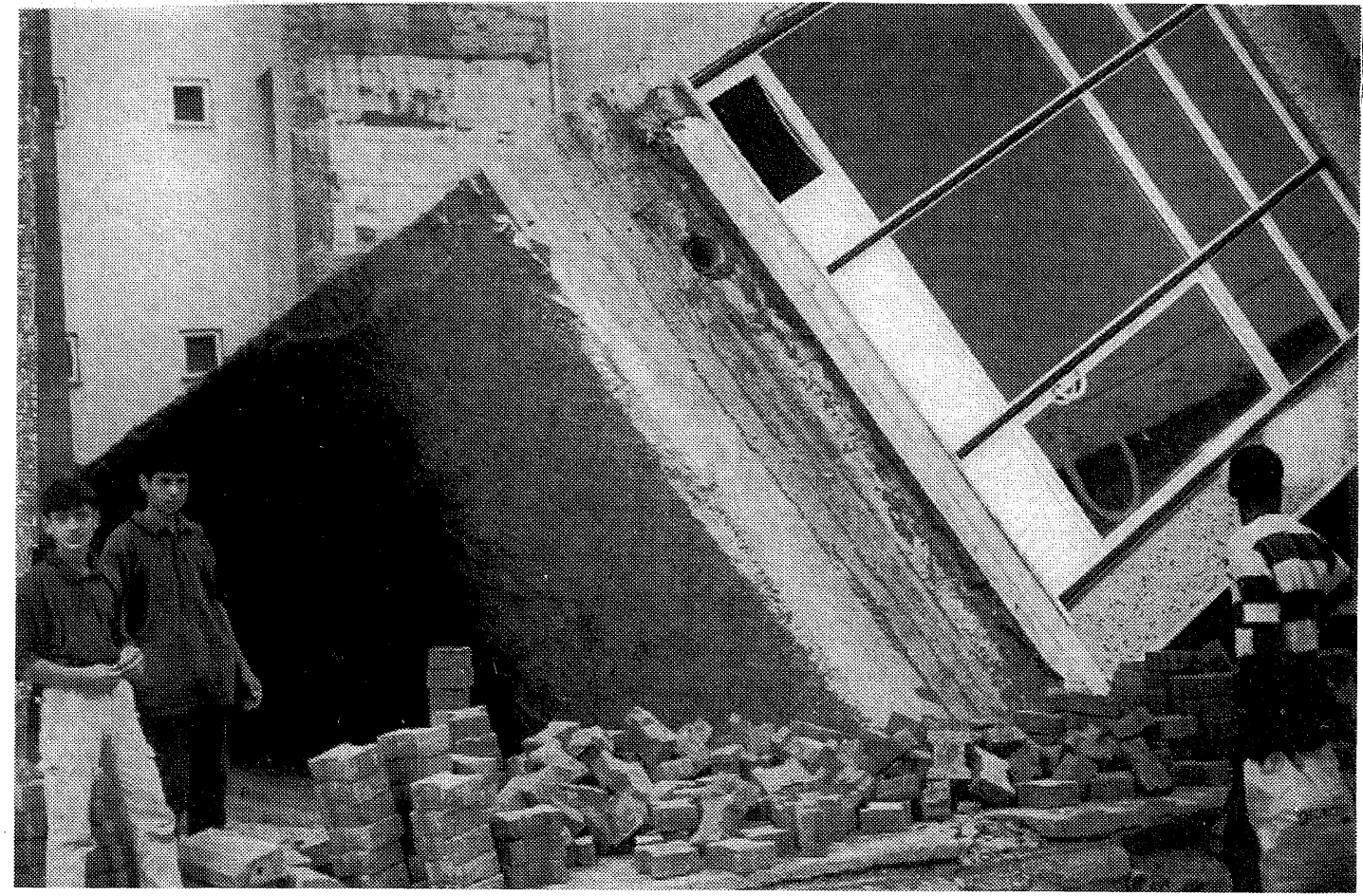

Figure 16: $\quad$ Overturned building near Central Adapazzari exposing a typical foundation system of a 1 metre thick hollow raft. One corner has sunk because of soil liquefaction. Note the lack of structural damage.

\section{5}

\section{Fault Rupture}

Although the existence and general location of the North Anatolian fault was well known prior to the earthquake, and in several places the exact location of the fault was known, there appeared to be no enforced policy preventing construction on, or across, the fault. We were able to follow the fault trace for a distance of several kilometres and observe the affect on a number of structures and systems.

The fault trace consisted typically of a right-lateral displacement of approximately 2 metres, varying from place to place. In some locations graben structures were developed causing localised subsidence and undermining of a number of structures which had collapsed.

A number of buildings were observed straddling the fault trace in situations with almost pure lateral offset. One, on a typical raft foundation, seemed unaffected with the foundation remaining intact and the trace simply offset to the building perimeter. A small portal frame factory had been wrenched with the fault tearing the floor slab and offsetting the portal frames. The roof, however, remained up and the building may still be able to function. One three story house had been badly damaged by the fault which passed through it. The foundation of this house appeared to consist of a suspended slab on foundation walls. The slab and walls had been torn by the fault and the building columns had been offset causing major structural damage.

A major electrical transmission line crossed the fault obliquely at one location, causing approximately 2 metres of "stretch" across the line. Apparently, the line was able to cope by pulling wire from adjacent spans as evidenced by insulator columns being pulled out of plumb towards the fault.

The main water supply pipe for Izmit crossed the fault at 90 degrees. The pipe is approximately 1.5 metre diameter, of wellded steel construction with plastic wrapping, and was installed by Thames Water. The pipe, shown in Figure 17, had been excavated and recently repaired after a 2 metre offset across the fault trace. One motorway overbridge was destroyed by the fault trace offset causing spans to drop.

\section{BUILDINGS}

The earthquake destroyed some 20,000 buildings with another 30,000 ruled uninhabitable. Most of the building stock within the epicentral region are low to medium rise (410 storey) reinforced concrete residential/commercial buildings (see Figure 18) and related services buildings including hospitals and schools along with some office buildings. Many of the buildings have been built in the last 20 years as the region has experienced considerable growth in its industrial sector, now accounting for about one third of Turkey's industrial productivity. 


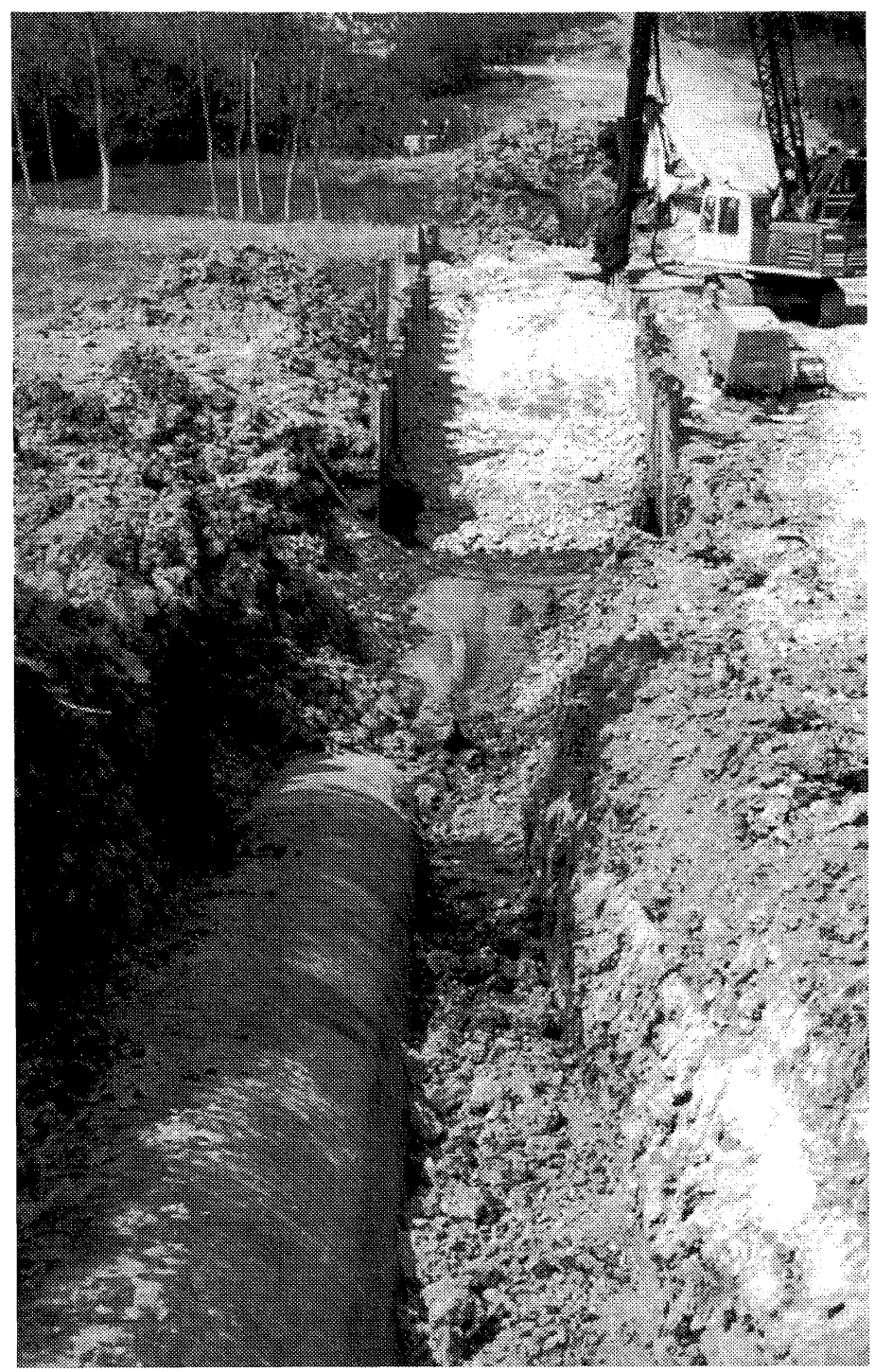

Figure 17: $\quad$ Main water pipeline supplying Izmit after repair. Note the right lateral offset where the pipe crosses the fault trace.

\subsection{Codes and Regulation Enforcement}

Lateral load design requirements for buildings and bridges have existed in Turkey since 1936. The first stringent set of seismic requirements came into affect after the 1939 Erzincan earthquake. These were revised a number of times over the next 30 or so years and were followed by introduction in 1975 of the more comprehensive Turkey Earthquake Code. The current code came into effect in January 1998 and is an adaptation of the Uniform Building Code (UBC) with reasonably sophisticated and extensive seismic design provisions.

Existing local government regulations require building approvals to be obtained for building developments. The approval process is understood to include review of the building design for conformance with the design codes and regulations as well as a check of the planning and geometrical aspects of the developments. Construction monitoring is also required to be undertaken by the local government engineers.

It was widely reported in the newspapers that most local governments however have been unable or incapable of enforcing the existing regulations, due to lack of manpower, lack of qualified personnel, and the sheer quantity of work. Furthermore, the approval process when applied does not often focus on the technical aspects of building developments and it can often take months for a project to be approved. It was also reported that monitoring of the construction process by the local government engineers is very often non-existent. Because of the difficulties associated with the legal approval process, the majority of housing developments do not go through any approval process. 


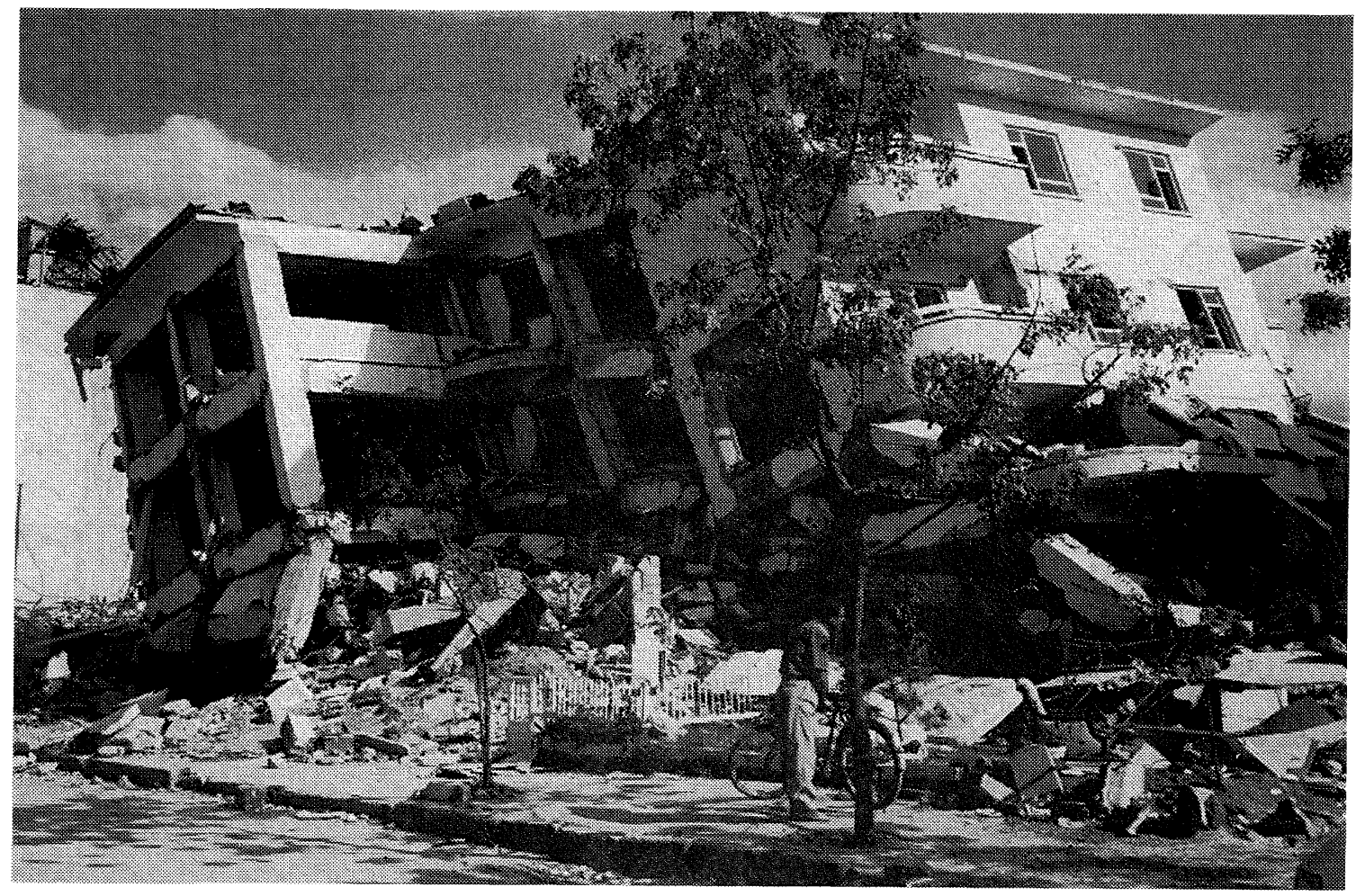

Figure 18: $\quad$ Typical collapsed masonry infill, reinforced concrete frame apartment block.

It is estimated that more than 70 percent of buildings in Turkey are illegal. These most commonly comprise buildings as high as 12 stories constructed by legal owners of the land without local government approval.

\subsection{Construction Practices}

Under the current system the design engineer and architect are employed directly by the building contractor. The contractor is also required under Turkish law to appoint suitably qualified personnel to supervise or monitor construction. Such inspections are often very lax or nonexistent with some inspectors prepared to sign off on a project without ever visiting the site. Typically no on-going construction inspections are undertaken by the design engineer to ensure compliance with the design intent.

Many of the smaller contractors responsible for construction of much of the 4-8 storey residential housing comprising the majority of the building stock do not bother with employing engineers. These buildings are simply built according to past experience adopting standard framing arrangements, detailing and construction practices used in the region for many years. Little or none of the structure is engineered. These designs fall well short of the current code requirements. Such housing in the region constitutes more than $90 \%$ of all residential buildings.

Contractors involved in public housing projects are required to be certified by the Ministry of Housing and Public Works. Tighter control exists in respect to compliance with codes and regulations and construction monitoring. Accordingly, public housing is viewed to be better built with fewer of the problems of private developments. Understandably the prices of public housing are higher than those of private developments and the population is less inclined to purchase public units.

\subsection{Residential/Commercial Buildings}

Much of the building stock throughout the region are multistorey residential /commercial buildings of reinforced concrete construction, typically 4 to 8 storeys high. Most are framed structures utilising rectangular columns distributed throughout the building plan and oriented, though sometimes in a haphazard fashion, in both directions. Floor construction comprises either rib slabs with hollow masonry infill, approximately $400 \mathrm{~mm}$ in overall depth, with similar depth solid beam elements between columns or alternatively solid in-situ slabs and down-stand beams, depending upon the local area.

Exterior columns, in many of the residential buildings, are set back some 1.0 to $1.5 \mathrm{~m}$ from the exterior building line of the upper floor levels, with the floor beams cantilevered to the building edge. Non-structural unreinforced masonry (hollow brick or Ytong block) infill is used for the external cladding at these levels, fitted tightly between the floor structure with window penetrations through the infill panels. The ground floor levels are often used for commercial/shopping premises and the masonry infill is replaced around much of the 
building perimeter glazed or open shop fronts and garages. In many cases the ground level floor-to-floor height is greater than that of the upper levels. Non-structural masonry infill fitted tightly between the structure is also commonly used for internal partitioning, see for example Figure 19.
Almost without exception, foundations to these buildings comprise raft structures. From observations made, typical construction consists of a base slab, of the order of 300-400 $\mathrm{mm}$ in thickness, with up-stand beams on column grid lines with a total overall depth of approximately $1 \mathrm{~m}$.

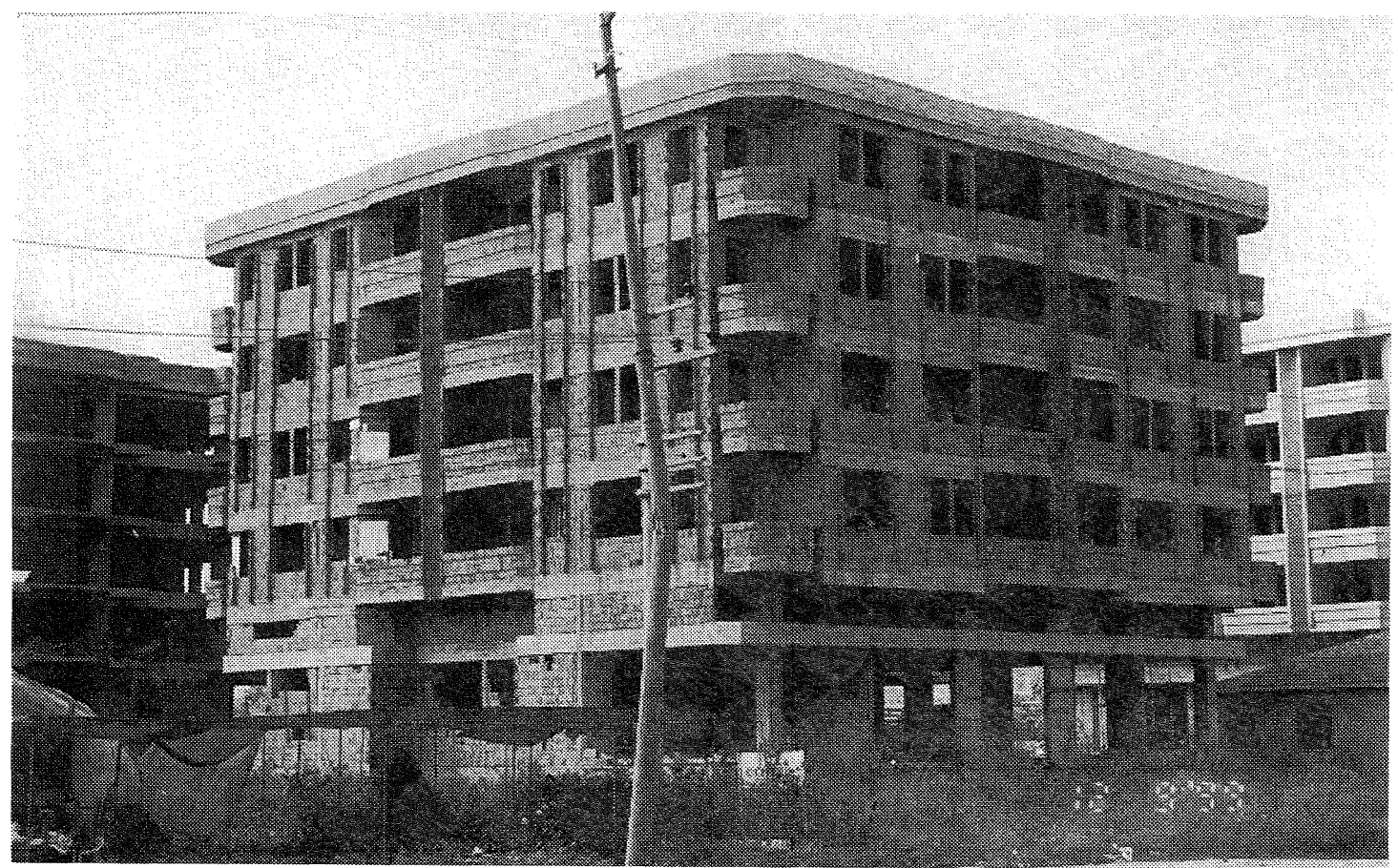

Figure 19:

Typical apartment building under construction showing setback concrete columns, hollow brick infill in progress and soft storey ground floor.

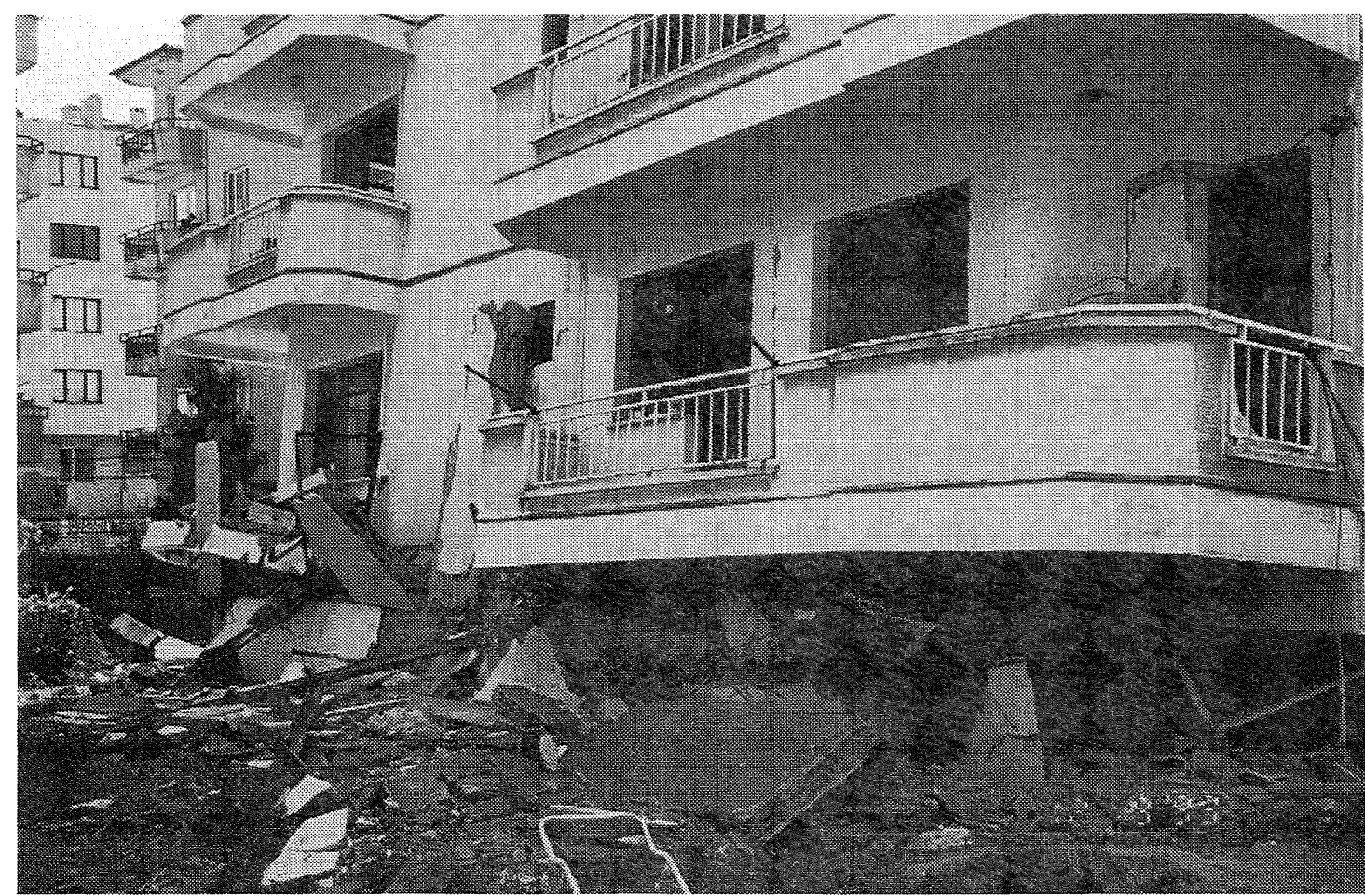

Figure 20:

Near new apartment building with collapsed ground floor. 
This type of building responded particularly poorly to the earthquake, with a large number suffering heavy damage and collapse to be seen throughout the region. Buildings in areas of Golcuk and Adapazzari were particularly devastated, with Izmit and Yalova to a lesser extent. Many of these buildings appeared to have been built in the last 5 to 10 years or were under construction.

The failures can be attributed to a number of contributing factors:

- $\quad$ Soft Stories. Soft storey mechanisms at ground floor level (Figure 20) were common as a consequence of the reduced extent of infill at this level. Collapse was often initiated by this effect, with either partial collapse of the lower one or two levels or total collapse of the building. Whilst the masonry infill walls would not have been considered as primary lateral force resisting elements, their presence would have enhanced the stiffness and lateral strength of the upper levels. Where collapse of upper levels was averted, damage to the infill inevitably occurred along non-separated corners, along the interface of the upper courses of the infill panels and the structure over and along the interfaces with column elements. Diagonal cracking through the infill was often observed.

- Design and Detailing Practices. Reinforced concrete detailing fell far short of the requirements of both the current and the previous seismic codes and was clearly inadequate to accommodate strength and ductility demands in key elements during the earthquake. Beams and columns were often only nominally reinforced, typically with R16 longitudinal reinforcement and single R8 stirrup hoops at $200 \mathrm{~mm}$ centres over the full length of each member, as seen in Figure 21. R12 longitudinal reinforcement was observed in a number of collapsed buildings and D25s in no more than half a dozen buildings. Lap lengths to R16 column starter bars seen at a number of sites under construction did not appear to exceed $800 \mathrm{~mm}$. Stirrups typically incorporated 90 degree hooks with modest extensions, as seen in Figure 22. Failures of columns at the connection to beams were often observed due to the inadequacy of the confining reinforcement.

- Construction Quality. The quality of construction and materials used was often poor. Concrete strengths appeared low with a high level of voids and high sand content evident in many buildings. Concrete vibrators had in many cases not been used. Seashells and corroding reinforcement were observed in one badly damaged building in Yalova indicating the use of sea sand, apparently common practice in the Gulf of Izmit area. Concrete covers were generally low as seen in Figure 23, with reinforcement often to be seen on the outside face of elements. The use of hand mixed concrete was common. Failure of ground floor columns initiated by crushing of concrete, with subsequent buckling of inadequately confined longitudinal reinforcement, was often observed.

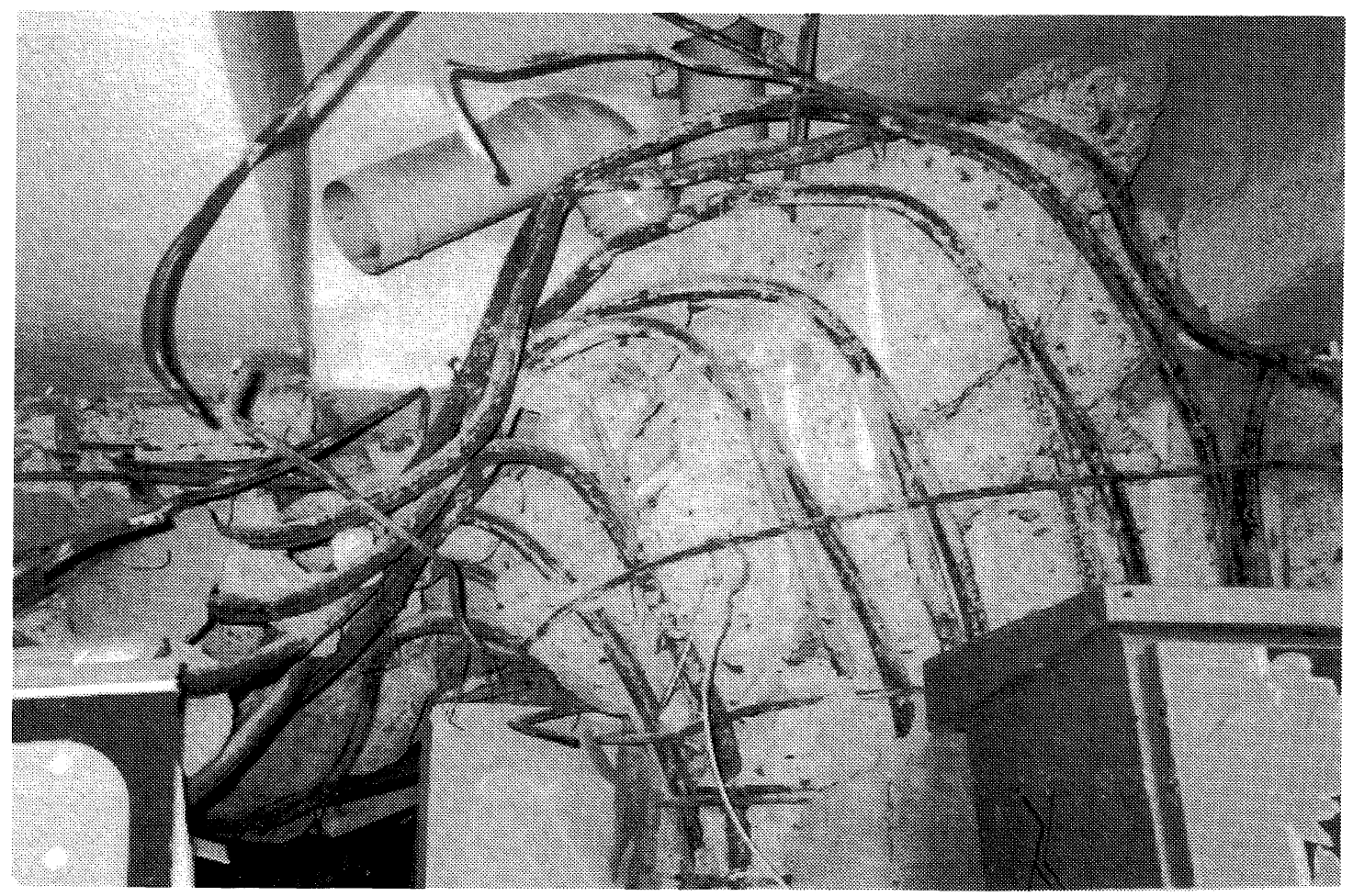

Figure 21: $\quad$ Typical failed column showing R16 longitudinal bars and single R8 hoops. 


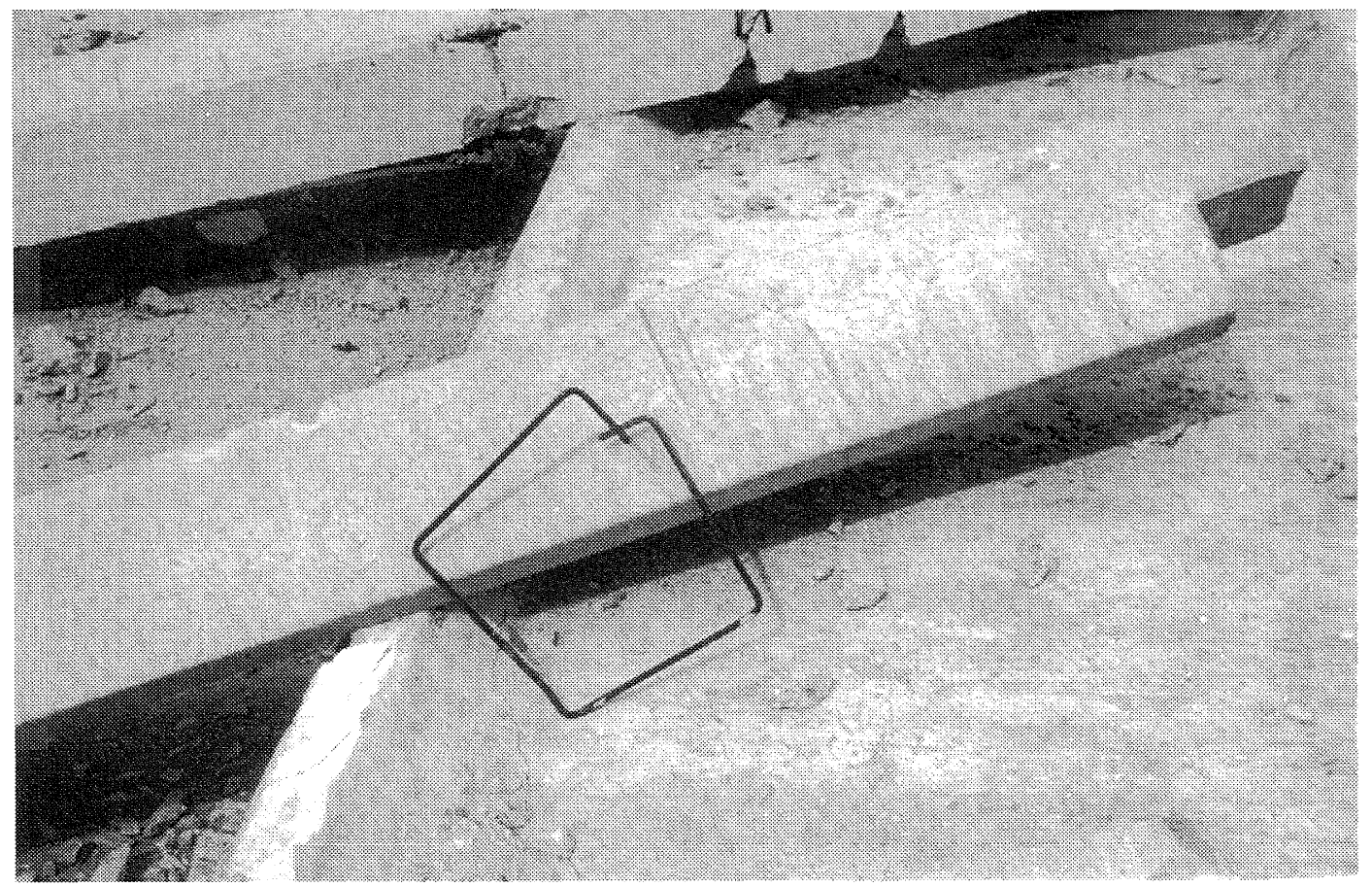

Figure 22: $\quad$ Typical column tie showing poor detailing with 90 degree hook and short extensions.

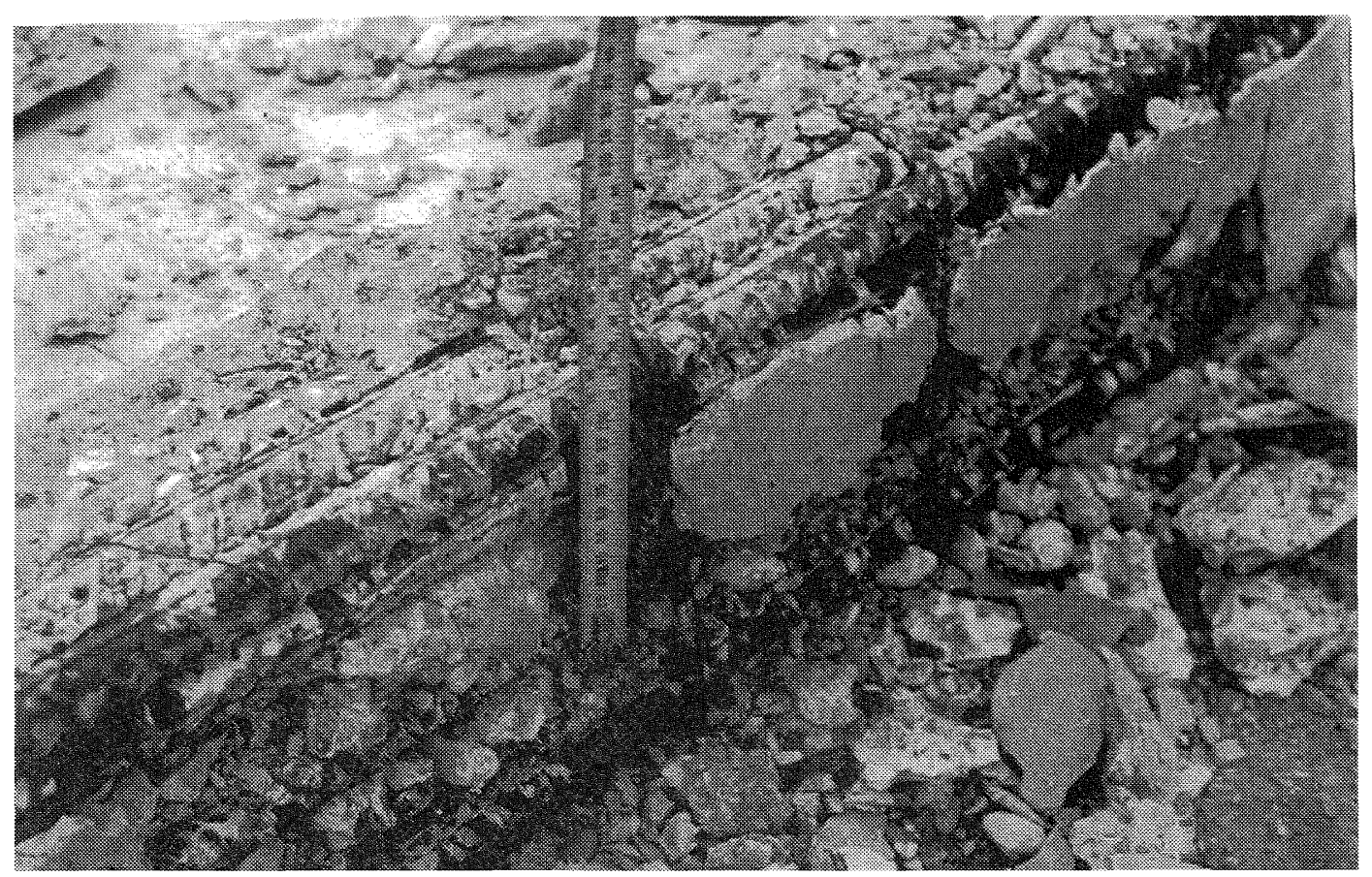

Figure 23: $\quad$ Inadequate concrete cover in a precast concrete purlin. 
- Ground Deformation. Ground deformation and surface faulting was responsible for extensive damage to local areas, as described in Sections 4.3 to 4.5.

\section{$5.4 \quad$ Government Housing}

Public government housing in the epicentral region was generally only to be seen in any concentration in areas around the city of Izmit and at the Turkey Naval Base at Golcuk. These buildings were typically of the order of 6-12 storeys in height, incorporating brick infill in the openings formed by the reinforced concrete frames together, in some cases, with reinforced concrete shear walls. They generally did not exhibit the soft storey phenomenon of the private housing developments. The buildings appeared to have performed very well structurally, with no or little damage observed externally. It was locally viewed that the majority of these buildings complied with the modern design codes, incorporated construction materials of appropriate standards and had been adequately supervised during construction.

\subsection{Other Buildings}

Buildings not included under the residential/commercial category are generally limited in number. The range and performance of these are best illustrated by reference to the following case studies.

T C Ziraat Bankasi Building, Adapazzari, Figure 24: This building is located in the city centre of Adapazzari and had been constructed by a Japanese contractor. It was founded on driven steel piles with no evidence of settlement. The front half of the building is 6 storeys in height and the rear 5 storeys, with a single level basement. Framing to the building exterior, comprising reasonably substantial closely spaced columns coupled by deep beams, forms the major lateral stability system to the building. The building appeared to have minimal damage and was fully operational when inspected.

Some nominal flexure-shear cracking was observed in two columns at ground floor to the rear half of the building and diagonal cracking through two 1 st floor coupling beams. Local cracking was also to be seen in two 1st floor columns to the front half of the building and nominal spalling at the base of two ground floor corner columns. Internal nonstructural masonry infill walls had been damaged, with cracking at the interface of panels with the structure.

Turk Telekom Building, Adapazzari, Figure 25: This 5 storey telecommunication building is located immediately adjacent the T C Ziraat Bankasai building in the city centre of Adapazzari. The structural system comprises internal core walls around the stair and lift shafts and peripheral framing of reasonably light proportions. Cracking occurred to the nonstructural masonry infill panels to the building exterior typically at the interface between the upper courses of the panels and the floor structure over. Some areas of the 3rd level infill to the street facade had collapsed onto the footpath and street below and fallen switching cabinets had been visible in the interior of the building. These masonry infill panels were being reinstated at the time our inspection. Cracking had also occurred to internal masonry infill.
The building was constructed in 1988 and is founded on $15 \mathrm{~m}$ driven steel piles with no evidence of settlement. This building and the adjacent bank building were understood to be the only buildings in Adapazzari to be founded on piles. Observed structural damage was minimal and the building was understood to be fully operational.

Sakarya Birth and Childcare Home, Adapazzari, Figure 26: This 5 storey, 160 bed maternity hospital facility comprised three separate buildings structurally separated from one another and was constructed in 1993. The buildings were reinforced concrete framed structures with non-structural masonry infill panels in the openings between. Whilst the structures had undergone very little structural damage, considerable cracking was evident in the masonry infill. The plaster finishes over the movement joints between each building had also cracked open, with gaps up to $20 \mathrm{~mm}$ evident.

The gable end walls at the ends of the outer two buildings of the facility had collapsed between the effective ceiling height of the upper floor and the upper roof level, principally due to lack of out-of-plane restraint at the upper roof level. It should be noted that common construction practice for the majority of buildings in the area was for a reinforced flat concrete roof or "lid" to be constructed over the upper most floor at effective ceiling height, with a timber framed, tile covered roof erected over.

All three buildings had undergone almost identical vertical settlements of 70 to $100 \mathrm{~mm}$.

The buildings were unoccupied at the time of our inspection and the electric power supply had not been restored. Exactly one month after the earthquake, the staff of the hospital were still waiting for university engineering personnel to undertake an inspection to advise whether or not the buildings were safe to reoccupy. The hospital was in the meantime operating out of an adjacent 50 year old, 40 bed, building built by the Germans, located behind the main facility, supplemented by tents pitched in the adjacent garden.

It was reported that the two other Government run hospitals in Adapazzari, Devlet Hospital and the SSK ( Social Security Organisation) run hospital, had incurred little structural damage, apart from a wing to one of the hospitals, during the earthquake though some non-structural building damage and damage to equipment. Initially patients were moved out of these hospitals immediately following the earthquake but the hospitals were later reoccupied. A private hospital in Adapazzari was reported as being badly damaged.

Basketball Stadium, Golcuk Ataturk Stadium,Golcuk. This facility comprises a 2 to 3 storey amenities building at the front of the site with a covered basketball stadium behind, both structurally separate.

The stadium structure incorporated internal tiered seating along each side, utilising reinforced concrete bleachers and raking support beams. Two levels of changing and associated facilities existed behind the tiered seating, supported by concrete frames rigidly infilled with masonry brickwork. High level glazing was present along the exterior side walls at each floor level. The end walls were essentially solid, apart from entry doors, and comprised concrete framing to approximately eaves height, rigidly infilled with masonry brickwork, and solid reinforced concrete apex end walls 
above. The roof structure was a proprietary space frame system supporting lightweight metal roofing on metal purlins. Support of the space frame at the end walls was via tube props off the frame structure below. The purlins were the only elements of the roof structure connected to the upper level of the end walls.
The fault trace had passed under the north east comer of the stadium building resulting in slumping and lateral spreading of the ground to the north. The foundations to the northeast corner of the structure had been exposed, with piles to the corner of the building and the adjacent external stair structure to be seen.

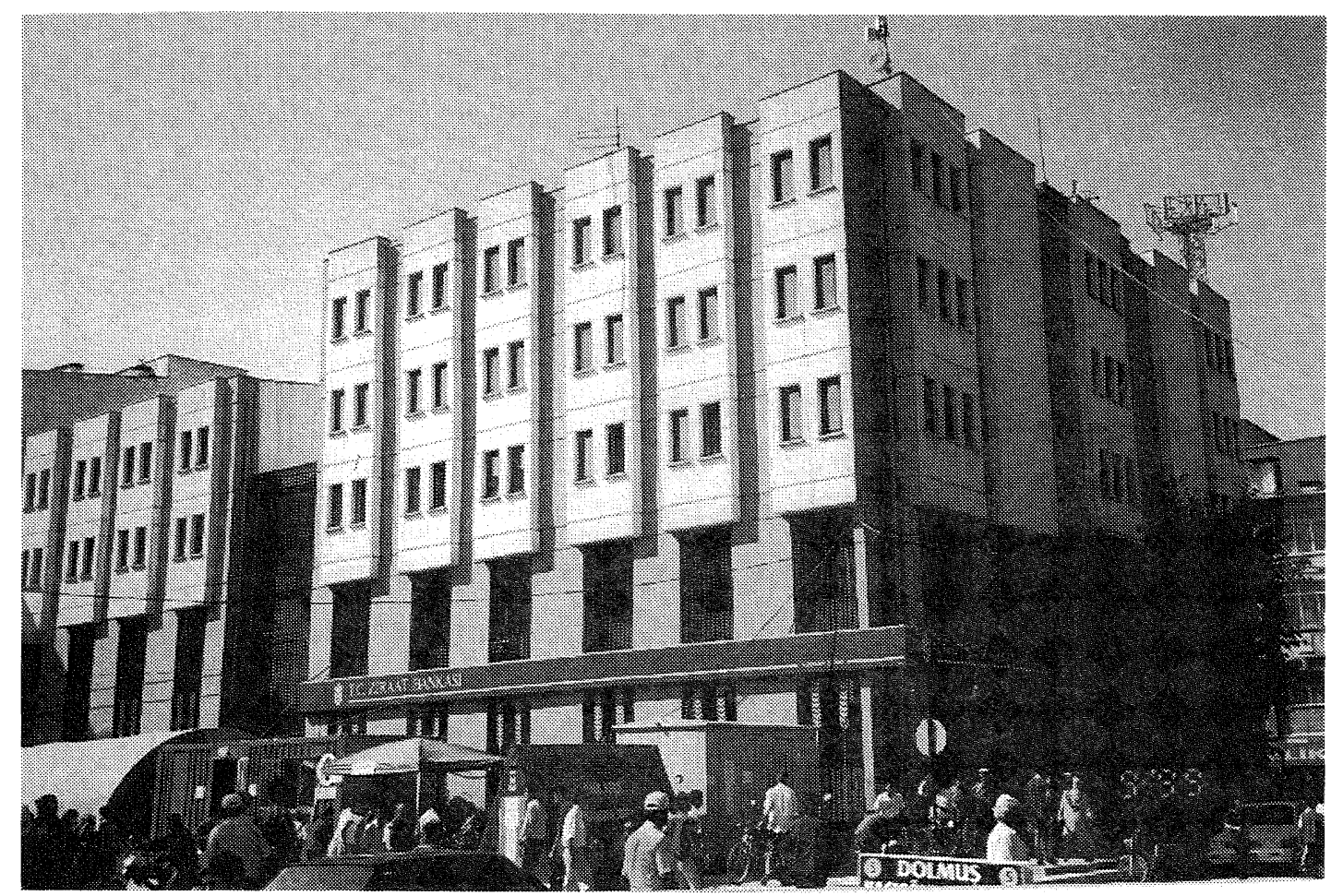

Figure 24:

T C Ziraat Bankasi Building, Adapazzari.

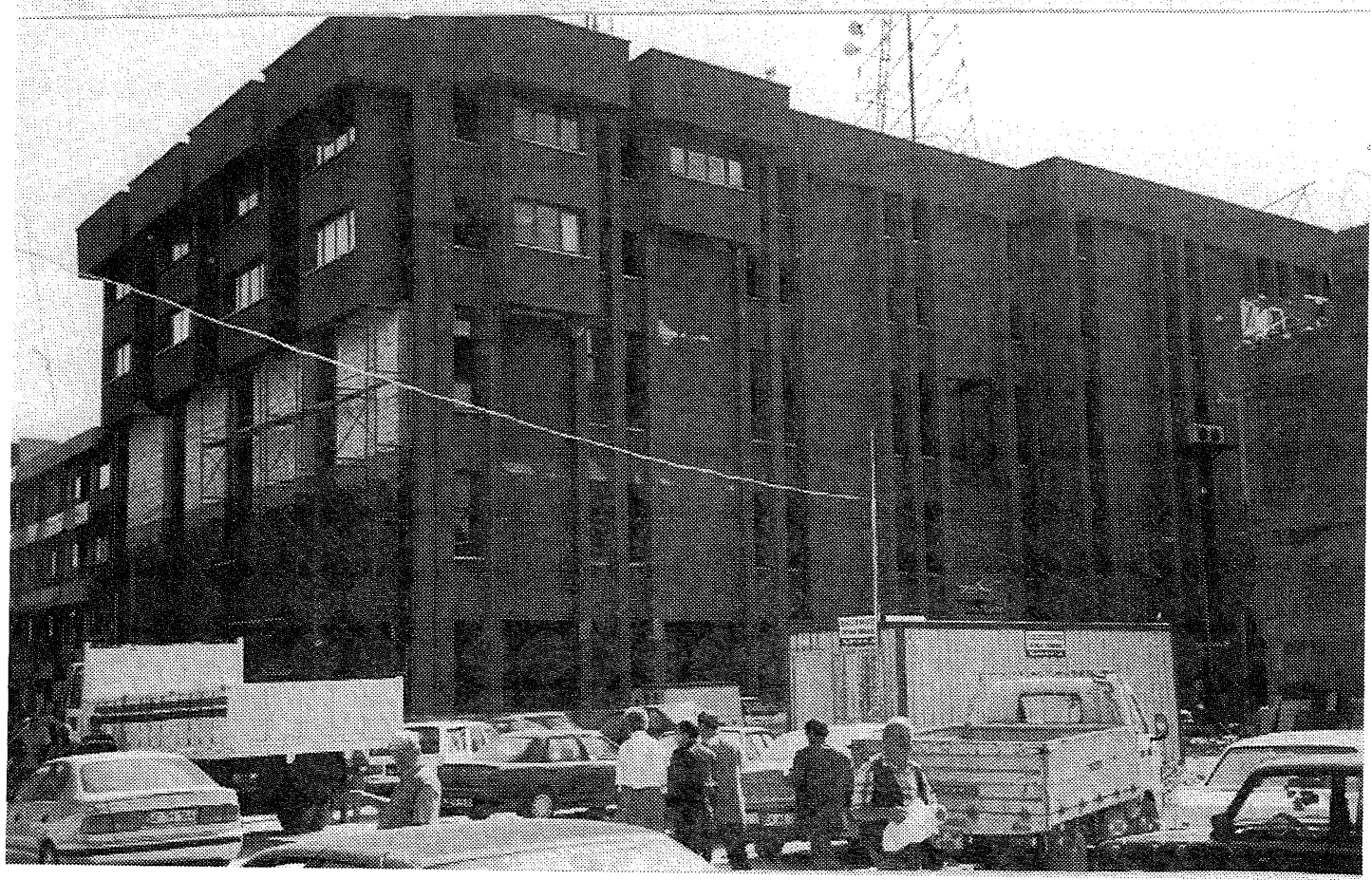

Figure 25:

Turk Telekom Building, Adapazzari. 


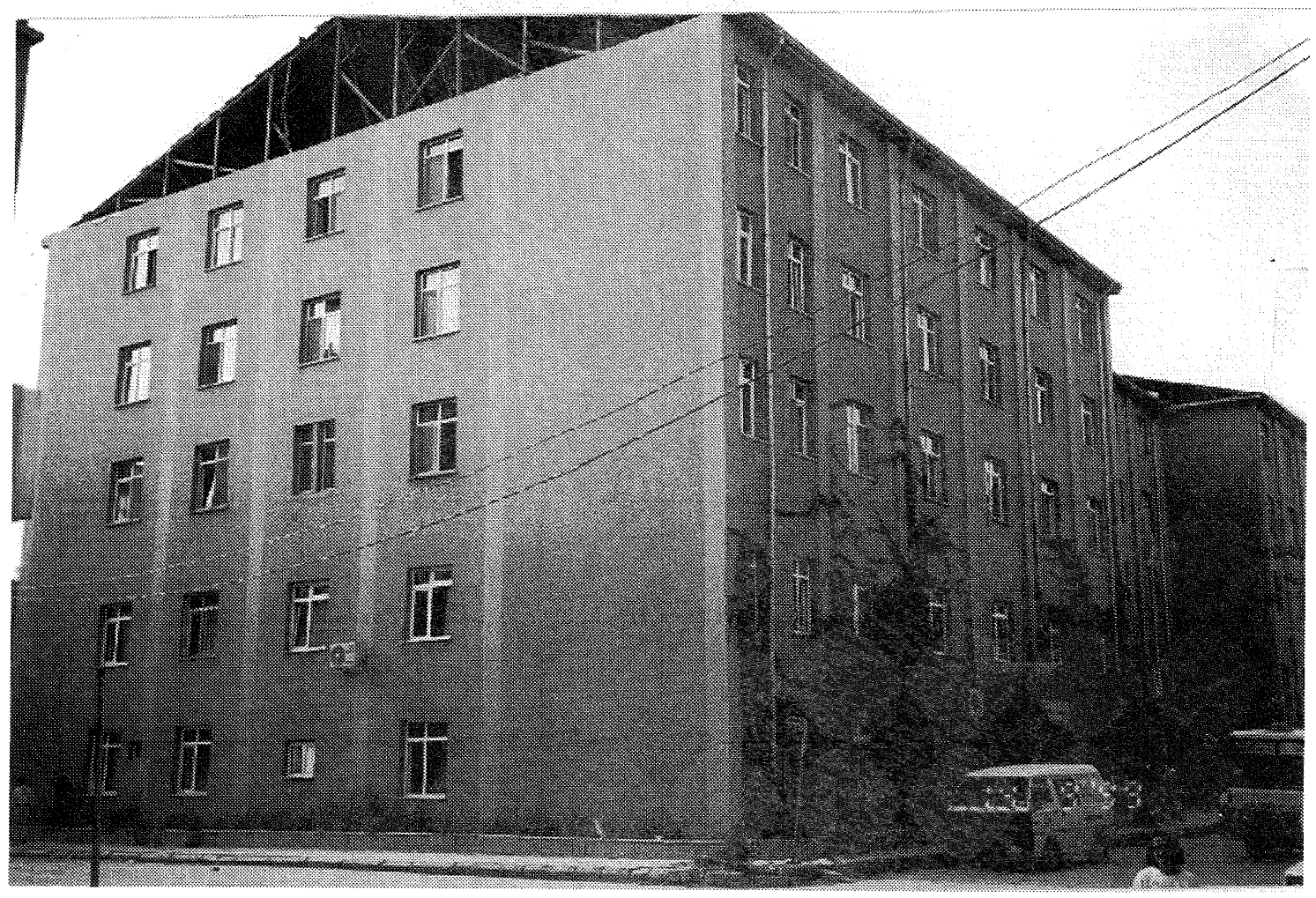

Figure 26: $\quad$ Sakarya Birth and Childcare Home, Adapazzari.

Shear failure had occurred to several ground floor columns to the north exterior side wall at window level due to a short column effect resulting from the presence of masonry brick infill below, as seen in Figure 27.

The connections between the roof purlins and the top of each end wall had parted over approximately half the building width and these walls had subsequently pounded against the underlying roof space frame structure. Once the purlin connections had failed the end wall structures had apparently cantilevered, under face loading, from their connection to the internal tiered seating and the building base. Hinging of the lower columns within the end wall was evident. Some damage to the space truss structure adjacent the end walls was also seen.

Significant cracking of the masonry infill panels to both exterior and internal walls occurred.

The stadium appeared to have only been recently completed and had possibly never been used.

Minarets. Not surprisingly hundreds, if not thousands, of mosques and associated minarets are to be found in the region. From casual observations only a very small number of minarets were toppled or suffered damage and these were usually located in the badly damaged areas of Golcuk and Adapazzari or immediately adjacent the fault rupture. The associated mosque buildings often incurred damage as well.

The minarets are typically of hollow tubular reinforced concrete construction.

\subsection{Industrial Buildings}

A range of building types, with a varying extent of damage, were inspected. Generally the buildings near the fault, and thus subjected to higher ground accelerations, suffered more damage than the more distant ones. The most common structural systems were steel portal or braced frames (generally older buildings) and precast concrete column and beam systems. Less common systems were in-situ concrete portals and precast concrete portal frames.

The frequently observed characteristics were as follows:

- Older building systems appear to be more robust - these are typically steel framed structures utilising trussed roof framing supported on box type or UC type columns with cross bracing in roof and wall planes.

- Newer building systems tend to utilise more precast concrete. While this is reasonably massive it is not robust. Joint detailing is the main weakness. Pins, dowels and the like typically have insufficient edge distance and a lack of hairpin type confinement. In some cases we noted that the beams had been trimmed to length (not obvious whether in the factory or the field) and new holes created for the pins. In these cases there appeared to be no form of confinement at the member end. Connection of purlins to beams is typically achieved with a length of wire extending from the purlins twisted around a short length of rebar projecting from the top of the beam. The roof cladding is fixed with $\mathrm{J}$ bolts to the concrete purlins. 


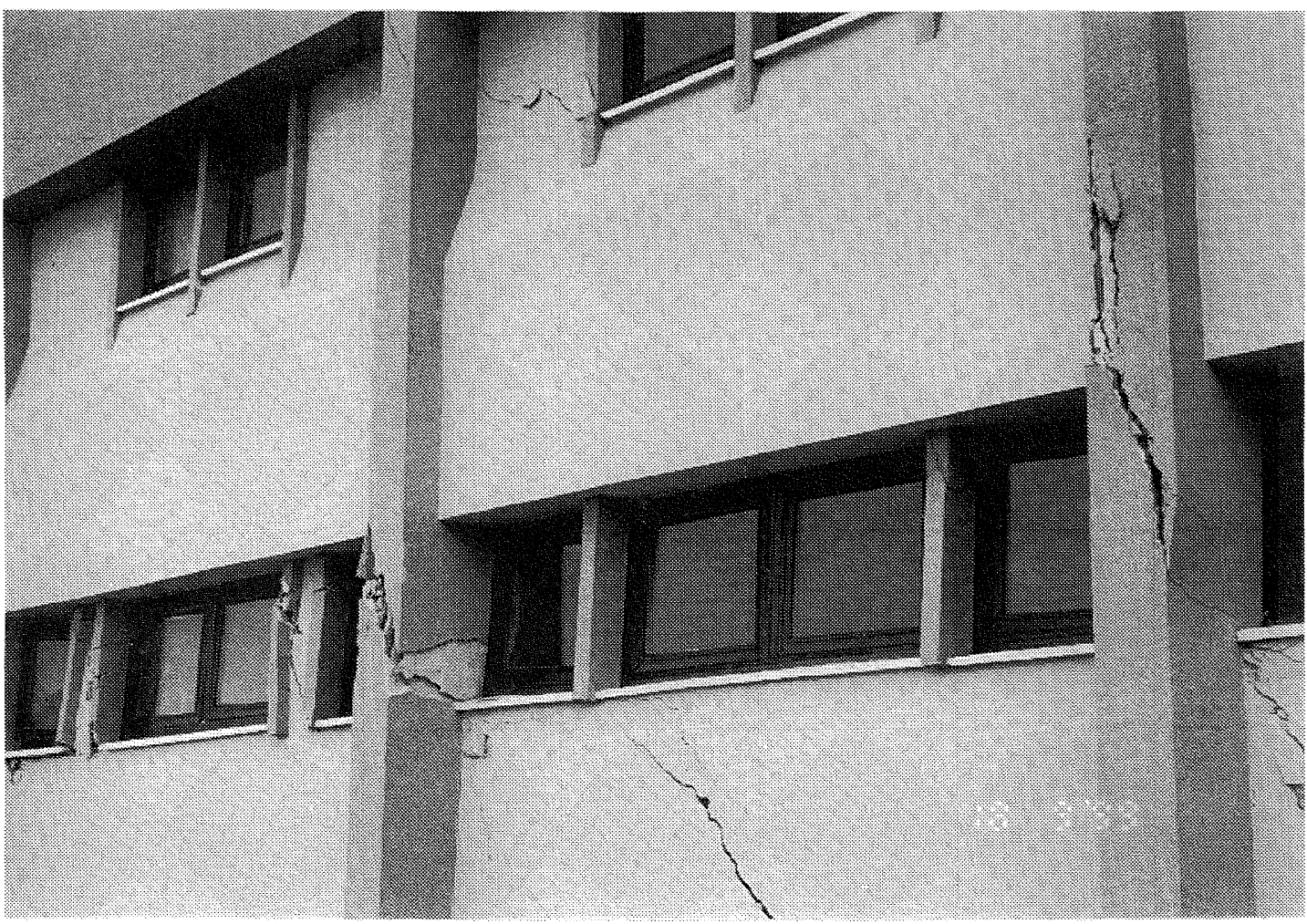

Figure 27: $\quad$ Ataturk Stadium, Golcuk, showing short column shear failure.

- Infill masonry using Ytong (a low-density masonry unit) or "killer bricks" (extruded hollow clay brick) is typical for all but a few of the precast buildings, which use vertical precast panels. The masonry infill panels are unreinforced and are not separated from the structure. Infill panels were observed to fail by in-plane shear, face load bending or, where not adequately tied to the surrounding structure, by falling out completely.

- There appears to be a lack of understanding of structural systems in newer buildings. For example older precast buildings tend to be only one bay wide, with the longitudinal walls providing the longitudinal seismic load path. These appear to have performed reasonably well, except where face loading has effectively removed the shear walls. Newer precast buildings are more commonly multiple bays wide, with perimeter walls only and no bracing. The inference is that the adequate performance of the one bay system has been assumed to apply to multiple bay systems without consideration of the load path for longitudinal loads. This lack of longitudinal structural system appears to have caused failure in many cases.

The performance of all the buildings inspected was predictable. Despite the large magnitude of the event, the ground accelerations were not particularly high, yet much damage was sustained in poorly engineered industrial buildings. In contrast two major car manufacturing plants immediately adjacent or partially straddling the fault sustained minimal damage. These buildings had been properly engineered.
The most frequent problems with the buildings stemmed from the lack of consideration of the full seismic load paths, and the lack of separation and restraint of secondary elements, particularly infill walls. Ductility of precast concrete component joints was poor. The commonly used infill wall materials are brittle and perform poorly. Brittle roof sheeting material was a further, but relatively minor, problem.

Collapsed precast concrete building near TEM Adapazzari exit, Figure 28. A precast concrete industrial structure 4 bays wide ( 90 metres) by 20 bays long ( 150 metres), with rafter soffit at 7.5 metres. External walls were plastered infill brickwork. The structural system comprised cantilever precast concrete columns with corbels, precast rafters of varying depth and precast $L$ shaped purlins. Precast $U$ beams were positioned on column lines longitudinally to complete the structure and act as box gutters. The structure appeared to have been constructed some months prior to the earthquake but the roof sheeting had not been installed. The $400 \mathrm{~mm}$ square columns were reinforced in 2 faces, thus presumably were designed to carry moment only in the transverse direction.

The longitudinal load system was not evident, unless either the roof sheeting was intended to act as a diaphragm or a bracing system was to be installed. In either of these cases the building side wall infill panels must have been intended to carry the longitudinal forces to ground. Since many of these fell over from face loading only, even had the building been completed with a roof diaphragm the side walls may have failed to carry the load and thus caused the building to collapse. 


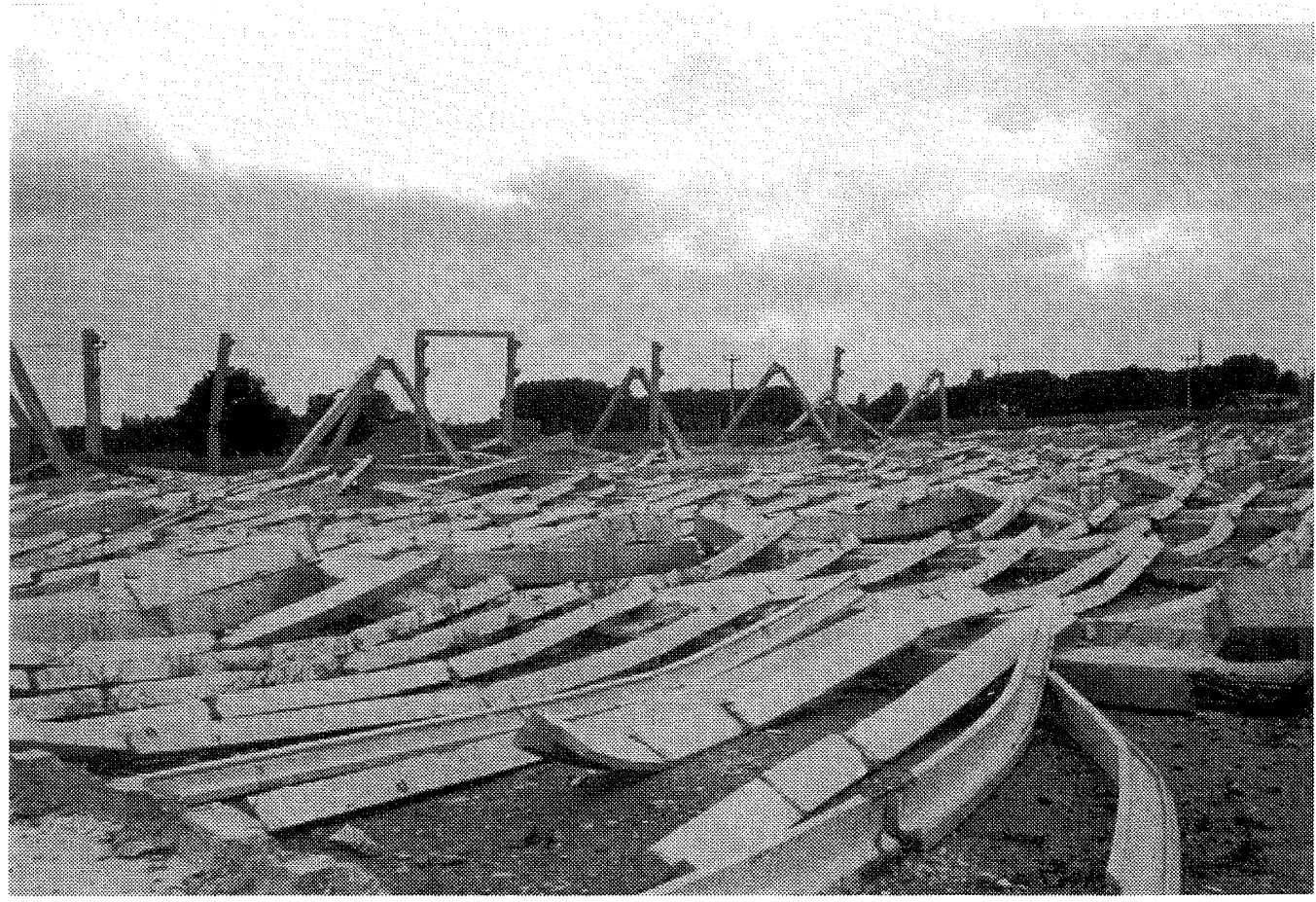

Figure 28: $\quad$ Collapsed precast concrete building near TEM Adapazzari exit.

Other facilities inspected but not significantly damaged:

\begin{tabular}{|c|c|}
\hline & Goodyear Tyre Factory - Izmit \\
\hline & Bastas Light Factory - Izmit \\
\hline & PaKmaya (yeast manufacturer) - Izmit \\
\hline & Unilever - Gebze \\
\hline & Alstom - Gebze, Ilhan Gökçen R \& D Manager \\
\hline & Steel Factory and Power Plant - Gebze \\
\hline
\end{tabular}

\subsection{Non-Structural Building Components}

\subsubsection{Suspended Ceilings}

Suspended ceilings systems, whilst not widely used, generally experienced considerable damage. Such systems were observed to have experienced local collapse in retail, low-rise (industrial) office buildings and industrial facilities (e.g. the Goodyear factory office building and amenities facility at Izmit, Hyundai dealers office building at Adapazzari, the McDonalds Restaurant in the bridge structure over the Trans European E6 Motorway).

Damage was most commonly concentrated at the perimeter of the ceiling where impact had occurred with adjacent perimeter support bulkheads and infill walls. This is consistent with pendulum action as the result of lack of lateral bracing to the ceilings. Tiles and rails had been locally crushed and buckled when compressed against the ceiling bulkheads and had fallen. No bracing or tile clips had been used in any of the systems inspected. Light fittings and air conditioning vents fitted to the ceiling rails in the local areas of collapse also fell. In most cases tiles consisted of lightweight fibreboard materials and they themselves would not have posed a high level of safety hazard. In the one case observed where heavier plaster tiles had fallen, the building owner was replacing these with a lighter alternative.

\subsubsection{Building Contents}

Building contents were apparently ejected throughout the region. Files and books were often disgorged from shelves and work tables and the shelves themselves overturned. Computers walked across desks and, similarly, chairs across rooms in a number of office facilities visited.

Damage within the residential buildings was reasonably substantial, not surprising given the extent of collapse experienced by this building stock. Appliances, utensils and foodstuffs were reported as being thrown from benches and cupboards.

\section{DAMS}

There were a number of dams in the general area with none being significantly affected. The most notable dam was the $108 \mathrm{~m}$ high Yuvacik dam just south of Ismit. The dam is mid way between Adapazarri and Golcuk right in the epicentral area of the earthquake. The dam was about $3 \mathrm{~km}$ from the movement trace of the North East Anatolian fault which caused the earthquake. The dam axis was parallel to the direction of the fault. 
The water delivery pipe was ruptured by fault displacement 3 $\mathrm{km}$ from the dam. Ground accelerations in the vicinity of the dam are estimated to have been approximately $0.45 \mathrm{~g}$ (reference paper by Hasan Cetin). The dam is listed on the official Turkish dams list as Kirazdere dam but there has been a subsequent change of name. It is privately owned by Thames Water. The dam provides water supply into the Ismit area supplementing the existing Istanbul water supply by $15 \%$ with a supply flow of $3000 \mathrm{l} / \mathrm{sec}$.

The dam is $108.5 \mathrm{~m}$ high with $400 \mathrm{~m}$ crest length and has a clay core with compacted gravel shoulders. The dam side slopes are 1:2.75 upstream and 1:2.5 downstream. The dam was completed in 1998, and achieved first filling in June 1999. The dam had been full for three months prior to the earthquake. The dam has substantial freeboard, and a gated spillway of 1600 cumec capacity.

The water level of the dam reservoir is recorded and when the earthquake struck the recorder showed an initial depression of $2.5 \mathrm{~m}$ in the lake level followed by an increase of $2.5 \mathrm{~m}$ indicating that a wave of about $5 \mathrm{~m}$ occurred as a seiche in the reservoir. The dam has adequate freeboard and there was no apparent damage. The dam is carefully monitored for settlement and seepage. The seepage flow below the dam actually reduced as a result of the earthquake presumably from consolidation of the materials near the drains.

The most significant record was from settlement monitoring. The crest and downstream face is monitored for settlement on a grid. The results of this monitoring showed that the dam did settle by up to $9 \mathrm{~mm}$. It is interesting to note that the dam monitoring pins moved along the dam axis slightly in the main earthquake and moved back the other way slightly when a strong aftershock occurred some veeks later. The dam axis is parallel to the fault rupture line.

The excellent performance of this dam is a valuable record of the safety of well built modern dams in moderate earthquakes.

\section{LIFELINES}

\subsection{Transportation - General}

The primary transportation links for the Marmara region are shown in Figure 2. These links include the E80 motorway and the D100 old main highway on the north side of the Marmara sea, connecting Istanbul to Izmit and beyond to the east, the D130 highway around the south side of the Mamara sea between Yalova and Izmit, and the Istanbul to Ankara railway via Bilecik. The E80 motorway includes a number of major viaducts and tunnels. Ferry services also ply across the Marmara sea, in particular from Istanbul and Eskihisar (near Gebze) on the north side to Yalova and Topcular (near Altinova) respectively on the south side.

The earthquake caused significant damage to many structures over some $49 \mathrm{~km}$ of the motorway and damage to some of the structures on the $410 \mathrm{~km}$ of the state and provincial highway and local road network in the region [14]. The E80 motorway was severed by collapse of an overpass onto it and severe damage to the carriageways where the fault crossed the motorway at Arifre, near Adapazzari. A bus collided with the collapsed bridge superstructure with following trucks colliding in turn with the bus and each other in a series of nose to tail impacts. 10 people were killed. The motorway was reopened for use after two days.

Substantial damage was sustained by the railway track and installations on a $61 \mathrm{Km}$ section and a $29 \mathrm{~km}$ section of the double track between Istanbul and Adapazzari, and on a section of the southbound track from Beskopru train stop to Bilecik [14]. Figure 29 illustrates the damage to the track near Sapança, where it was intersected by the fault. Service was restored within a day. The damage cost to the railways and railcar factory are estimated to be US\$72 million [14].

There are a number of airports within the region, but as far as is known, these did not sustain any significant damage. Use of these airports in the early days of the recovery was, however, hampered by a shortage of staff to operate the air safety control systems and lack of appropriate fuel for refuelling helicopters for their return journeys.

\subsection{Roading}

Road surfacing construction is generally of a thick asphaltic concrete.

At the time of the reconnaissance team's visit, little evidence remained of damage to the E80 motorway. In the vicinity of the fault rupture, the motorway carriageway was buckled due by compression of the ground over a $200 \mathrm{~m}$ length. Repairs have been carried out to 40 kilometres of the motorway. Figure 30 , illustrates damage sustained by the E80 carriageway

The following are the observations of John Mander, a member of the EERI reconnaissance team:

"The extent of damage to the engineered fills on the E80 motorway extended some $10 \mathrm{~km}$ to the west and east of the Adapazzari area. Settlements ranging from $100 \mathrm{~mm}$ to 500 $\mathrm{mm}$ were observed. This was evident at most single span bridge and culvert locations on the road, resulting in classic bump-onto-the-bridge problems. Repair of this damage was swift. Initial repairs, made in the first few days following the earthquake, consisted of placing asphalt ramps and maintaining a $50 \mathrm{~km} / \mathrm{h}$ speed restriction. Within 10 days, more long-term repairs were made. Re-profiling and repaving large stretches of the road surface enabled the speed restrictions to be removed and the motorway returned to its normal $120 \mathrm{~km} / \mathrm{h}$ operating speed."

Damage to local roading was evident at locations in very close proximity to the fault trace and where the fault had crossed roads, e.g. in the vicinity of the collapsed motorway overpass at Arifre, but otherwise little direct damage appeared to have been sustained by local roading.

In Adapazzari, segmental concrete block kerbing and footpaths was severely disrupted. In areas where there had been liquefaction accompanied by the settlement of buildings, e.g. in the Tigcilar area, there were areas of heave and disturbance of the road surfacing. Also in the Istiklal area there was a zone of left lateral ground shear which intersected several streets with consequent disruption to them. In the course of recovery from the earthquake it is inevitable that street surfaces will be further damaged by the operation of heavy plant in removing the rubble of collapsed and damaged buildings, and by the repair and replacement of water supply and sewerage lines. 


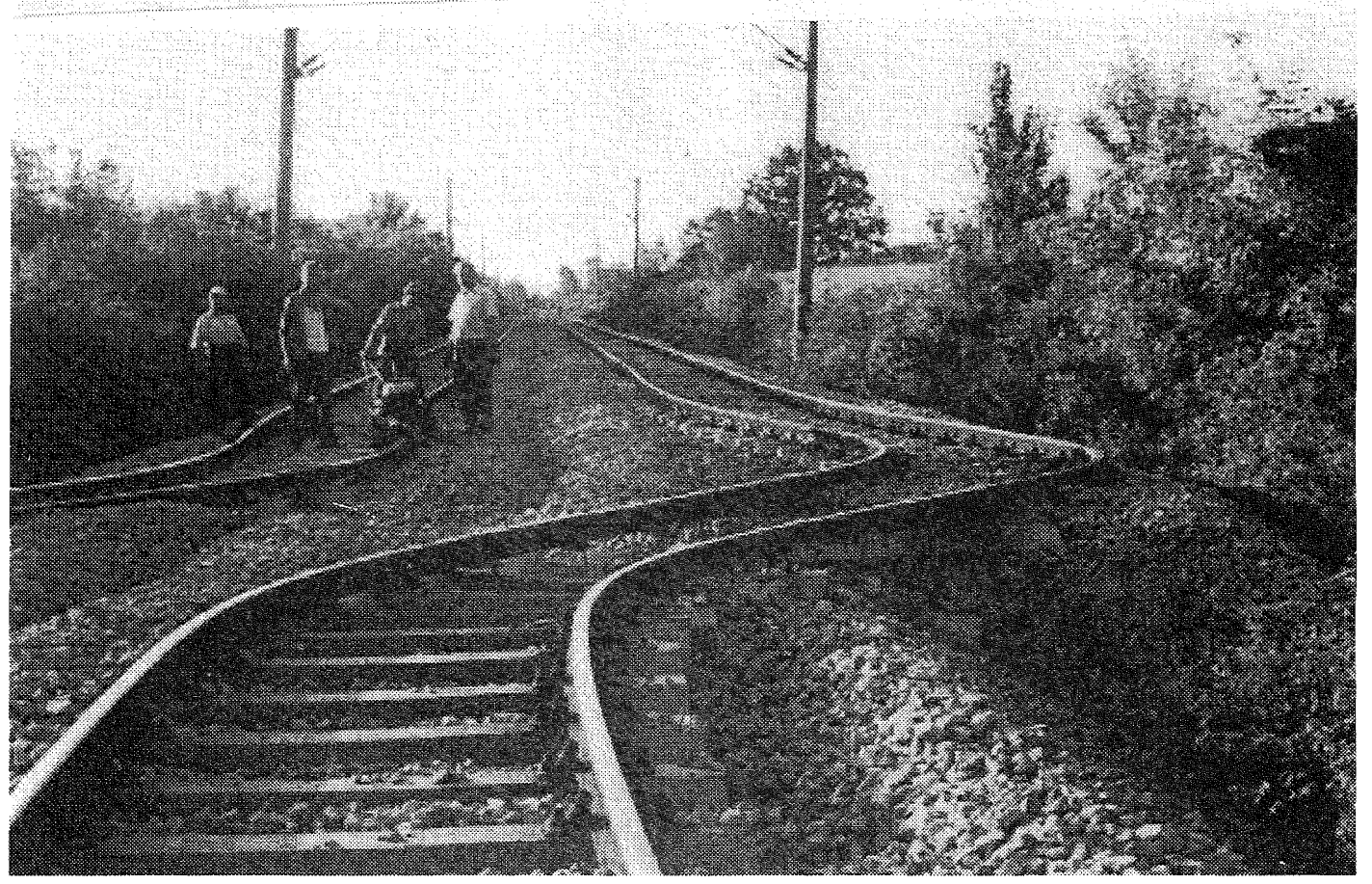

Figure 29: $\quad$ Damage to rail track near Sapance, showing right lateral offset caused by fault trace.

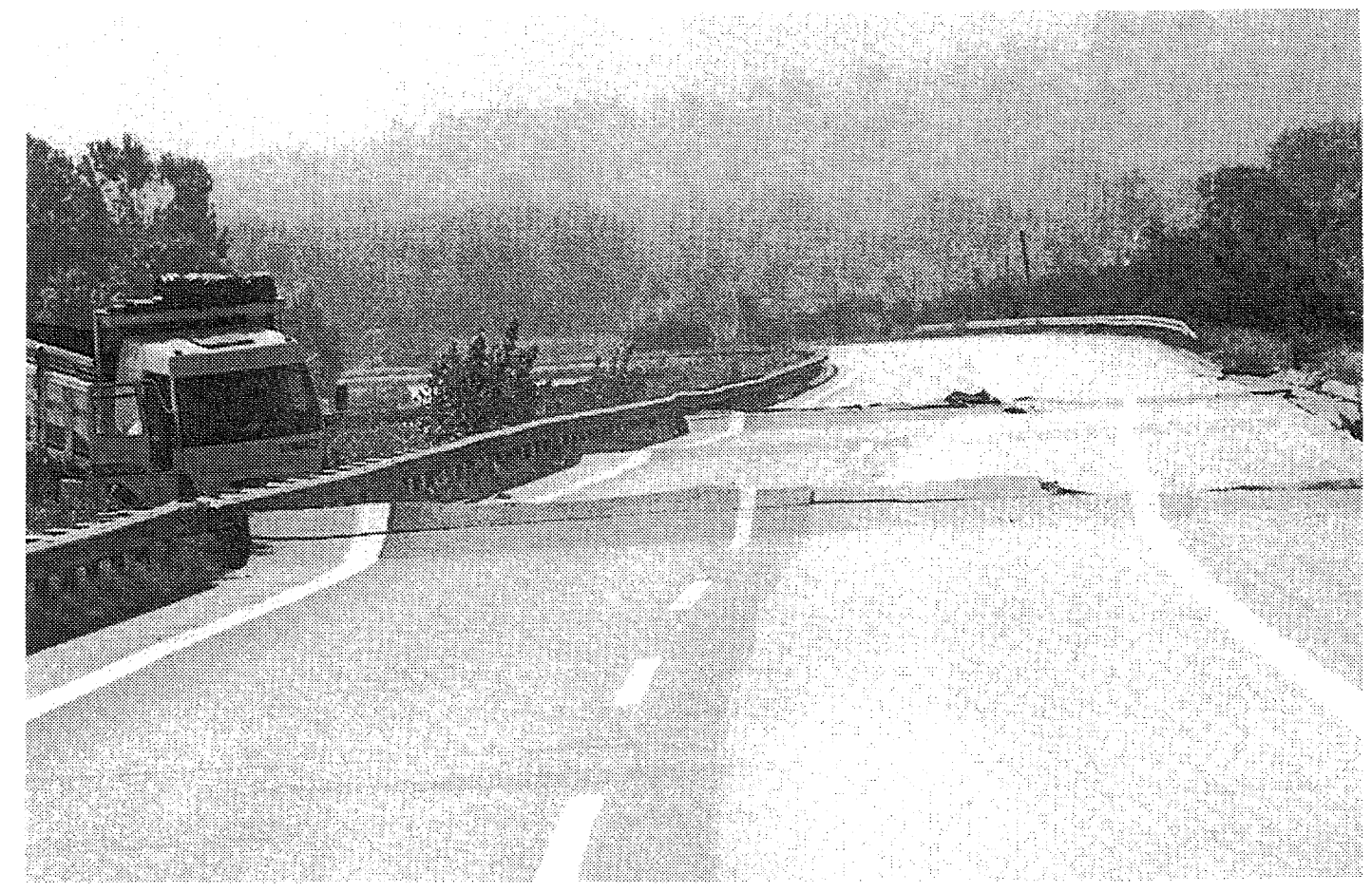

Figure 30: $\quad$ Damage to E80 motorway carriageway caused by fault trace. 


\section{3 Bridges}

7.3.1 Design Codes, Earthquake Resistant Design Practices, and Seismic Retrofitting

Turkey does not have a nationally adopted design standard for bridges. AASHTO Standard Specifications for Highways Bridges have generally been applied, with local modifications for design live loading, earthquake loading and environmental conditions, for motorway and highway bridges falling under the jurisdiction of the Highways Directorate. A 50 year design life is adopted for bridges and the earthquake loading is that for a 475 year return period event, with a peak ground acceleration of $0.4 \mathrm{~g}$ in the zone of highest seismicity.

Base isolation incorporating mechanical energy dissipation has not been applied to bridges within the area affected by the earthquake, but is being incorporated into some bridges for a new motorway now being constructed in the south of the country. To date, no seismic retro-fitting has been undertaken of existing bridges but a plan to undertake seismic retro-fitting has been under development by the Highways Directorate with the CALTRANS approach having been studied.

\subsubsection{Forms of Construction of Modern Bridges}

In the Istanbul to Adapazzari area, three forms of bridge construction appeared to be predominant in the modern highway and motorway bridges. These were:

- Type 1: bridges with their superstructures constructed using simply supported, precast, prestressed concrete trough sections with an in-situ deck to form a multiple box girder cross-section.

- Type 2: bridges with their superstructures constructed using simply supported, precast, prestressed, shallow Ibeams units. These units were placed side by side to create a flat soffit to the superstructure, with an in-situ deck slab cast on top.

- Type 3: 3 span, cast in situ, fully integral "Swedish table" bridges, i.e., symmetrical bridges with the piers inclined inwards.

With the type 1 and type 2 forms of bridges, the in-situ deck slabs were generally continuous over the piers, providing diaphragm action to resist horizontal loads. Also, piers were generally of a wall form. The modern bridges generally possess generous overlap of the superstructure girders with the supporting sub-structure, but lack linkages to limit longitudinal displacement of the superstructure and tie the structure together. Provision of settlement slabs behind abutments is standard practice.

\subsubsection{Performance of Bridges to the Earthquake}

A number of bridges in the Adapazzari and Izmit areas, where the greatest amount of bridge damage was understood to have occurred, were inspected. These included:

- the collapsed bridges at Arifre and in the vicinity of the E80 motorway Adapazzari link road interchange;
- four E80 motorway overbridges between the Adapazzari link road interchange and Sapança;

- a suite of 5 new bridges under construction in the vicinity of the D100 highway at the east end of Izmit;

and several other bridges, both old and modern, to which damage was minimal.

A further bridge, the twin-bridge, 10 span Sakarya viaduct on the E80 motorway, although not inspected, was damaged. Several of the simply supported spans of the western bridge sheared their restraining shear keys and unseated from their elastomeric bearings.

With the exception of the Sakarya viaduct and possibly the Sakarya river bridge, it is believed that all the bridges would have been aligned in an approximately north-south direction, though this was not checked at the time of the inspections. They would therefore have been more-or-less aligned with the direction of fault-normal impulses.

The following are observations on the performance of the bridges inspected:

Collapsed Four Span Overpass Over the E80 Motorway at Arifre, Figure 31.:The form of this bridge was that of a type 1 described above. This bridge comprised four simply supported, $26.0 \mathrm{~m}$ spans of precast, prestressed concrete trough girders with a $200 \mathrm{~mm}$ thick, continuous, in situ concrete deck. It was supported on wall piers and cantilever retaining wall abutments skewed at 23 degrees. Foundations comprised $1.2 \mathrm{~m}$ diameter cast in place reinforced concrete piles, 8 per pier and 4 per abutment.

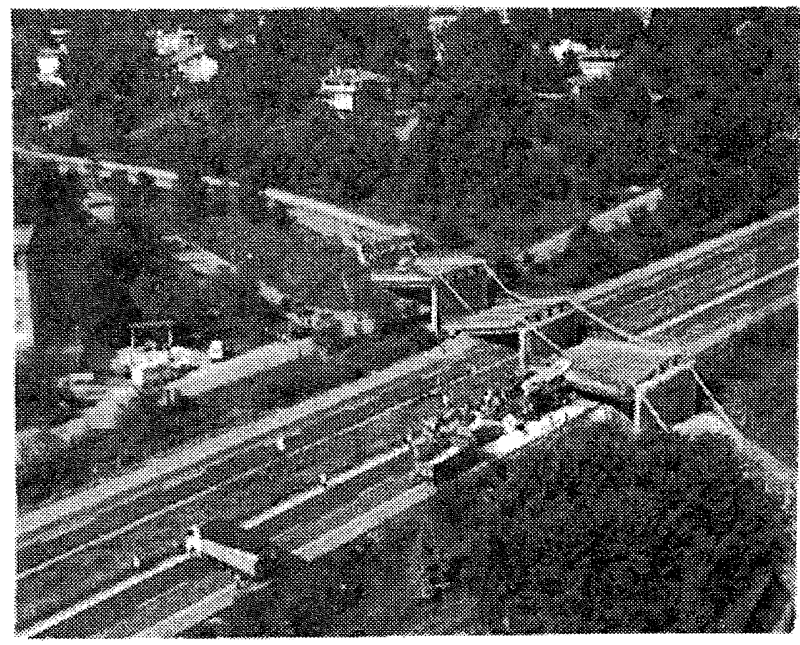

Figure 31: Collapsed four span overpass, E80 near Arifre.

At the abutments, the sill supporting the girders was $600 \mathrm{~mm}$ wide with the girders being placed with $75 \mathrm{~mm}$ clearance from the backwall. Shear keys between each pair of girders restrained the superstructure against transverse movement. The piers were $1.0 \mathrm{~m}$ thick, with the beams placed with 50 $\mathrm{mm}$ clearance between adjacent spans.

No restraint against lateral movement was provided at the piers other than that provided by the elastomeric bearings. 
Photographs on the internet indicate that while the deck slab is believed to have interconnected the spans, deck slab longitudinal reinforcement was not continuous from one span to the next.

The northern approach embankment was retained by Reinforced Earth Walls on both sides, not interconnected. A. twin cell reinforced concrete box culvert passed beneath the embankment not far from the back of the abutment. Founding level of the Reinforced Earth Wall is at the level of the base of the culvert, adjacent to the culvert, stepping up to $1.5 \mathrm{~m}$ above the base of the culvert away from the culvert.

At the time of the inspection, the collapsed spans and southern abutment had been demolished and cleared away, and demolition of the piers was well advanced. The exact location of the fault trace could not be clearly defined, but is believed to have passed beneath the embankment.

Collapse is considered to have been caused by the general alignment of the fault rupture relative to that of the bridge applying an extensive force to the bridge, and the wave motion of predominantly fault-normal ground shaking, dislodging the northern span from its seating. The first span, in collapsing, would have pulled the remaining three spans off their seats also. Positive keying of the spans to the piers and linkage of the superstructure to the abutments might have prevented this collapse, but alternatively, the relative displacement between supports and the forces generated may have been just too great. The Reinforced Earth Walls, while having suffered some distortion and settlement, performed very well (Figure 13.)
Sakarya River Bridge on Local Territorial Authority Road Figure 32: This bridge is located immediately south of the E80 - Adapazzari link road interchange. Little is known of the detail of this bridge and only the northern abutment area was accessed, an extensive drive being required to get to the other abutment.

The bridge appears to have been a multiple span structure of simply supported steel I-beams. Piers located in the river have disappeared altogether. On the southern bank an unbraced timber trestle pier could just be discerned.

There was no evidence of there having been any form of shear keys or linkage between the superstructure and the abutment, and only a minimal overlap of the beams with the abutment sill. Cracking could be seen in the ground surface on the south bank, suggesting possible liquefaction and slumping towards the river.

Four E80 Motorway Overpass Bridges in the Adapazzari Sapanca Area: The form of these bridges are all similar, and similar in form to the overpass at Arifre that collapsed, but ranging from two spans up to four, varying in the alignment of the piers and abutments, some square and some skewed, and in the form of the abutments, some cantilevered retaining walls and some of a spill-through form.

These all exhibited significant settlement of their approach fills adjacent to their abutments requiring major ramping up to enable passage over the bridges. In more than one case the depth of this ramping up extended to the top of the guardrail.

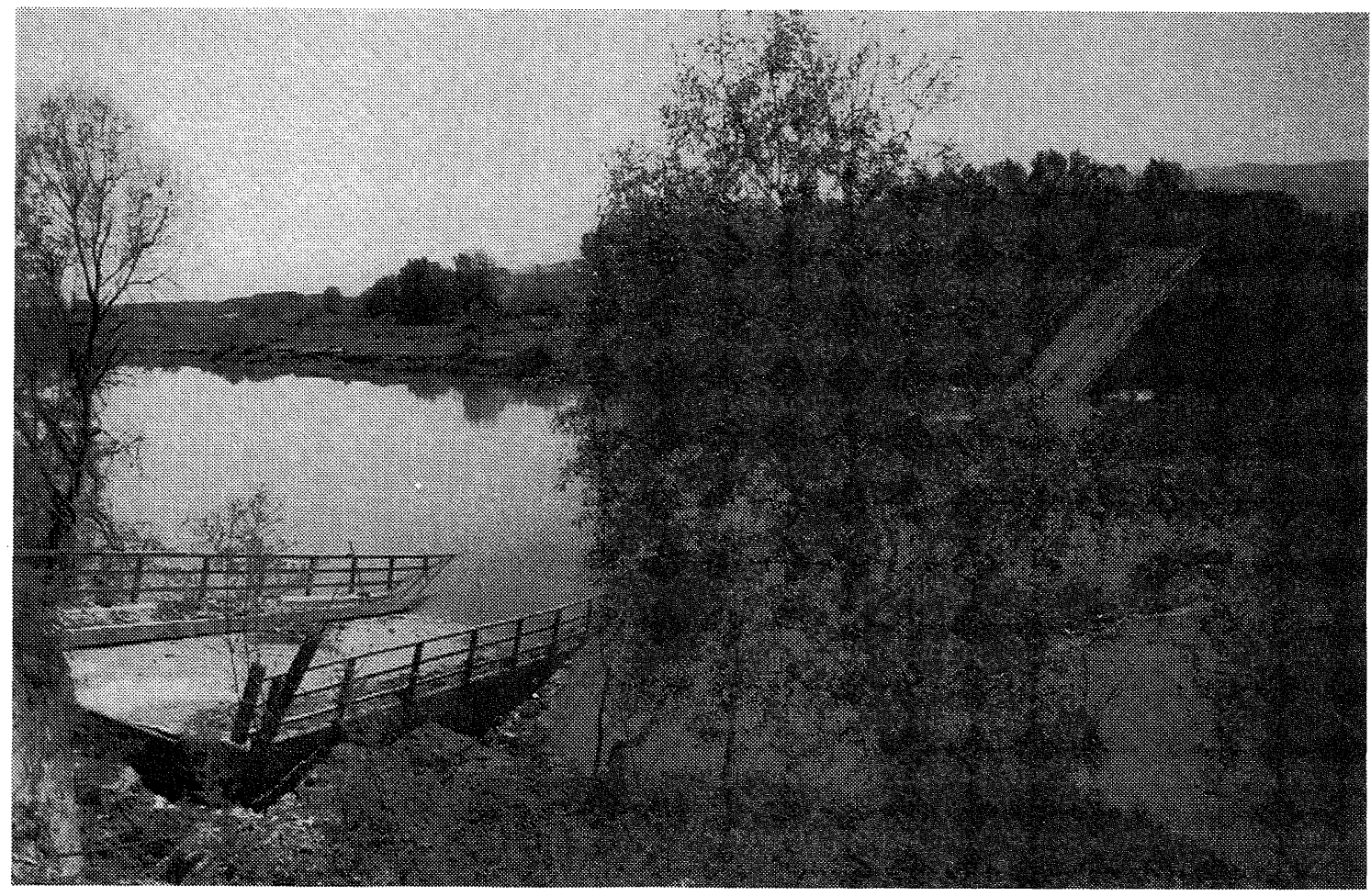

Figure 32: Sakarya River Bridge. 
Suite of 5 New Bridges at the East End of Izmit: These bridges, under construction, comprise a 6 span overpass over the D100 highway and the adjacent waterway, and two sets of bridges, each set comprising two, two-span bridges across the waterway. The waterway crossing bridges were formed on curves with each of their two spans having different skews. All superstructures are of the type 2 form described above. The in-situ deck slab had been cast on the waterway crossing bridges but appeared to have not yet been cast on the higher level overpass.

The waterway crossing bridges exhibited spalling damage at their abutments due to pounding between the superstructures and the abutments, a significant crack in their decks, typically $1.5 \mathrm{~mm}$ wide, above the piers, corresponding roughly to the position of the gap between the ends of the precast beams, and gapping between the abutments and the soil behind them of the order of $50 \mathrm{~mm}$.

Beams of the overpass bridge, over the southern three spans, had split apart on the bridge centreline and displaced to either side, down the cross-fall, shearing off the inadequate looking shear keys at the extremities of the piers. The beams were supported on individual bearing pads, which had "walked", with many projecting out over the faces of the pier, resulting in spalling of the pier faces in some locations. The pier built integral with the waterway wall was misaligned by $50 \mathrm{~mm}$ with the top of adjacent sections of the waterway wall.

\subsection{Wharf Structures}

The TCCD (Turkish railway corporation) operated port facility at Derince, which handles some 2 million tons of cargo annually suffered heavy damage to docks, cranes, and warehouses, including severe subsidence. This facility is not expected to be operable until extensive reconstruction is completed through 2000 [14].

Many industries around the Marmara sea coast operate their own private jetties, some of which were observed to be severely damaged. Figure 33 illustrates one example of these, the SEKA Paper Mill jetty located at the west end of Izmit. The supporting single column piers appear to have moved out from the shore, presumably as a result of mass outward movement of the harbour bed material in which they are embedded. This had resulted in unseating of the abutment end span, with the columns failing in shear / flexure between the upper and lower decks. There was also signs of the first pier having displaced and rotated over transversely, separating from the adjacent sea wall.

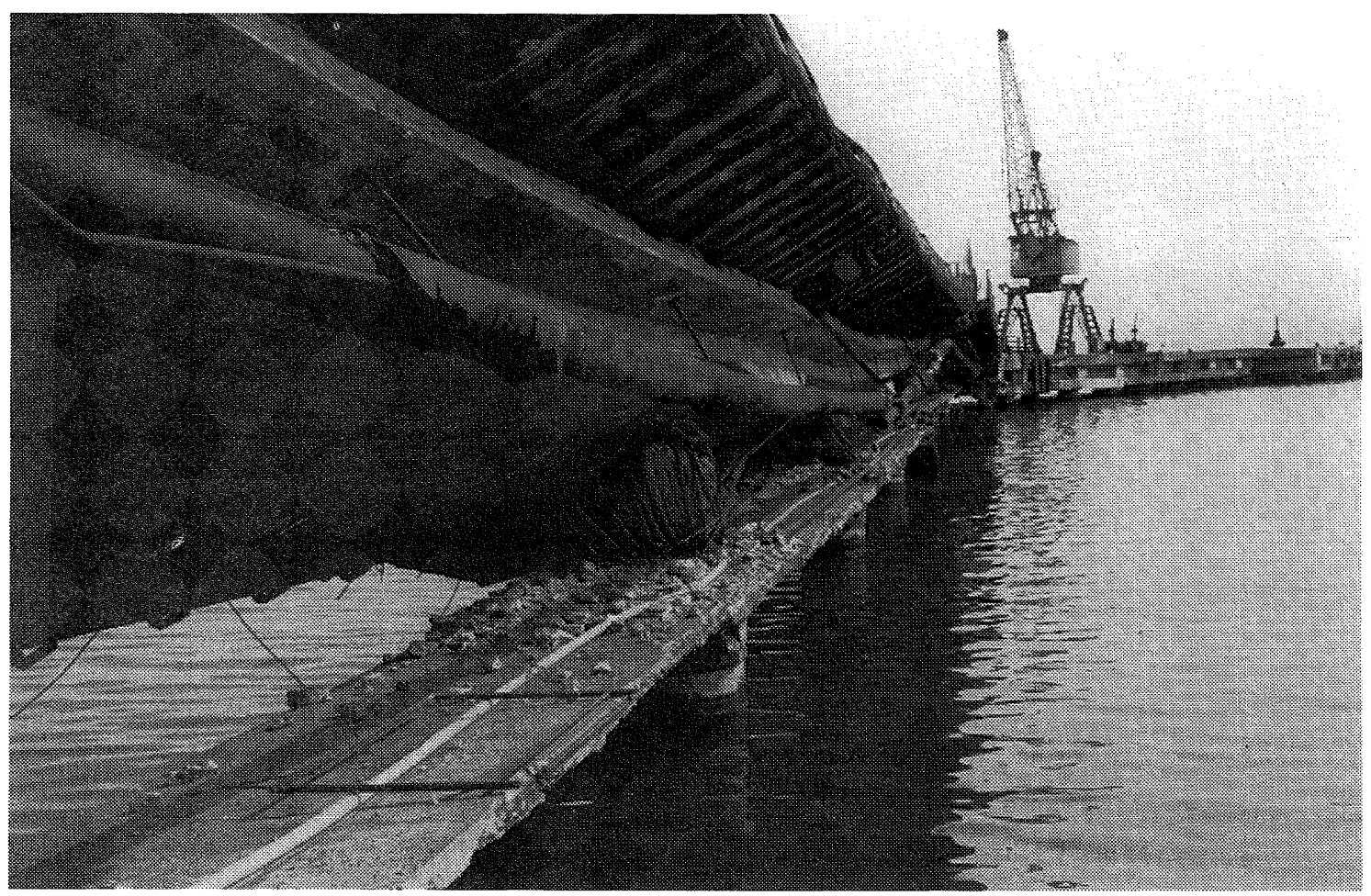

Figure 33: $\quad$ Collapsed SEKA paper mill jetty. 
Prior to the August earthquake, part of the Greater Adapazzari area received its water from a modern treatment plant (built in 1997) in the suburb of Maltepe. It has a treatment capacity of 100,000 tonnes per day with two reservoirs on site, one of 2.5 million litres and the other 5 million litres capacity. The Maltepe facility sources its water from Lake Sapanca, some $5 \mathrm{~km}$ to the west. The water is drawn from the lake via two intake pipes and pumped via the intermediate pumping station at Esentepe. Chlorine in gas form is added at the Esentepe pumping station. Esentepe is the main pumping station for the region and provides water from Lake Sapanca to the entire Adapazzari region, including Serdivan.

Prior to the earthquake of 17 August 1999, the suburb of Serdivan had never been linked to the new Maltepe treatment plant (it was suggested that the local municipality could not afford to contribute towards the new system). Its water came directly from the Esentepe pumping station and relied on the chlorination added at this facility. The distribution network in Serdivan was in poor condition prior to the earthquake and the city was working on improvements. New reservoirs and pumping stations had been built and some of the older stations were planned to be removed from the network. It was also investigating the possible purchase of chemical treatment facilities to address other water quality issues.

\subsubsection{Performance}

One of the two intake pipes in Lake Sapanca was damaged and the supply was limited to one pipe. The strike slip fault probably crossed the pipeline between the intake and the lakeshore. As of the date of the tour, the submerged pipeline had not been inspected and repairs were yet to be scheduled since the engineer considered there was probably still movement across the fault. Power was lost to the pumping and treatment stations and there were no back-up generator facilities. There were breaks in the lines between the pumping station as Esentepe and the Maltepe treatment facility (there were two feed lines, one $700 \mathrm{~mm}$ and the other $1200 \mathrm{~mm}$ diameter).

At the Esentepe pumping station a rack of Chlorine gas bottles overturned and broke their connections to the chlorinator. The plant workers stated that the bottles had been secured prior to the earthquake but the strap broke. On the day of the site inspection, there is no strap in place. A close inspection was not possible because there was a chlorine gas leak in the storage room.

Apart from the loss of power and the lack of raw water supply, the Maltepe facility had no apparent damage. The treatment system comprises a bank of 3000 litre capacity Culligan pressure purifiers. Supply of the feed water to the Culligan cluster is provided by ten $77 \mathrm{~kW}$ electric motorpump sets. (On the day of the inspection four motor sets were running). The only problem in the plant immediately after the earthquake was the breakage of galvanised iron supply pipes feeding the Culligan units and these were quickly repairs. The Culligan Company engineer inspected the plant shortly after the earthquake and reported no damage.
The distribution network with Serdivan suffered extensive breakages.

\subsubsection{Recovery}

Within three to four days, power was restored to the pumping stations - before the repairs to the pipelines had been completed. By day five the Maltepe plant had a water supply. On the day of the site visit, the plant was treating 65,000 tonnes per day compared to a capacity of 100,000 tonnes per day. While only a single intake pipeline is operational from Lake Sapanca the plant will have reduced capacity.

When the Canadian DART (Disaster Assistance Response Team) team arrived in Serdivan on 22 August (the advance team was in Serdivan on 19 August), the water supply was identified as critical and installation of a temporary potable supply was a priority. The team brought three reverse osmosis plants and installed them on the shores of Lake Sapanca. At the base a facility was set up to package some of the treated water in 1.3 litre plastic pouches (the same system used in Canada for household milk). This proved a very effective solution for local distribution to tent camps. Distribution could be via plastic crates on trailers, or in bulk using dump trucks.

Prior to the earthquake residents of Serdivan did not drink the local water and relied on bottled water. Demand for the bottled water after the earthquake quickly exceeded the supply. The DART team established an analysis laboratory at the base and obtained and tested as many brands of bottled water as they could find. None of the bottled water product met the standards for potable water. Nevertheless it is possible that disease outbreaks were kept in check, at least in part, because the residents already had distrust, even before the earthquake, for the local water supply.

At tent camps and other strategic locations, temporary water supply was provided by 500 litre tanks and by 15,000 litre bladder, seen in Figure 34. With the Maltepe plant expected to be functional within days (approximately one month after the earthquake) there should be a stable water supply and the DART treatment units which have a much smaller capacity will be withdrawn. One remaining problem is the bulk water transportation from the filling station at the base of the treatment plant to the storage locations. Most of the trucks being used have come from Istanbul or Ankara and many were not purpose-built for the task. Some trucks had been sewer pump-out trucks and another, when the label on the tanker was translated, had been used for caustic soda. The trucks were returning to their home cities and the problem remained to co-ordinate a stable, reliable transportation network.

In the longer term, Serdivan (and most of Adapazzari) will need to reinstate a potable water supply network in the city. An interim solution has been proposed to run pipes on the surface, but this is still under consideration by the local officials. Freeze-up in winter could be a problem with such a solution. In some areas new buried supply pipes were being reinstated, but the time and resources required for such an undertaking does not address the need for an intermediate stable water supply solution. 


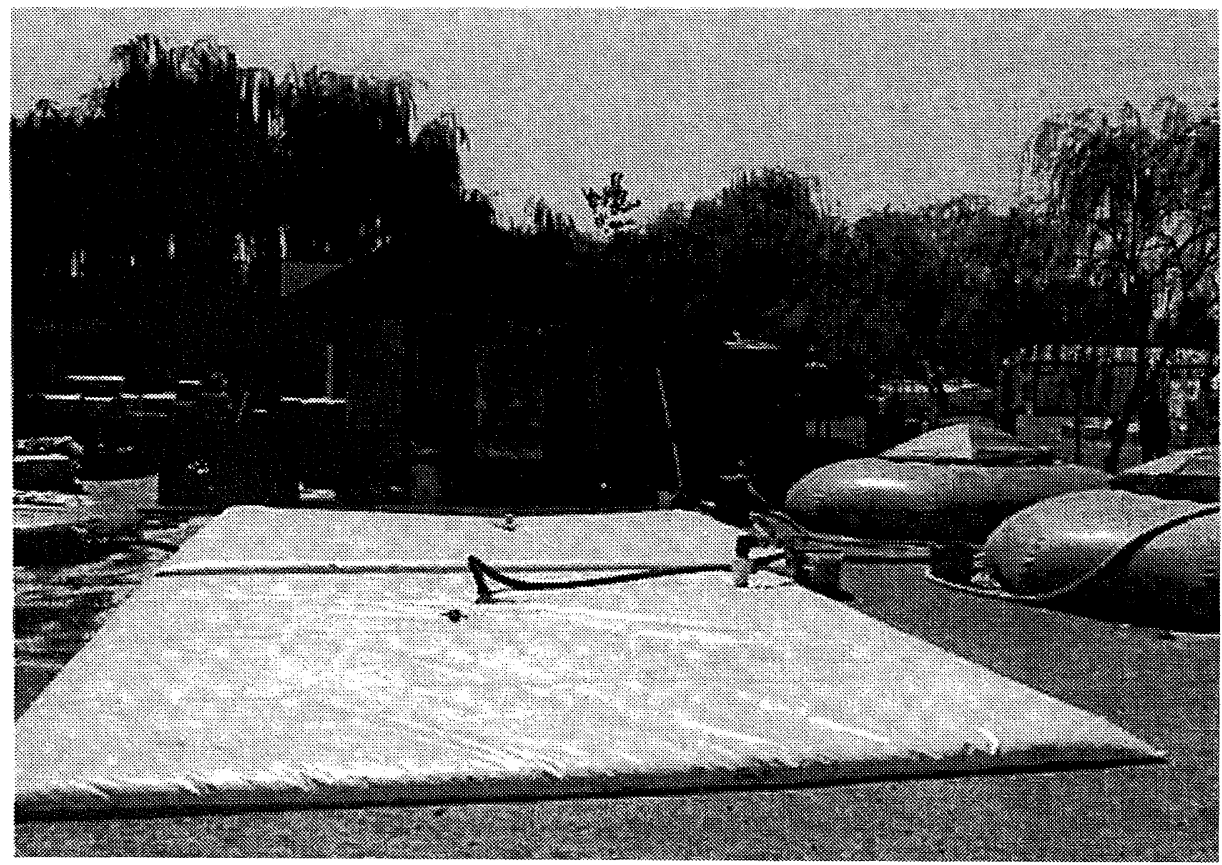

Figure 34:

Water bladders, Canadian Disaster Assistance Response Team camp at Adapazzari.

7.6

Electricity Supply

\subsubsection{System}

Electricity network in the earthquake-damaged areas is provided by:

- Turkiye Elektrik Uretim - Iletim AS (TEAS).

- $\quad$ Turkiye Elektrik Daditim AS (TEDAS)

- Private Cogeneration and Independent Power Producers.

Turkey had an installed capacity of 20,858 MW in 1994 of which $7 \%$ was controlled by independent power producers.
$53 \%$ of installed capacity was thermally-fired with the remaining being hydro-electric. Production of electricity amounted to $78,322 \mathrm{GWh}$ in 1994 . Both TEAS and TEDAS are government owned.

The transmission system operates at 380,154 and $66 \mathrm{kV}$ with the distribution network operating at $34.5,15$ and $6.3 \mathrm{kV}$.

\subsubsection{Performance}

TEDAS has provided the following damage statistics for the seven affected provinces:

Table 1. Damage to Distribution Network in Provinces Affected by Earthquake as at 30 August 1999.

\begin{tabular}{|c|c|c|c|c|c|c|c|c|}
\hline & \multicolumn{2}{|c|}{$\begin{array}{c}\text { Distribution } \\
\text { Transformers }\end{array}$} & \multicolumn{2}{c|}{$\begin{array}{c}\text { Overhead Lines } \\
(\mathrm{km})\end{array}$} & \multicolumn{2}{c|}{ Underground Cables (km) } & Poles \\
\hline & $\begin{array}{c}\text { MV/M } \\
\text { V }\end{array}$ & MV/LV & MV & LV & MV & LV & MV & LV \\
\hline Total & 212 & 16,660 & 14,779 & 141,696 & 2,901 & 8,003 & 137,843 & 524,532 \\
\hline Destroyed & 2 & 279 & 365 & 580 & 795 & 910 & 2,085 & 7,749 \\
\hline Damaged & 19 & 1,154 & 302 & 2,720 & 195 & 1,756 & 2,250 & 18,310 \\
\hline $\begin{array}{c}\text { Percent } \\
\text { affected }\end{array}$ & $10 \%$ & $9 \%$ & $5 \%$ & $2 \%$ & $34 \%$ & $33 \%$ & $3 \%$ & $5 \%$ \\
\hline
\end{tabular}


TEDAS has estimated the total cost of earthquake damage as follows:

Table 2. Cost of Damage to Distribution Network.

\begin{tabular}{|l|l|}
\hline MV \& LV Distribution Transformers & US\$ 14 million \\
\hline MV \& LV Overhead Lines & US\$ 21 million \\
\hline MV \& LV Underground Cables & US\$ 35 million \\
\hline TOTAL COST & US\$ 70 million \\
\hline
\end{tabular}

\subsubsection{Adapazzari Reconnaisance}

Adapazzari is a major substation in TEAS network. There were at least $6 \times 380 \mathrm{kV}$ lines and $2 \times 154 \mathrm{kV}$ lines connected to the substation. The substation is located at about $10 \mathrm{~km}$ from the city centre where most of the heaviest damage to the buildings occurred. The damage to the substation was surprisingly light relative to the devastation of Adapazzari city, but was located on raised ground.

The electricity supply network around Adapazzari is quite extensive. There are 7 distribution substations at $34.5 / 6.3 \mathrm{kV}$ which feed the city centre. There were also 170 distribution transformers at $6.3 \mathrm{kV} / 400 \mathrm{~V}$ and 260 distribution transformers at $34.5 \mathrm{kV} / 400 \mathrm{~V}$.

Most if not all of the $6.3 \mathrm{kV} / 400 \mathrm{~V}$ transformers were polemounted. Most of the $34.5 \mathrm{kV} / 6.3 \mathrm{kV}$ were ground-mounted. The distribution substation buildings inspected appeared to have survived the earthquake. The pole-mounted transformers with a range of voltages at $40,50,63,100,160$, 250, $400 \mathrm{kVA}$ suffered damage to:

- Bushings.

- Conservator tank support.

- Tripping of Buchholz relays, internal damage to core/windings as the transformers fell off the poles.

The poles were mostly made from hollowed reinforced concrete tubing of about $400 \mathrm{~mm}$ in diameter and $50 \mathrm{~mm}$ in thickness at the base. Some were latticed steel towers. Generally, the transformers mounted on the concrete poles were not held down and quite a few fell off during the earthquake, as seen in Figure 35. Those mounted on the steel latticed towers appeared to be bolted down to a platform. The poles and towers withstood the earthquake reasonably well except for those which were damaged when the buildings collapsed on them, as seen in Figure 36.

Underground cables suffered heavy damage due to ground movements. Some of the damage was also caused by the diggers in the demolition and removal of debris from the collapsed buildings.

According to the Director of TEDAS at Adapazzari substation (TEAS and TEDAS share the same facilities there), power was lost immediately after the earthquake but was restored within 8 hours in the first day. Supply to the hospitals and government buildings in Adapazzari had the first priority. At the time of the reconnaissance, about one month after the earthquake, all distribution networks to
Adapazzari were back to normal operations except for the supply to the damaged areas.

Before the earthquake, TEDAS had about 150,000 customers in the Adapazzari region with a peak load of about $95 \mathrm{MW}$. The peak load reduced to about $70 \mathrm{MW}$ at the time of my visit even though the network was back to normal. The demand had dropped because so many customers were living in tents.

TEDAS estimated about 20,000 people lived in tents. TEDAS supplied electricity to these tent cities free of charge. For those who lived in undamaged buildings, they did not have to pay tax on their power bills for 12 months.

Five employees of TEDAS' Adapazzari office died in the earthquake. 50 others had relatives who died as a result of the earthquake and 80 employee's apartments were damaged. These employees now live in tents provided by TEDAS. The company was building 100 prefabricated houses for them.

In the first 3 days, there were not enough spare transformers and cables to replace the damaged items but after that, local manufacturers were able to provide the replacement quantities required.

Adapazzari is a major $380 \mathrm{kV}$ substation in the TEAS network. Most of the damage to TEAS equipment occurred at this substation.

- Six $380 \mathrm{kV}$ SF6 circuit breakers, type ASEA HLR420/915B were completely destroyed, as seen in Figure 37. These circuit breakers were installed about 16 years ago.

- $\quad$ Six $380 \mathrm{kV}$ disconnectors type CEME Spa CS630, 1979 were completely destroyed.

- Three $154 \mathrm{kV}$ surge arresters type DIAAS 31M2-3/44 were destroyed.

- One ITALTRAFO, $150 \mathrm{MVA}, 380 / 154 \mathrm{kV}$ transformer pushed aside the stops and rolled along the rail by 250 mm causing damage to $15.5 \mathrm{kV}$ bushings and $154 \mathrm{kV}$ surge arresters. This and other transformers at the substation were not bolted to the foundation. All were on wheels with stops on the rails designed to prevent them from rolling.

- One AEG 150 MVA type MLSN 8256 transformer moved along the rails by $300 \mathrm{~mm}$ causing damage to the Buchholz relay but there was no damage to the bushings. 
It was interesting to note that the transformer rails were generally laid in the north-south direction, which is at a right angle to the fault line running in the east-west direction. The north-south direction was where the earthquake ground acceleration was expected to be as the fault ruptured. If the transformer rails were laid in the east-west direction, the transformer may have overturned. In that case, the damage would have been much greater than a few broken bushings.

Other circuit breakers, current transformers, voltage transformers and other equipment in the $380 \mathrm{kV}$ and $154 \mathrm{kV}$ yards did not experience any damage. This would indicate relatively low ground acceleration of between 0.2 and $0.3 \mathrm{~g}$. If the ground acceleration was higher, say 0.4 or $0.5 \mathrm{~g}$, more damage would have occurred.

The undamaged $380 \mathrm{kV}$ circuit breakers were:

- $\quad$ ABB type HPL $420 / 4082$

- $\quad$ Alstom type FX22

- Hitachi type OFPI-400-50L

The damaged circuit breakers and disconnectors were replaced in 12 days including the first 2 days after the earthquake when little work was done. The circuit breakers were designed to withstand a $0.5 \mathrm{~g}$ ground acceleration earthquake.
There was little damage at Izmit $154 / 34.5 \mathrm{kV}$ substation. This substation fed Izmit but the power was quickly restored after 5 hours. Normally it provided $50 \mathrm{MW}$ but at the time of my visit, it was operating at $25 \mathrm{MW}$.

At Yamica Substation, all four 154/34.5 kV transformers rolled along the rails up to $1 \mathrm{~m}$ and caused damage to 7 surge arresters. The transformers weighed about 142 tonnes each.

\subsubsection{Generation Facilities}

TEAS did not report any damage to their power stations in the area. Power supply to Adapazzari came from a thermal power station west of Istanbul, combined-cycle power plant in Demirtas near Bursa in the south and also a thermal power station in Cakirca and a hydro station at Gokcekaya. We were not able to visit these but we did call in to see the Director of the Golakoglu Metalurji AS in Gebze about their combined-cycle power plant (230 MW) and a $150 \mathrm{MW}$ gasfired power station which was under construction.

Immediately after the earthquake, the combined-cycle power plant was tripped. However, no damage was found and the gas turbine was returned to full load 21 hours later with the steam turbine back to full load 48 hours later.

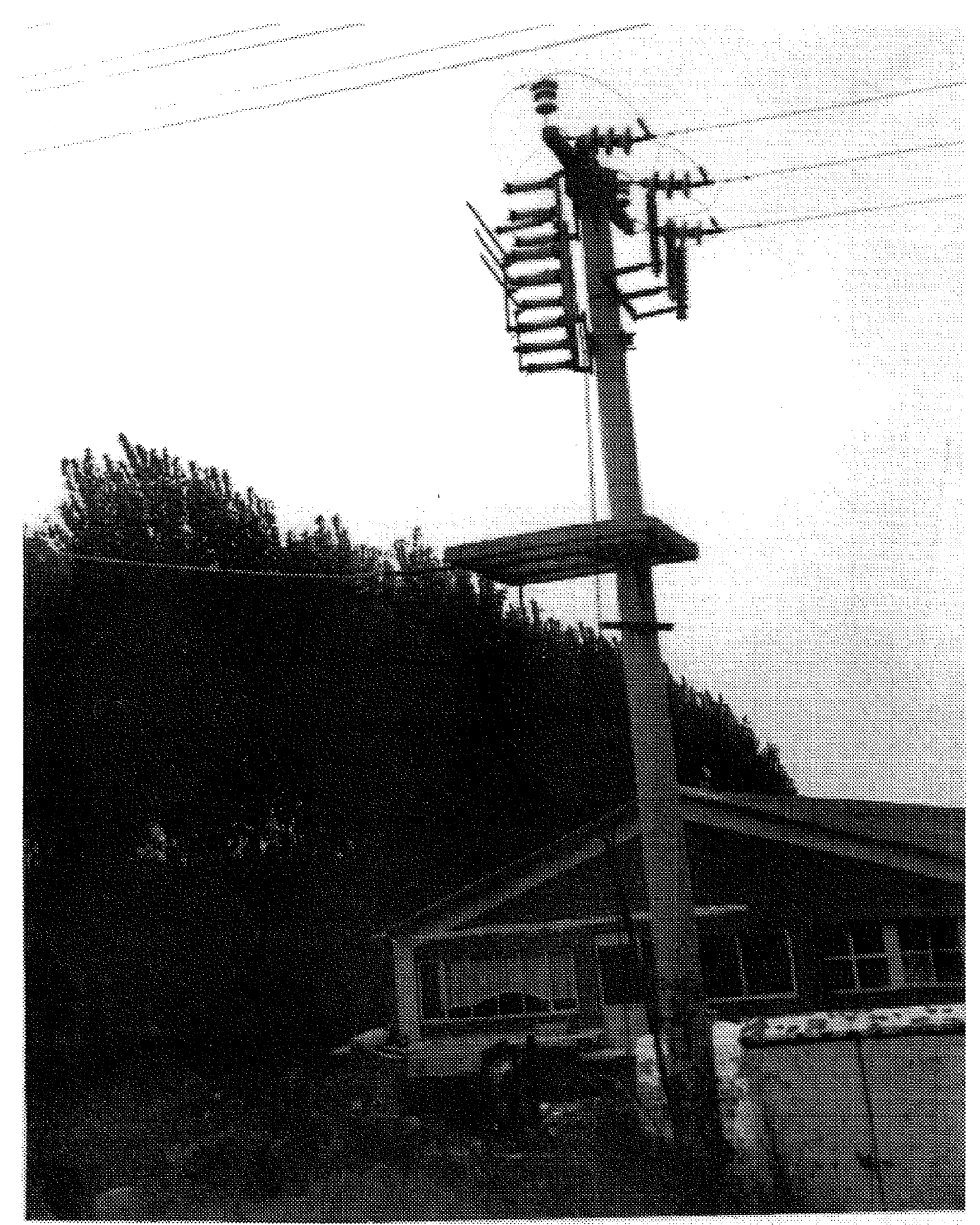

Figure 35:

Transformer fallen from pole near Izmit. 


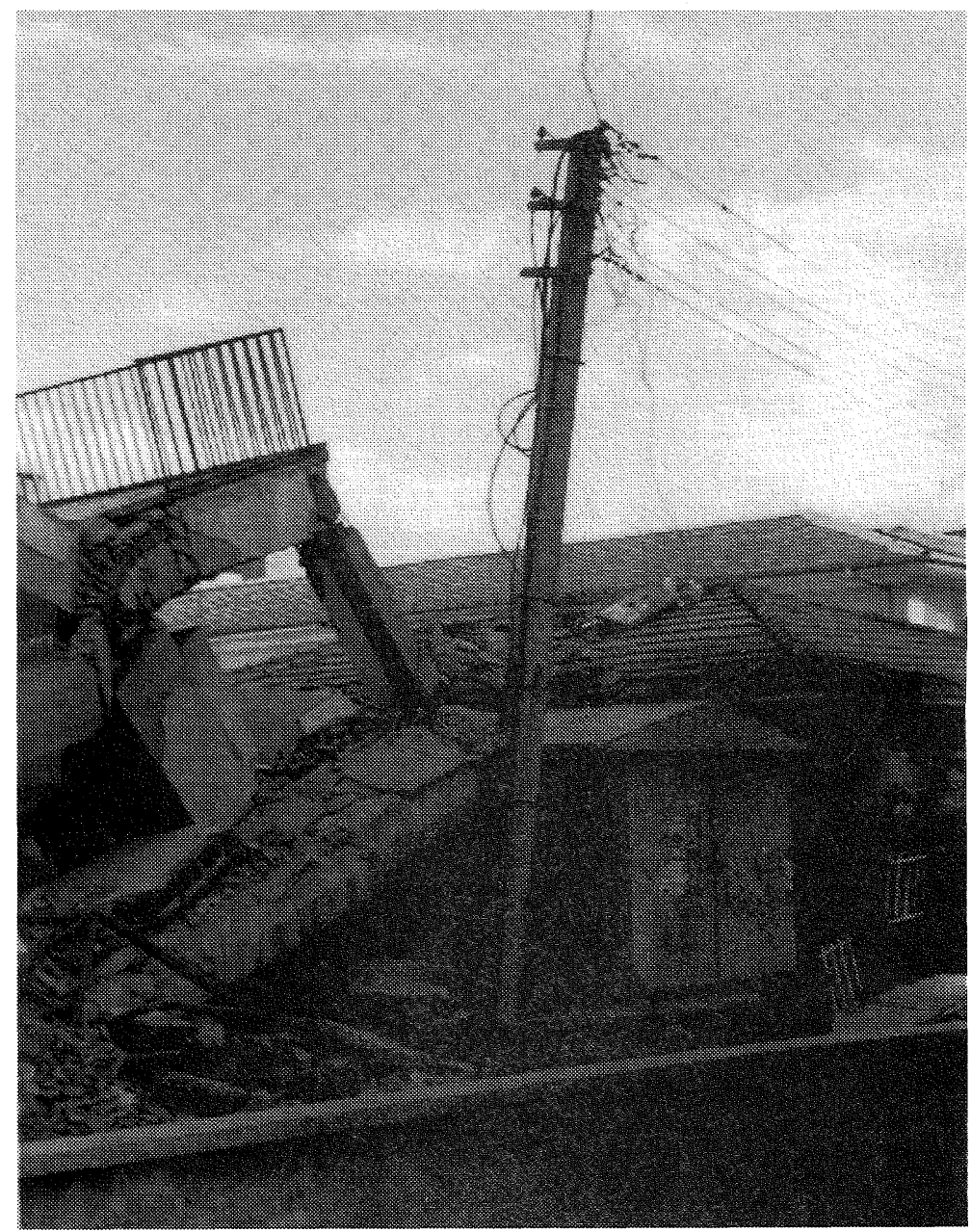

Figure 36:

Power pole damaged by collapsing adjacent building.

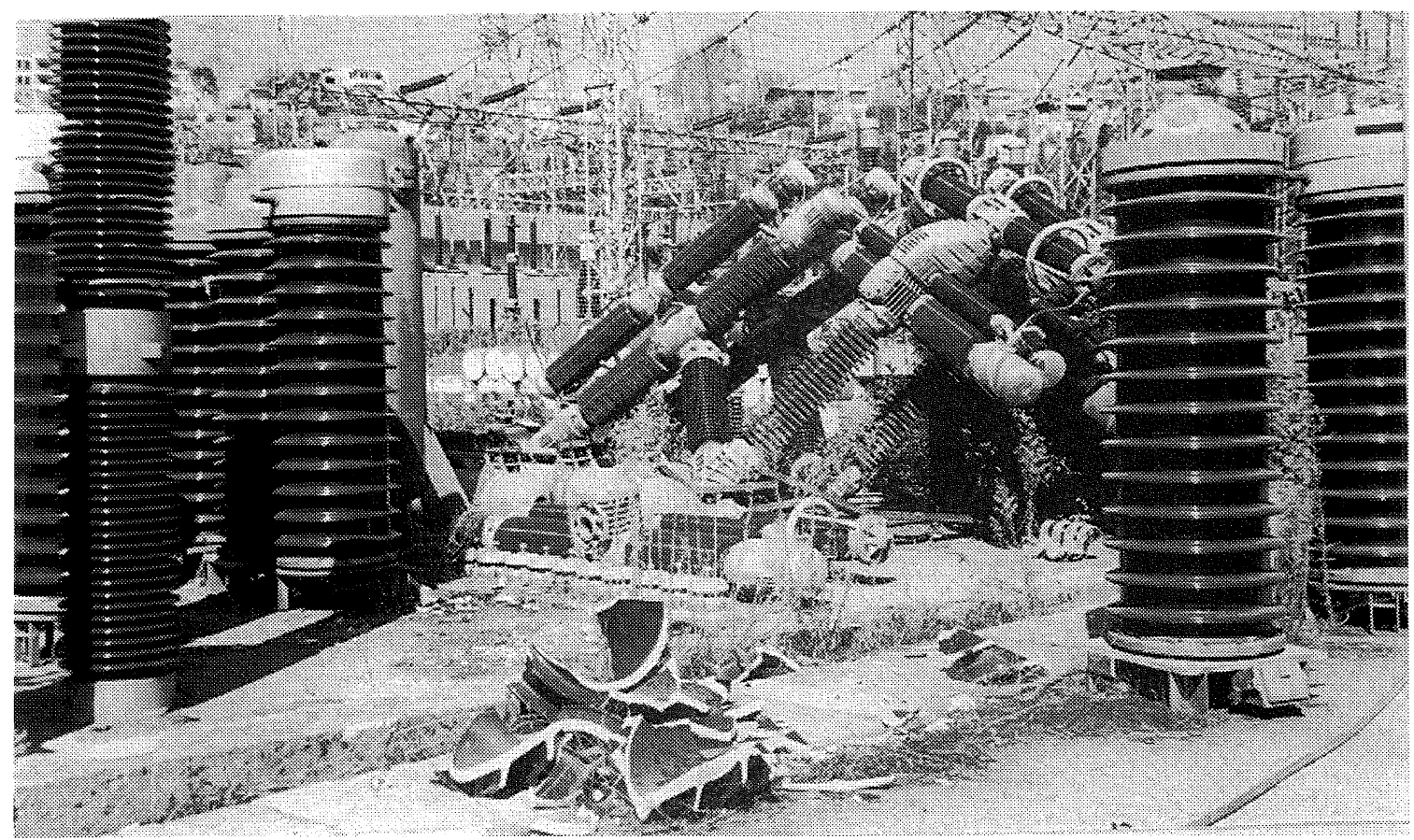

Figure 37: $\quad$ Damaged $380 \mathrm{kV}$ circuit breakers. 


\subsection{Telecommunications}

Turkey appears to be well serviced in telecommunications. Turk Telekom provides both landline and cellular telephone services via Telsim. Turcell is another cellular phone service provider.

To find out what had happened during and after the earthquake proved to be a little difficult. With the help of our Turkish student, we were able to locate the public relations department people for both Turk Telekom and Turkcell. They were willing to help provided that the questions were provided by fax. This fax was followed up during the visit to Ankara a week later.

Damage to Turk Telecom facilities was widespread from Istanbul, Adapazzari, Yalova, Izmit to Bolu, Duzce and surrounding areas at Golyaka, Cilimli, Gumusova and Cumayeri.

The main causes of service failures were:

- Loss of power

- Fibre optic cable failure

- Copper cable failure

- Telephone exchange damage

Three out of 459 telephone exchanges of various capacities were heavily damaged. One was at Adapazzari and the other two were at Golyaka and Ubashi. Loss of power was caused by the loss of main supply but also from damage to batteries, which fell off the support.

The fibre optic cable connection between Yalova and Izmit to the south of Istanbul was out of service for about 13 hours after the earthquake. It took a little longer (17 hours) to have the main telephone exchange back in service. A similar recovery time was experienced for the Golcuk, Izmit (Marmara Sea ) network. In Adapazarri, the telephone earth station was restored 17 hours after the earthquake and the transmission network was back in service after 21 hours. For the surrounding areas, it took another day (until $4.30 \mathrm{pm}$ of 18 August 1999) to restore the transmission network and telephone exchanges

Our site inspection showed that the telephone exchange building at Adapazzari was damaged, but not as extensively as other buildings in the same area. This building was 5storeys high with 2 antenna towers on top. Apparently the equipment inside was overturned during the earthquake. At the time of our visit, this building was not fully occupied but the equipment was apparently mostly put back in service. Turk Telecom had set up temporary offices on the boulevard nearby including a temporary satellite and exchange network, shown in Figure 38. They also provided 15 phone booths for local people to use.

Telephone lines in the affected areas were generally connected along wooden poles and supplied to individual houses or apartments by overhead lines. The poles generally performed well but the lines were badly damaged by the collapse of nearby buildings during the earthquake.

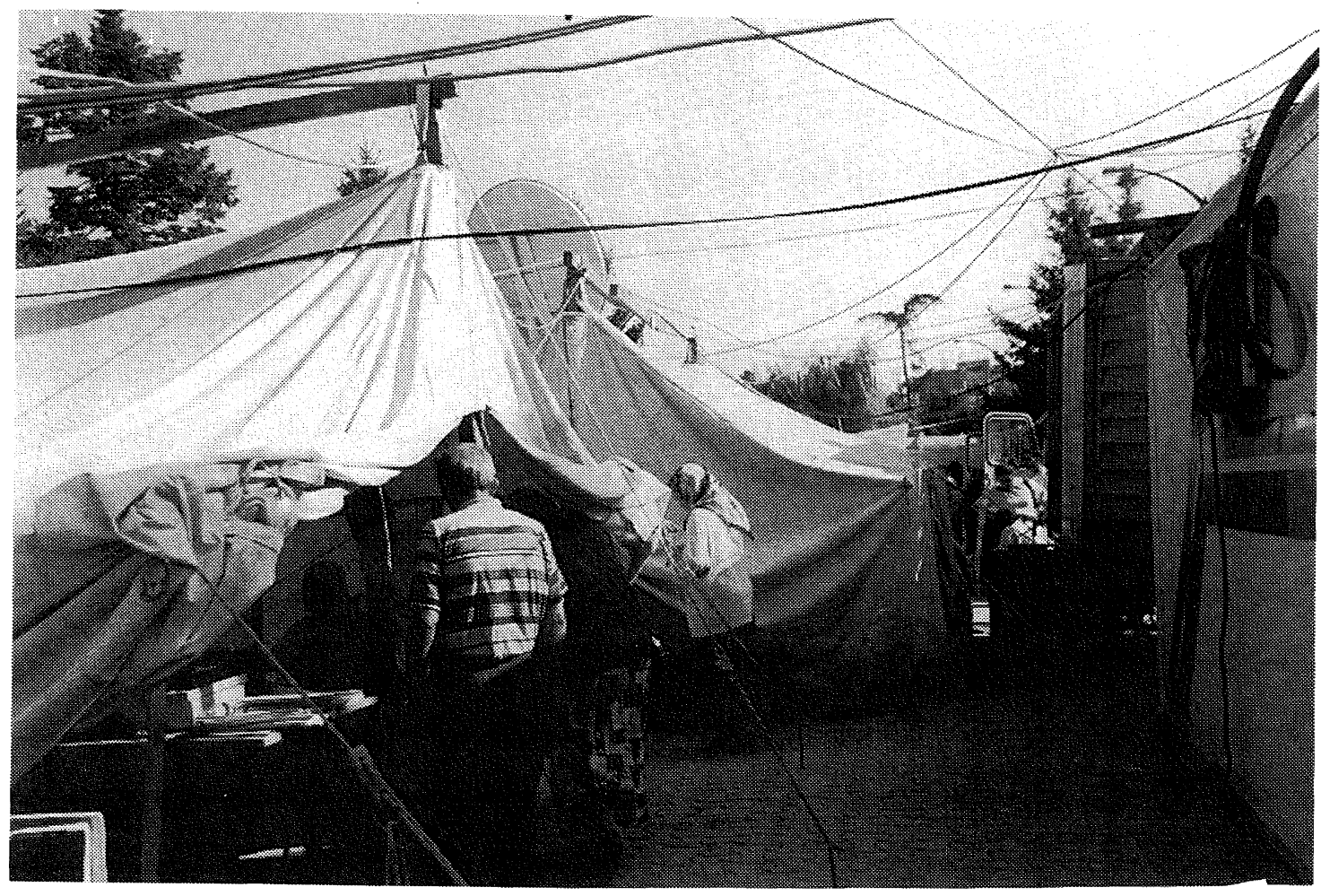

Figure 38:

Temporary Telecom office and satellite dish, Adapazzari. 
Immediately after the earthquake, all the telephone connections in the affected area were out of service including the cellular network. There were unconfirmed reports of damage at cell sites and repeater stations, but it would appear that most of the telecommunication failure was caused by the overloading of the cellular network. Certainly this was our experience after the after-shock.

Other services through the fibre optic submarine cables (from Yalova to Istanbul) and international connections to Italy, Ukraine, Russia from Istanbul were not fully restored until 2 September 1999 (17 days later).

Immediately after the earthquake, emergency low capacity mobile phone systems were sent to the area by helicopter (TES system code 0562). On the first day after the earthquake, most senior staff of Turk Telekom (such as the Group Chief Engineer, Regional Directors) came to work to co-ordinate the restoration work. Other key personnel and repair teams were sent in from Istanbul, Ankara and other centres around Turkey. In total 19 employees and 71 relatives of staff of Turk Telekom died during the earthquake.

Turk Telekom had a number of plans and emergency centres for all sorts of emergencies. These had helped after the earthquake. Most of the damaged equipment was replaced from spares or purchased from supplies based in the main centres (Istanbul, Ankara and Bursa).

Prior to the earthquake, Turk Telekom had specified seismic loads for the installation of the equipment and the design of buildings but there was no special bracing system design for the telephone exchange equipment. Racks were installed between the walls of the buildings to help stabilise them.

Some special precautions were taken in laying fibre optic cables. The design included a ring configuration to provide the network redundancy.

There was no problem with back-up generators but the startup batteries fell over. These were quickly replaced or repaired

One other problem facing Turk Telekom was the damage to the underground cables during the demolition of the damaged buildings and the laying of new distribution water pipes in the affected areas. Given the scale of the damage and the high priority put on reconstruction work, it would be hard to imagine how this secondary damage could be controlled or avoided. Some 40 percent of cable duct lines in the affected area were damaged.

In general, the cellular network had performed well during the earthquake and had provided communications during the crucial days and weeks that followed. The landline telephone network did not fare as well and in many ways that was to be expected. It will take months and millions of dollars to restore the network back to normal. The World Bank estimated the earthquake has caused US\$38 million of damage to the telecommunication facilities.

Telecommunication technicians were generally reluctant to work inside buildings in the affected areas for fear of aftershocks. This had slowed down the telephone restoration work.

\section{SUMMARY AND RECOMMENDATIONS}

\subsection{Summary of Key Points}

On 17 August 1999 a $M_{w} 7.4$ earthquake struck western Turkey killing at least 15,000 people (probably 30,000 ) and leaving some 600,000 homeless. Some 25 days after the event, the NZSEE reconnaissance team arrived in Istanbul comprising five consulting engineers, one university engineer, a geoscientist, and an emergency manager spent 10 days in Turkey, 6.5 of these in the field in the worst affected areas.

Measured peak ground accelerations ranged from $0.23 \mathrm{~g}-$ $0.41 \mathrm{~g}$, somewhat lower than would be expected in New Zealand for a $\mathrm{M}_{\mathrm{w}} 7.4$ shallow earthquake. However, the duration of shaking was long (45 seconds) with high peak ground velocities approaching $1 \mathrm{~m} / \mathrm{sec}$. This long duration of shaking probably exacerbated the plight of much of the building stock, which was of very limited ductility.

Some 20,000 buildings collapsed, mostly 4 - 8 storey apartment buildings, a further 30,000 have been condemned. Typically, the collapsed apartment buildings were built by the private sector of light reinforced concrete frame construction with hollow brick infill walls. Concrete strengths were low (some very poor hand mixed concrete was found), undeformed longitudinal steel was common, and accepted seismic detailing virtually non-existent. Failure was typically initiated as a soft storey mechanism at the ground floor level with open shop fronts or garages and overhanging upper storeys.

There are no private consulting engineers in Turkey. Engineers work either for the Government or directly for construction companies. The only independent engineers available to assess critical damaged structures such as hospitals seemed to be university professors, who were in short supply.

One city, Adapazzari, was badly affected by soil liquefaction with large scale ground deformation and cracking. Few buildings were on deep foundations and consequently either settled deeply (typically by 1 metre) or tilted wildly and are a complete economic loss. The water distribution network in Adapazzari was also badly affected by the ground deformation. Elsewhere, little ground deformation was observed and in-ground services have remained largely intact.

One large area east of Golcuk adjacent to the coast was subject to tectonic settlement of 2 metres as a result of a tectonic pull-apart structure leading to widespread inundation. The $150 \mathrm{~km}$ long fault surface rupture cut through many buildings and facilities causing collapse and severe damage.

The main infrastructure (roads, water supply, electricity, telephone) were relatively undamaged or were restored quickly, with the exception of the Adapazzari water supply network which needs major reconstruction. The cellphone system was resilient but was subjected to frequent overloading, especially after each after shock. Portable cellphone stations were in use indicating that some emergency response plans were in place before the event.

Damage to industrial plants and warehouses was very light, especially for international companies who had used international design and construction standards. 
International response was rapid, particularly the Israeli and Egyptian medical teams. A Canadian Army DART team provided potable water for 40,000 people in Adapazzari within a week of the earthquake. Turkey's own Red Crescent was the only officially sanctioned non-governmental organisation involved in the emergency response.

Central government response was said to be virtually noneffective. However, private citizens have apparently organised themselves to tackle problems in a way not seen in recent decades.

A massive clean-up operation was well under way in all affected cities and towns visited. Much heavy equipment was at work demolishing damaged buildings and removing rubble. More heavy equipment was clearly available but either not required or not in use. It was unclear who was organising and/or paying for all the activity. Private contractors were said to have been working voluntarily on their own initiative. The main problem seemed to be finding environmentally acceptable disposal sites.

It would be impossible to find as much heavy equipment for a similar scale disaster in New Zealand.

Very little temporary housing was under construction during the visit, only tent based camps of variable substance. During the winter months of December, January, and February 18 inches of rain per month and temperatures as low as $-5^{\circ} \mathrm{C}$ are expected.

\subsection{Recommendations for New Zealand}

The clear message for New Zealand from the reconnaissance is the need for overall nationwide co-ordination of resources to respond to a major earthquake disaster. There was no evidence of such co-ordination happening in Turkey. However, Turkey has a much bigger economy than New Zealand and is undergoing rapid expansion, meaning that much more resources were available to respond to the earthquake, if somewhat inefficiently and haphazardly. Turkey is also connected to Europe by land allowing rapid movement of equipment and supplies. New Zealand's economy by contrast is "lean and mean", our construction sector is comparatively small and will need careful husbanding and co-ordination to cope with a major earthquake disaster. Mobilisation of offshore equipment and supplies will take much more time.

New Zealand must recognise the importance of international emergency response teams after a major disaster and have planned systems at a national level for their reception, briefing, and deployment. Local emergency planning should provide for the logistical support and accurate tasking of these teams. The Ministry for Emergency Management should establish formal support agreements with international rescue teams.

New Zealand must also ensure that sufficient expertise exists at a national level in all disciplines of emergency response to be deployed to any area struck my a major disaster. A national system must be established for identifying, training, and deploying such personnel. The Turkey experience was that local personnel will be more concerned with their own and immediate family safety and circumstances and should not be relied on. Also, New Zealand should be prepared to reciprocate by sending emergency response teams to disasters in other countries.

International protocols for searching and marking damaged structures should be incorporated into national and local rescue planning and training. The ready availability of accurate mapping including detailed maps of business areas identifying individual buildings should be assured at local level. Provision of a dedicated, robust, and effective back-up communications system for control should remain a priority at both national and local level.

The Turkey earthquake emphasised the importance of identifying and mapping hazards and sound land use planning practices. The city of Adapazzari, for example, was subject to widespread soil liquefaction hazard yet most structures were on shallow foundations and the lifeline systems seemed ill prepared. A recent major hotel constructed on the immediate shorefront of Lake Sapance was destroyed by soil liquefaction, a hazard that should have been easily identified, even anticipated. We in New Zealand need to improve our efforts in hazard mapping and land use planning if we are to fare any better. We need to prevent, or, at least, restrict new construction on, across, or immediately adjacent to, known active fault traces and to identify additional unknown ones. Other identifiable hazards witnessed in Turkey include coastal sub-sea landslide and tectonic subsidence.

The value of a sound building control process was brought home very strongly. New Zealand must ensure that under the new commercially contestable building approval process high standards of inspection are maintained or improved.

For lifeline systems, an adequate amount of spare equipment (transformers, power cables, bushings, HV circuit breakers etc) should be held in stock for emergencies.

\section{ACKNOWLEDGEMENTS}

New Zealand's Earthquake Commission (EQC) generously met the air travel costs of seven of the team, with the Dunedin City Council providing for the travel of their Emergency Manager. Accommodation and other costs of the team were met from the special reconnaissance fund of the NZSEE. Team members time was contributed freely by their employers. Clearly, these time costs are the major expense of such a reconnaissance, and without the employing organisations support, these visits would be impractical.

Dr Tony Gillies accompanied the team for part of the time and contributed the notes on the Adapazzari water supply. Dr Peter Riley contributed the notes on dams.

An outstanding feature of the response to the Turkey earthquake was the availability via the Internet of much technical and photographic information within a few days of the main event. The hard work and dedication of those in the earthquake engineering community in Turkey and those international teams in the field in the first few days was much appreciated by the team.

Kandilli Observatory and Civil Engineering Department of Bögaziçi University, Istanbul and graduate students Afsin Beker and Murat Selcuk

Nergis Dincer, who was acting as an interpreter for the Canadian DART Team and helped gain access to the 
Governor's office and provided much information about the emergency response.

\section{Middle East Technical University, Ankara}

Türk Mühendis Ve Mimar Odalari Birliği (Union of Chambers of Turkish Engineers and Architects), Ankara

The Goodyear Tire Company and Unilever in Turkey, especially their local management and staff, for their help and for allowing us to inspect their facilities.

The New Zealand Embassy in Ankara.
The Japan Institute of Architects Reconnaissance Team, especially Jin Tanaka, for sharing their information and thereby saving us much valuable time.

The team were present in Turkey for 10 days. Towards the end, we were all very tired. Partly physical, the weariness came mainly from daily witnessing the total devastation and suffering of the local people trying to get their lives together. At the same time we were overwhelmed by the friendliness (Figure 39) and helpfulness of the people we met who went out of their way to assist us with our tasks and to provide what information they could. Our task seemed so small in comparison to what they were facing. It will take many years for them to recover and rebuild - We wish them well.

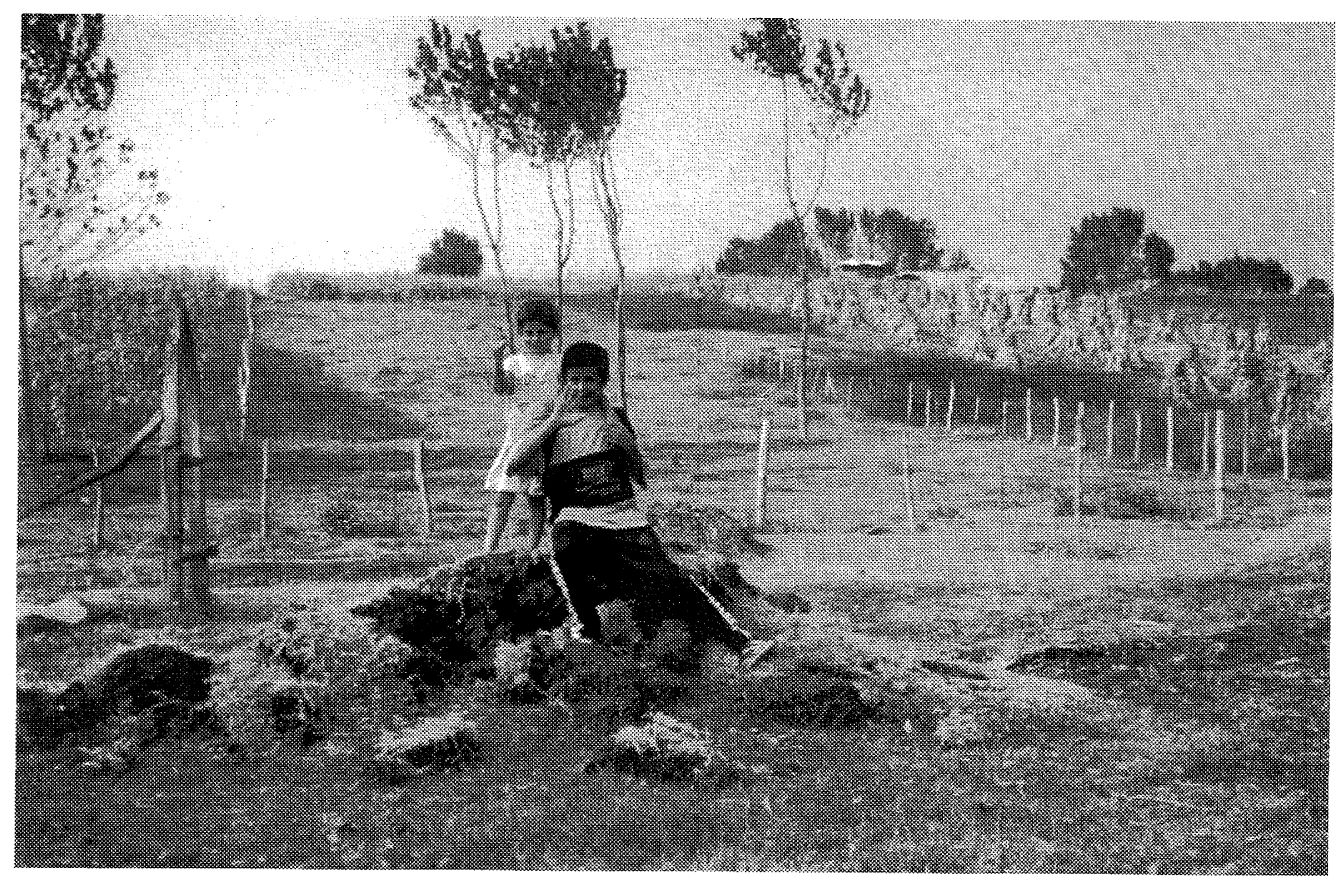

Figure 39:

Children playing on fault trace.

\section{REFERENCES}

1. Ambraseys, N.N., 1970, "Some characteristic features of the Anatolian fault zone". Tectonophysics 9: 143-165.

2. McKenzie, D.P., 1970, "Plate tectonics of the Mediterranean region". Nature 226: 239-243.

3. Jackson, J, McKenzie, D., 1988, “The relationship between plate motions and seismic tremors, and the rates of active deformation in the Mediterranean and
Middle East”. Royal Astronomical Society Geophysical Journal 93: 45-73.

4. Barka, A.A., 1992, "The north Anatolian fault zone". Annales Tentonicae, special issue, supplement to vol. VI: $164-195$

5. Armijo, R., Meyer, B., Hubert, A., Barka, A., 1999, "Propogation of the North Anatolian fault into the north Aegean: timing and kinematics". Geology 27:267-270. 
6. Sengor, A.M.C., 1979, "The North Anatolian transform fault: its age and tectonic significance". Geological Society [London] Journal 136: 269-282.

7. Westway, R., 1994, "Present-day kinematics of the Middle East and eastern Mediterranean". Journal of Geophysical Research 99: 12,071-12,090.

8. Straub, C., Kahle, H.-G., Schindler, C., 1997, "GPS and geological estimates of the tectonic activity in the Marmara Sea region, NW Anatolia". Journal of Geophysical Research 102: 27,587-27,601.

9. McClusky, S., et al., 2000, "GPS constraints on plate motion and deformation in the eastern Mediterranean: implications for plate dynamics". Journal of Geophysical Research (in press).

10. Barka, A.A., 1999, "The 17 August 1999 Izmit Earthquake". Science 285: 1858-1859.

11. U.S. Geological Survey, 1999, "Implications for earthquake risk reduction in the United States from the
Kocaeli, Turkey, earthquake of August 17, 1999”. U.S. Geological Survey Circular 1193: 64 p.

12. Stein, R.S., Barka, A.A., Dieterich, J.H., 1997 , "Progressive failure on the North Anatolian fault since 1939 by earthquake stress triggering". Geophysical Journal International 128: 594-604.

13. Reilinger, R., Toksoz, N., McClusky, S., Barka, A., 2000, "1999 Izmit, Turkey Earthquake was no surprise". GSA Today 10: 1-6.

14. Robinson, R., Benites, R., and Van Dissen, R., 1998, "Evidence for temporal clustering of large earthquakes in the Wellington region from computer models of seismicity". Bulletin of the New Zealand National Society for Earthquake Engineering 31: 24-32.

15. "Turkey - Marmara Earthquake Assessment", Turkey Country Office, The World Bank, September 14, 1999. 